RESURFACING RACE: RECRUITMENT AND RETENTION OF FACULTY IN CALIFORNIA COMMUNITY COLLEGES

A dissertation submitted to the faculty of San Francisco State University

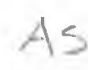

35

2016

EDD

$\cdot .557$
In partial fulfillment of

The Requirements for

The Degree

Doctor of Education

In

Educational Leadership

by

Supinda Sirihekaphong

San Francisco, California

May 2016 
Copyright by

Supinda Sirihekaphong

2016 


\section{CERTIFICATION OF APPROVAL}

I certify that I have read Resurfacing Race: Recruitment and Retention of Faculty in California Community Colleges by Supinda Sirihekaphong, and that in my opinion this work meets the criteria for approving a dissertation submitted in partial fulfillment of the requirements for the degree: Doctor of Education in Educational Leadership at San Francisco State University.

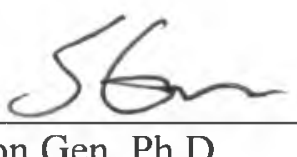

Sheldon Gen, Ph.D.

Associate Professor of Public Administration,

San Francisco State University

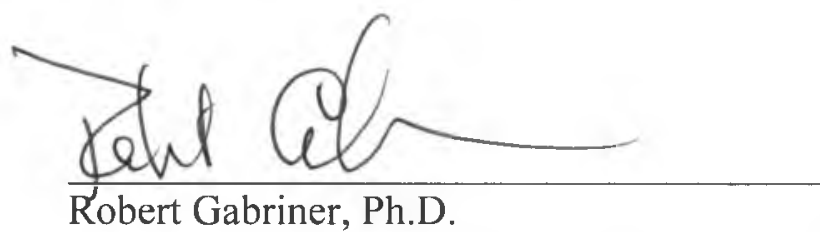

Director of the Educational Leadership Program, San Francisco State University

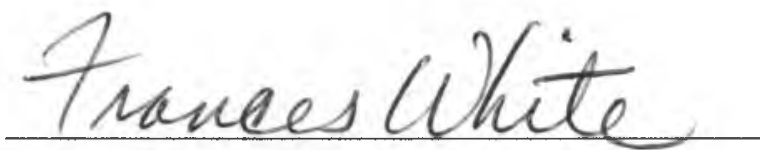

Frances White, Ph.D.

Superintendent/President, Gollege of Marin (retired)

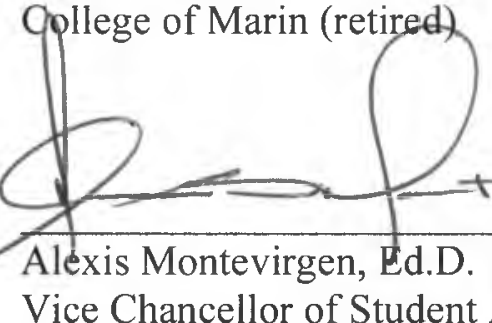

Vice Chancellor of Student Affairs \& Enrollment Management, Indiana Universicy NW 


\title{
RESURFACING RACE: RECRUITMENT AND RETENTION OF FACULTY IN CALIFORNIA COMMUNITY COLLEGES
}

\author{
Supinda Sirihekaphong \\ San Francisco State University \\ 2016
}

Despite the Civil Rights Act of 1964, which protects equal employment opportunity for all, and other California legislation to increase faculty diversity, the disparity between the demographics of California's community college student population and the makeup of the faculty is striking. Specifically, underrepresented minority (URM) students who represent the largest student population at $49 \%$, yet only $22 \%$ of faculty are URM. In 1992 the California legislature adopted regulations that allow community colleges to establish Faculty Diversity Internship Programs (FDIP), to "promote inclusive efforts to locate and attract qualified graduate students who are members of monitored groups identified by gender, ethnicity, and disability." Despite being passed over 20 years ago, less than half of community colleges have implemented FDIPs. This study used a program evaluation to examine two FDIPs sites. The program evaluation revealed four benefits of participating in FDIP 1) mentorship, 2) teaching experience, 3) professional development, and 3) networking and collaboration opportunities. Barriers and challenges included 1) mentor matching, 2) mentor training, 3) class assignment, and 4) FDIP Coordinator transition. Finally, the program evaluation revealed that although the FDIP does not have a significant impact on increasing faculty diversity, it does have a significant impact on preparing faculty to serve in a diverse community college. The study provides evidence and recommendations for implementing FDIPs as a strategy to increase faculty diversity. I certify that the Abstract is a correct representation of the content of this dissertation.

\section{Dissertation Committee Chair}

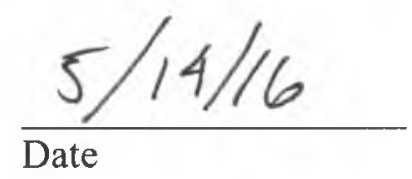




\section{ACKNOWLEDGEMENTS}

Thanks to my family, Daddy, Suraphol Sirihekaphong, Mommy, Sumon Paoin, Lily, Nong Yui, Mangus, Tristen, and Sean, my strength, determination, and passion comes from you and I look forward to spending more family time with you.

Dr. Sheldon Gen, thank you for chairing my committee, your guidance was invaluable in developing and completing this dissertation. Dr. Robert Gabriner, thank you for stepping in at the last hour and providing your depth of knowledge to an issue we are both passionate about. Dr. Fran White, thank you for being an exemplary role model for so many people of color like myself, your questions and insight polished this dissertation. Dr. Alexis Montevirgen, you serve as an example of how far students of the SFSU Ed.D. program can go, your critical comments made my dissertation much more transformative.

I want to thank all my students, colleagues at Cañada College and the SMCCD, and my dear friends, who have supported and provided the daily encouragement and inspiration throughout this process.

Thank you to my SFSU Ed.D. 2013 cohort. We made it! I'm truly honored to grow intellectually, professionally, and emotionally with an inspiring group of educators, committed to improving our educational system. 


\section{TABLE OF CONTENTS}

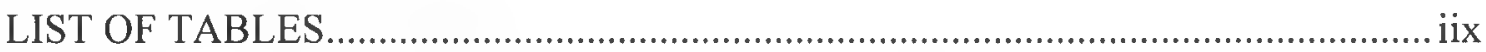

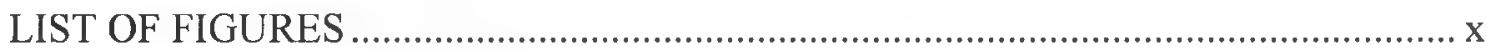

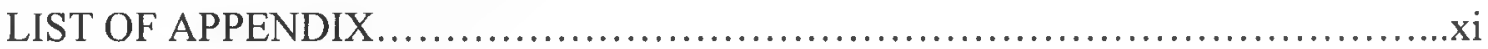

Chapter One: Purpose of the Study

Introduction and Problem Statement ............................................................................ 1

Purpose of Study and Research Questions .............................................................. 4

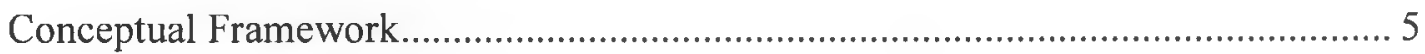

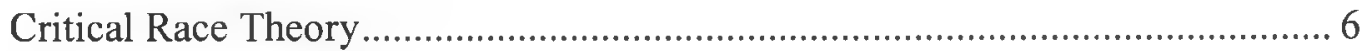

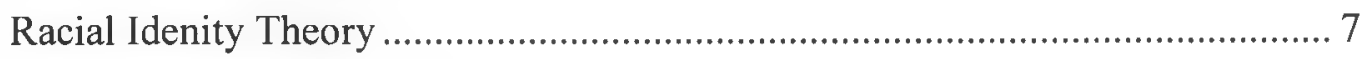

Critical Wealth Theory ………………………………................................... 9

Representative Bureauracracy Theory ................................................................ 10

California Community Colleges and Faculty Diversity ...................................... 12

Policy Implementation Theory .......................................................................... 14

Operational Definitions of Key Terms ................................................................. 15

Statement of Delimitations and Scope of Study ................................................... 16

Significance of the Study.......................................................................................... 17

Chapter Two: Literature Review

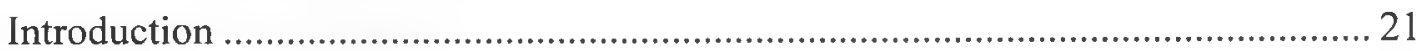

Structure and Scope of Review ......................................................................... 21

The Experience of Faculty of Color....................................... 23

The Employment Practices that Hinder or Support Faculty Diversity...........26

The Impact of Faculty of Color on Teaching and Learning....................22

California Community Colleges and the Faculty Diversity Internship Program 32

Implications for Further Research ......................................................................... 36

Conclusions and Implications............................................................................. 37 
Chapter Three: Methodology

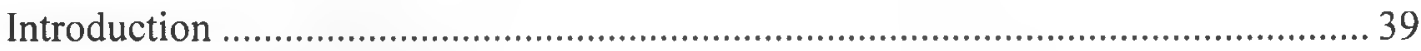

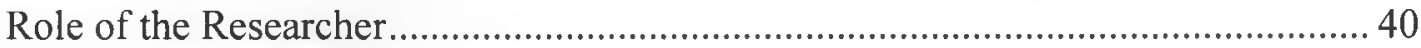

Research Objectives and Questions........................................................................ 42

Context and Participant Selection............................................................................. 42

Ethics and Protection of Human Subjects ................................................................ 49

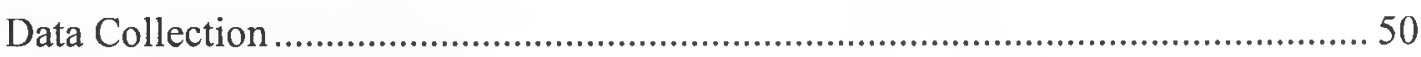

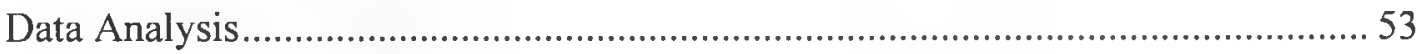

Chapter Four: Report of Findings

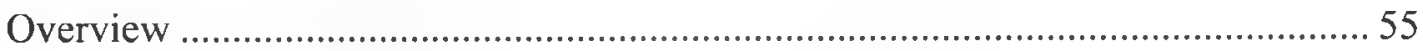

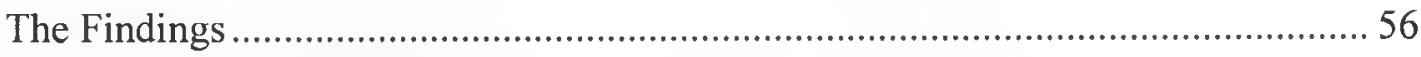

Participant Profiles and Interest \& Expectations in the FDIP .................................. 56

Research Question \#1: What are the benefits of participating in the FDIPs?

Mentorship: More than just shadowing ................................................................. 65

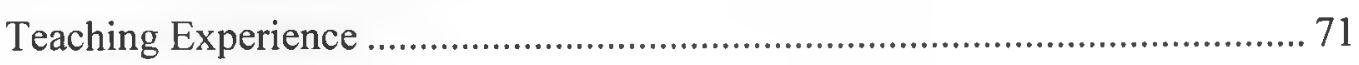

Professional Development............................................................................ 75

Networking and Collaboration ....................................................................... 76

Research Question \#2: What are the barriers and challenges of implementing FDIPs?

Mentor Matching ............................................................................................ 79

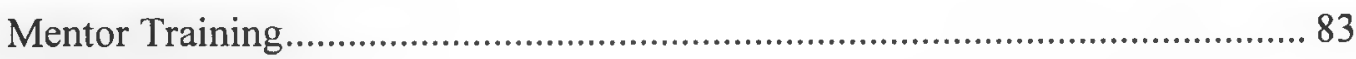

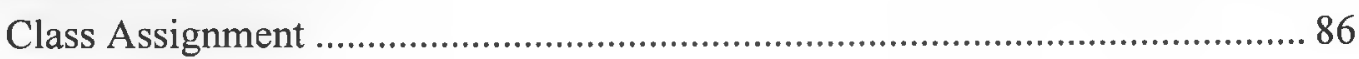

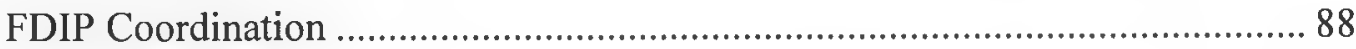

Research Question \#3: What is the impact of the FDIP on faculty diversity as a recruitment and retention tool?............................................................................90

Summary and Synthesis..................................................................................... 100 
Chapter Five: Discussion and Recommendations

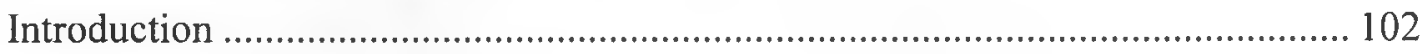

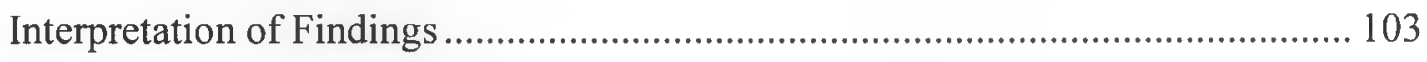

Implications on Policy and Practice ..................................................................... 106

Recommendations for Action........................................................................... 110

Recommendations for Further Study .................................................................... 111

Reflections on the Research Process ..................................................................... 112

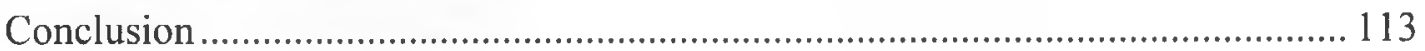

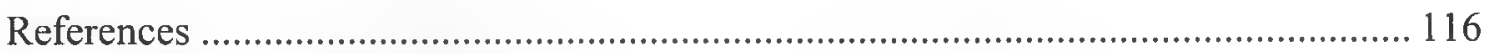

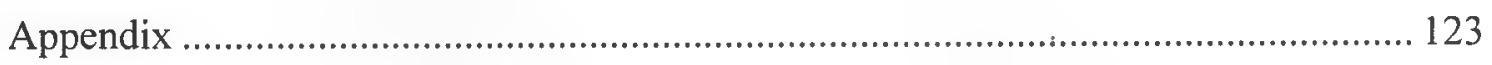




\section{LIST OF TABLES}

Table

Page

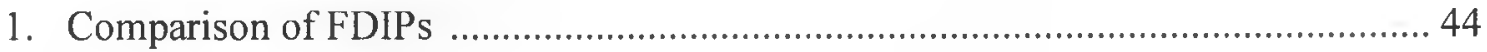

2. Logic Model of FDIPs ..................................................................................... 47

3. Codes Identified in Survey and Interview Responses …………………………....... 53

4. Survey Participant Profile …………………………................................................ 57

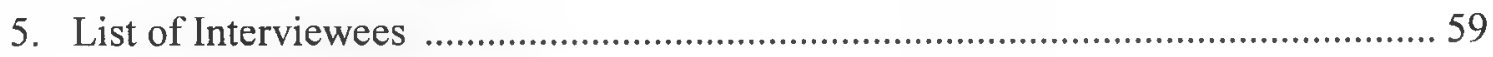

6. Demographics of Faculty from 2000 to 2015 ......................................................... 92

7. Demographics of Intern Survey Responses ........................................................... 94 


\section{LIST OF FIGURES}

Figure $\quad$ Page

1. URM Student and Faculty Demographic Trends .................................................... 2

2. Student Completion Rate by Ethnicity ..................................................................... 2

3. Conceptual Framework ……………………………........................................... 5 


\section{LIST OF APPENDICES}

Appendix

Page

1. FDIP Online Survey and Interview Protocol ...................................................... 123

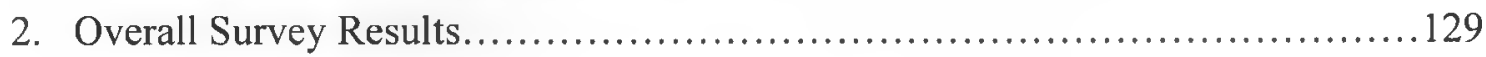


Chapter One: Purpose of the Study

Introduction and Problem Statement

"Whereas, Our community college student population is increasingly diverse and reflects the demographic trends of the state (based on the 2000 Census Report); and

Whereas, The faculty and staff in the California Community College System do not reflect this demographic diversity;

Resolved, That the Academic Senate recognize that faculty diversity must be an integral part of any learning environment that increases student success; and

Resolved, That the Academic Senate take a leadership role in promoting the diversification of faculty of the colleges."

-Academic Senate for Calıfornia Community Colleges, Spring 2001, Faculty Diversity, Resolution Number 03.02

The California community college system is the largest higher education system in the nation, serving over 2.3 million students across 113 campuses (CCCCO, 2016). However, despite the Civil Rights Act of 1964, which protects Equal Employment Opportunity for all and other California legislation passed to increase faculty diversity, the disparity between the ethnic demographics of California's community college student population and the makeup of the faculty is striking. Specifically, underrepresented minority (African-American, Native American and Latino/a) students represent the largest student population at $49 \%$, yet only $22 \%$ of community college tenure/tenure track faculty and 19\% adjunct faculty are underrepresented minorities (URM) (CCCCO MIS Data Mart, 2015). Although the population of URM students increased $15 \%$ in the last 15 years, the population of URM faculty increased only $4 \%$ during the same time period (CCCCO MIS Data Mart, 2015). More importantly, despite being the largest student population, URM students complete a certificate/degree at rates $15 \%$ and $30 \%$ lower than their White and Asian counterparts, respectively. In addition, the percent of 
Asian faculty now match the percent of the Asian student population (CCCCO MIS Data Mart, 2015).

Finally, the disparity between the demographic makeup of URM students compared to faculty is projected to widen as the White population is expected to shrink, while the Latino population is expected to grow to over half in California by 2025 (Darling-Hammond, 2010).

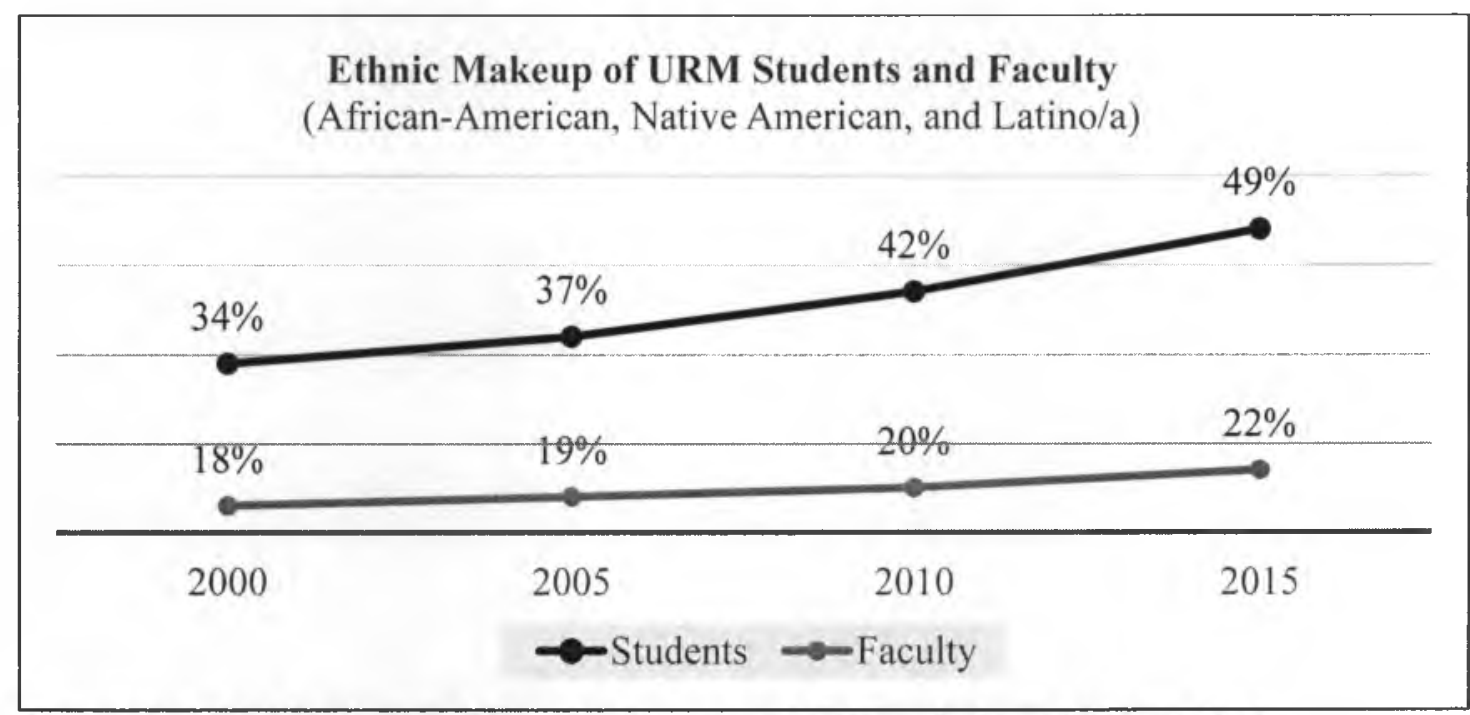

Figure 1: URM Student and Faculty Demographic Trends from 2000 to 2015

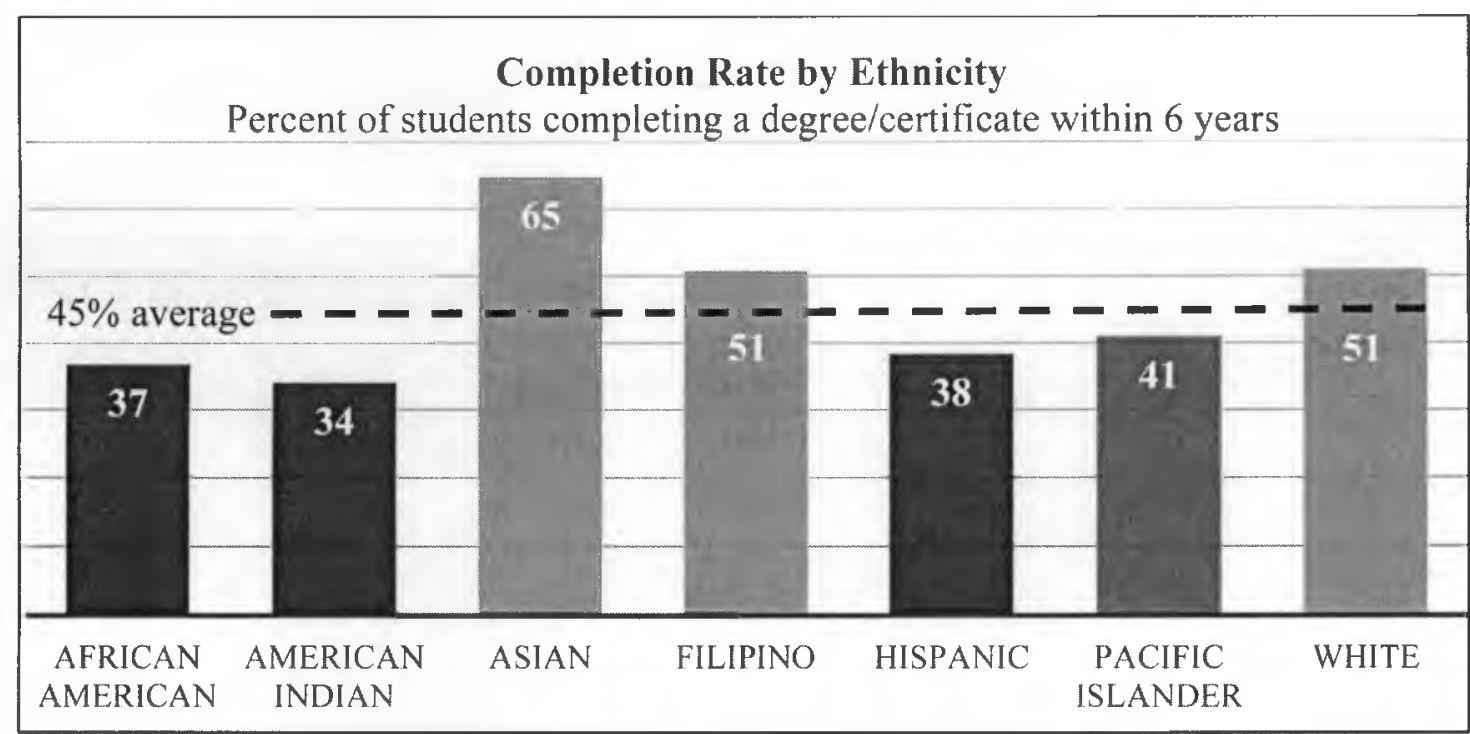

Figure 2: Student Completion Rate by Ethnicity, 2015 
This study examined one strategy that the California community college system adopted in 1992 to increase faculty diversity, the Faculty Diversity Internship Program (FDIP). The main purpose of the FDIP is "to enhance the recruitment of qualified persons pursuing the master's or doctoral degrees, or both, into faculty positions in community colleges in California...(by) promoting inclusive efforts to locate and attract qualified graduate students who are members of monitored groups as defined in section 53001(i)" (Title V, Section 53500). Title V Education Code describes monitored groups based on gender, ethnicity and disabilities but does not identify which groups should be monitored. However, the legislation does require colleges to collect data to determine if there are any significant underrepresentation of monitored groups (Title V, Section 53006). The FDIP allows interns, under the supervision of a faculty mentor, to teach or serve in a discipline that they would be qualified to teach or serve after completion of their studies or equivalent minimum qualifications (Title V, Section 53500).

Despite being passed over 20 years ago, less than half of the community colleges have implemented FDIPs, according to a 1996 report commissioned by the California Community Colleges Chancellor's Office. Since then, there has been no comprehensive report on FDIPs. The same report referenced the lack of funding and organizational and governance issues as reasons why colleges did not implement FDIPs. Another reason why FDIPs have not been implemented, may be because the legislation and the CCCCO do not provide information on how to implement FDIPs and/or what activities and resources are required to run a FDIP. 


\section{Purpose of the Study and Research Questions}

Despite the increase in the URM student population and legislation protecting equal employment opportunity, this dissertation aimed to answer questions regarding the history, politics, and trends of faculty diversity in the California community college system, specifically as it pertained to the Faculty Diversity Internship Program (FDIP). With this purpose, the research questions were:

1. What do FDIP participants find beneficial in participating in the program?

2. What are the barriers and challenges in implementing FDIPs?

3. What is the impact of the FDIP on faculty diversity as a recruitment and retention tool?

A program evaluation of two FDIPs was conducted to answer the research questions. The overall goal of this study is to provide evidence and recommendations to community colleges and districts that want to implement FDIPs as a means to increase faculty diversity and achieve the California community colleges' commitment to "provide access...for all citizens and create a skilled, progressive workforce to advance the state's interests" (CCCCO, Mission and Vision Statement, 2015). 


\section{Conceptual Framework}

Studies on faculty diversity are often framed by three theories, Critical Race Theory (CRT), Racial Identity Development Theory, and Cultural Wealth Theory. From a policy perspective, the lens of representative bureaucracy theory is also provided to discuss how faculty diversity is important within an educational setting. Scholars have used these theories to identify and recommend important elements and/or activities in supporting faculty diversity initiatives, such as an institution's commitment to diversity, programs that prepare faculty to teach and serve in educational institutions, and resources in both time and money. However, most of the literature is focused on the experience of faculty of color and less on how institutions support faculty diversity. This study will use a conceptual framework informed by Critical Race Theory, Racial Identity Development Theory, Cultural Wealth Theory, and Representative Bureaucracy Theory. The history and overview of the California community college context and Faculty Diversity Internship Programs (FDIP) will also be provided. Finally, this section concludes with a discussion about how these theories can inform policy implementation, particularly how bottom up implementation theory informs the implementation of FDIPs at community colleges in California.

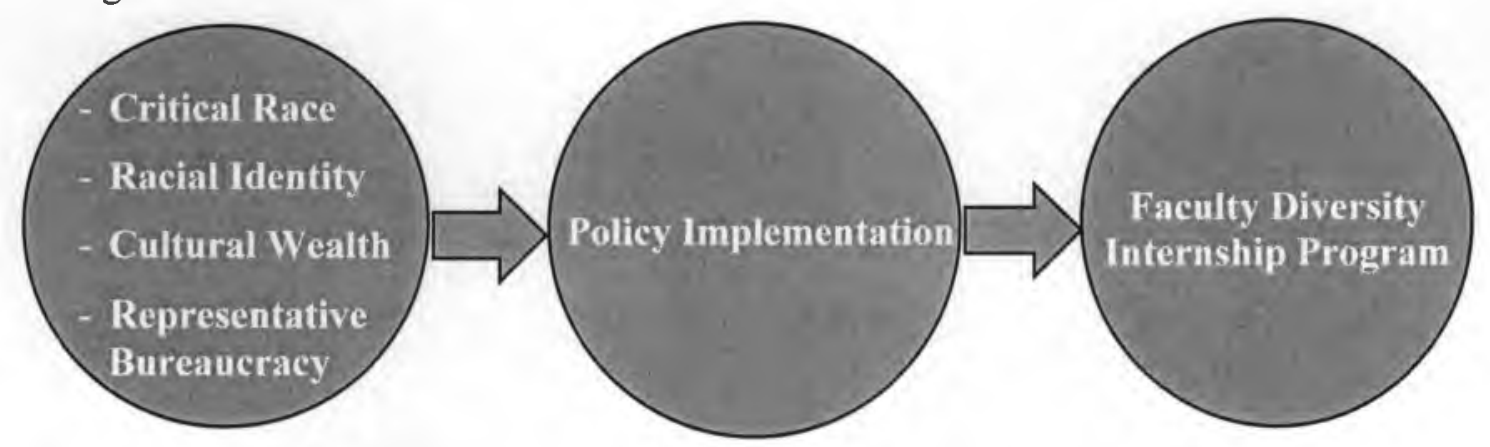

Figure 3: Conceptual Framework integrating theory and practice in program implementation of the Faculty Diversity Internship Program 


\section{Critical Race Theory}

Many scholars have examined the experience of faculty of color through the lens of critical race theory (CRT). CRT assumes that racism is a normal part of American political, economic, and culture that influences a social order that favors the dominant White race (Ladson-Billings, 1995, 1998). CRT assumes that privilege in the United States is in direct relation to property ownership, which has historically favored Whites, with non-Whites having limited access to these same opportunities (Ladson-Billings, 1995).

CRT emphasizes the importance of storytelling to analyze racism within society (Ladson-Billings, 1998). The use of storytelling is widely used in the literature surveyed to illustrate the challenges faced by faculty of color. These "stories" or testimonies are meant to give voice to an often marginalized population, which can then be used as supporting evidence for program implementation and/or improvement to confront racism and improve campus climate (Ladson-Billings, 1998).

Since one of the goals of the FDIP is to "promote inclusive efforts to locate and attract qualified graduate students who are members of monitored groups as defined in section 53001(i)," which include groups identified by gender, ethnicity, and disability (Title 5, California Code of Regulations, Section 53500), the program may be considered an affirmative action program that aims to right the wrongs of racism through selective recruitment. This study used a transformative approach in designing a program evaluation to identify social justice challenges, specifically faculty diversity. The program evaluation provided opportunities for interns and mentors to share their stories of participating in the internship program. The qualitative data collected through open 
ended questions in a survey and interviews revealed how race had an impact on their participation and experience in the internship program.

\section{Racial Identity Development Theory}

The experience of ethnically underrepresented faculty has also been explained through the lens of racial identity development theory. Understanding identity development as it pertains to faculty diversity is important because of the changing demographics of students and faculty that have an impact on interactions in classrooms and on the campus climate (Torres et al., 2003). In addition, identity development theory can inform decision-making in developing programs that support underrepresented faculty and diversity-related issues (Stanley, 2006).

Helm's (2003) racial identity development theory state that people of color fall within five categories of development: 1) conformity, where the idea that the dominant White identity is better; 2) dissonance, where people question their belongingness; 3 ) immersion/emersion, where one's racial identity is based on naiveté of one's race and is most likely based on the dominant culture's stereotype of that race; 4) internalization, where one comes to have a positive sense of one's racial identity; and 5) finally, integrative awareness where there is an understanding that certain groups experience differential treatment based on their demographic identity. These issues pose challenges for faculty in several ways. For example, faculty of color may assimilate to the dominant culture; resist or accept their marginalized position; or accommodate it by participating in the dominant culture. Ideally, faculty will have an integrative awareness and maintaining their racial identity (Cuyjet, 2008; Diggs et al., 2009). Examples of how this is exhibited in the workplace can include participating in multicultural initiative on campus and 
playing the "token" role in regards to assimilating to the dominate culture. An example of faculty taking an integrative approach include being a mentor to students of color or participating in community organizing/activism.

Helm's (2003) also explains three types of racial identity interaction theory; parallel, regressive, and progressive. In a parallel relationship, the identity of people of color are parallel to the dominant race's perspective of people of color. A regressive relationship is where people of the dominate race do not value people of color and a progressive relationship is where both people from the dominant race and underrepresented race support each other in their own identity development. Helm suggests that a regressive relationships can potentially lead to "disharmony, conflict, tension, and rebellion" (Helm, 2003, p. 54).

Conflicts between the identities of being a professor and a person of color have been coined the "divided self" or "imposter syndrome" (Dancy \& Brown, 2011; Levin, et al., 2013). These studies found that faculty of color contend with legitimizing their existence as a professor to fit within the institutionalized norms, practices, and assumptions by relegating their personal issues that usually pertain to their racial/ethnic identity.

The FDIP include induction practices and mentoring relationships that aim to prepare new faculty to teach and serve in California community colleges. Interns' experiences with their mentors and the institution may have an impact on the interns' racial and academic identity development that may influence their decision and/or experience as a new faculty of color. An awareness of the dynamics that influence racial 
identity development may help mentors understand the challenges that new faculty and students of color face in a learning environment.

This study conducted a program evaluation that included a survey with questions about diversity factors, including demographic information pertaining to their identity, their mentorship experience, and whether or not the FDIP had an impact on diversityrelated issues. The study also includes interviews with questions about the participant's interest and expectations, which may reveal how one's race may have influenced their participation in FDIP.

\section{Cultural Wealth Theory}

Cultural Wealth Theory provides an alternative and positive perspective on diversity. Cultural Wealth Theory proposes that communities of color possess cultural and social capital that enable them to thrive despite a society that supports White privilege; these cultural and social capital include aspirational, navigational, social, linguistic, familial, and resistant capital (Yosso, 2005).

The literature surveyed illustrates how faculty of color draw from their cultural wealth and continue to aspire, navigate, and resist unwelcoming campus environments. For example, as one faculty of color stated, "When you are one of a handful of faculty of color on campus, students of all colors often gravitate to you. Mentoring students is a privilege...I have found White students also hungry for advising time... with an older person of color truthfully and thoughtfully over issues and concerns about diversity" (Stanley, 2006, p.720-721). Faculty of color report not only wanting to fulfill their traditional instructional duties, but to also serve as agents of change for their students, communities, and educational institutions (Diggs et al., 2009). 
The program evaluation conducted aimed to understand how intern's cultural wealth may have influenced their decision to participate in FDIP as well as how it may have impacted their experience in the program. In addition, this program evaluation also aimed to understand how an intern's cultural wealth may have an impact on the students they teach and interact with as well.

The FDIPs call upon current faculty to serve as mentors to interns who aspire to teach in community colleges. Whether faculty mentors are faculty of color or not, it requires their skills and knowledge as veteran faculty to help aspiring interns to building their aspirational, navigational, social, linguistic, and perhaps familial and resistant capital. This mentorship relationship relies on the passing of social, political, and cultural capital from faculty to intern. The program evaluation may also reveal the FDIP's recognition and value of intern's cultural capital and how it may or may not influence their experience with their mentors as well as their integration into the campus community.

Representative Bureaucracy Theory

The theory of representative bureaucracy states that individuals who share similar demographic traits hold similar values, which assumes that when bureaucracies are representative of the societal demographic then policies are representative of those shared values (Meier et. al., 2006). The theory distinguishes between passive and active representation and argues that increased passive representation (quantity) leads to more active representation (quality) that have a stronger impact on policy making (Meier et. al, 2006). Lipsky's (1994) commentary “Why We Must Increase Diversity" argues for representative bureaucracy in policy schools so that minority students can find role 
models they can connect with and that faculty reflect the diversity of its students to provide the range of perspectives reflected in the population it serves.

Meier and Smith's (1994) research revealed that representative bureaucracy impacts both from the top-down and the bottom-up. Their analysis of 67 Florida school districts shows that a higher representation of Black school board members was a strong predictor of higher representation of Black administrators, and similarly, a higher representation of Black administrators was a strong predictor of Black teachers. However, the study also showed that political and bureaucratic representation is a reciprocal effect (Meier \& Smith, 1994). Meier and Bohte's (2001) research also states the structural organizations that support greater discretion among minority teachers have a greater impact on student performance.

Although these studies were done within a K-12 context, they provide compelling evidence to support faculty diversity at the community college level, since the majority of California's underrepresented students start higher education in community colleges (Geiser \& Atkinson, 2010).

One of the purposes of internship programs may be to introduce new employees to the culture of the institution, including its mission and values. This study will include qualitative data to examine whether the FDIP not only increases representative bureaucracy passively (quantity) and but actively (quality) as well. The qualitative data hopes to provide a deeper understanding into the benefits of participating and preparing new faculty to work and navigate a diverse community college both inside the classroom and collaboratively across the campus as well. Furthermore, the study may also reveal whether the FDIP is instrumental in developing shared values and mission in its interns. 
Community Colleges and the Commitment to Diversity

California is ranked first in the continental U.S. as being the most diverse state (Emerson, 2011) and the 113 California community colleges comprise the largest system of higher education in the nation serving over 2.3 million students who represent the diverse population of California, including $7 \%$ African-American, $15 \%$ Asian/Filipino/Pacific Islander, 43\% Latino/a, 4\% Multiethnic, and 28\% White (CCCCO MIS Datamart, Annual Student Count, 2015).

The California community college system also has multiple diversity statements that reaffirm their commitment to diversity. For example, the Chancellor's Office of the California Community College's Student Success Taskforce Final Report (2012) states, "Given California's changing demographic profile, the success of these historically underrepresented groups will determine the fortunes of our state" (p. 9).

In addition, the Accrediting Commission of Community and Junior Colleges (ACCJC) Standard III Resources, Part A Human Resources, requires, "Through its policies and practices, the institution creates and maintains appropriate programs, practices, and services that support its diverse personnel. The institution regularly assesses its record in employment equity and diversity consistent with its mission" (ACCJC, 2014, p. 10). Unfortunately, this illustrates the disparity between institutional statements of commitment to diversity and the reality of the lack of faculty diversity in community colleges.

Community colleges are at a crossroads in fulfilling their commitment to diversity since President Obama's America's College Promise will increase community colleges' capacity to decrease the achievement gap with an investment of over $\$ 60$ million over ten 
years to provide two years of free tuition to community college students (U.S. DOE, 2015).

Although much of the literature is focused on student diversity as it pertains to access and success, there is limited literature on faculty diversity. Reform bill of 1988, AB 1725 allowed community colleges to partner with California State Universities and Universities of California to provide graduate students with temporary teaching positions to 1) be a form of financial aid to the graduate students, especially for minority and disadvantaged students, and 2) provide access to graduate students who wish to enter into the teaching profession at the community college level" (Klein and Peralaz, 1996, p. 36).

In 1992, legislation was passed that allowed community colleges to set up faculty internship programs with three main goals, one being student success and the others 1) to introduce interns to the community college environment and its student population, 2) to expose industry interns to the community college environment and encourage community college students to complete a degree, and 3) to build a diverse faculty (Title 5, Section $53500)$.

More recently, the California Community Colleges Chancellor's Office EEO \& Diversity Committee launched a number of initiatives, including a new funding model, to address faculty diversity. The CCCCO EEO \& Diversity Committee have organized summits across California, starting in the Fall 2015 semester, to provide training to community colleges/districts to review the legislation that requires colleges to monitor EEO and diversity measures. These trainings provide an overview of the legislation and the importance of increasing faculty diversity. However, it does not provide specific guidelines on implementing programs that may lead to increased faculty diversity. 


\section{Policy Implementation}

The resurgence of faculty diversity initiatives demonstrates how issues are raised through policy making. Fowler (2013) identifies four theoretical frameworks of policy, 1) competing values, 2) Lowi's policy types, including distributive, regulatory, and redistributive, 3) institutional choice, and 4) international convergence. Based on Fowler's theoretical frameworks on policy, the California community college system's policy on faculty diversity works from all four frameworks. The Chancellor's office have already claimed their value of diversity in preparing the workforce on a local and global scale and the Chancellor's office work in both distributive, regulatory and redistributive means, but leaves the choice and design of implementation to the colleges. Despite the CCCCO's efforts in supporting faculty diversity, there is still a lack of information and understanding of whether the FDIP is being implemented and whether it has an impact on increasing faculty diversity. This study aimed to understand how policy is implemented and whether the goals of a policy is achieved through policy implementation, specifically for this study the FDIP as a strategy to increase faculty diversity.

Kohoutek (2013) examines the theory development of policy implementation in higher education and provides an overview of the two main perspectives, top-down and bottom-up. Top-down and bottom-up policy implementation theories provide opposing views of how policies take effect. Top-down theory argues that six conditions must be in place for top-down policy implementation: defined objectives; adequate causal theory; legal structures to ensure compliance; knowledgeable and skillful implementers; buy in from stakeholders; and the right socioeconomic conditions (Kohoutek, 2013). In contrast, bottom-up theory argues that top-down policies do not trickle down to actual 
implementers and that implementers have a greater influence on practices if policy makers engage implementers (Kohoutek, 2013). These opposing theories have led to other theories that integrate both top-down and bottom-up approaches, such as forward and backward mapping and advocacy coalition frameworks (Kohoutek, 2013).

As stated, in 1992 the California legislation passed a policy to allow community colleges to implement FDIPs as one strategy to increase faculty diversity. The intermediaries or implementers of this policy are community colleges/districts. According to Fowler (2013) the success of any policy implementation is dependent on "developing and maintaining the will and the capacity of the intermediaries" (p. 242).

Since the FDIP has not been widely implemented, policy implementation theory suggests that the FDIP legislation was a top down policy that did not provide community colleges/districts with a sense of urgency and resources for colleges/districts to have the will and capacity to implement the FDIP. This study aimed to provide evidence of if and how the FDIP can be used as a tool for recruiting and retaining faculty and increasing faculty diversity.

\section{Operational Definitions of Key Terms}

This dissertation includes the following operational definitions:

- Underrepresented minorities (URM): The term URM refers to African-American, Native American, and Latino/a ethnicities. This study will focus on this subpopulation because of its highest and projected growing population in California, which also has the largest disproportionality in faculty and student representation, and student outcomes (CCCCO MIS Data Mart, Student and Faculty Demographics, 
2015; CCCCO Scorecard, Student Completion; and State of CA DOF, State and County Population Projections by Race/Ethnicity, 2010-2060, 2014).

- Internship or induction programs: are a formal program that includes specific activities that introduce and orient new members to a culture or system with the aim of assisting them in becoming engaged and contributing members of the organization (Dancy \& Brown, 2011).

- Mentorship: Dancy \& Brown (2011) define mentorship as a relationship with "a more individualized effort where senior education professionals (teachers, faculty, and administrators) socialize their junior colleagues within departments, campuses, and the education leadership field" (p. 622). Socialization can be activities, including but not limited to providing networking opportunities, informing mentees of scholarship opportunities such as conference attendance, and providing feedback on pedagogy.

\section{Statement of Delimitations and Scope of Study}

This study is limited in scope because it only includes a program evaluation of two FDIPs, one at the Peralta Community College District located in the Bay Area with four colleges with urban and suburban campuses and the San Diego Imperial Valley Community College Association, located in Southern California, consisting of three college districts and ten colleges across urban, suburban, and rural areas. The program evaluation included an online survey emailed to 132 current and former FDIP participants with 96 respondents. The program evaluation also included interviews of seven interns and seven faculty mentors. Only quantitative data of faculty and student demographics from 2000 were able to be obtained, so long-term trends of faculty and student diversity were not able to be analyzed. Overall, this study is limited in scale and time period. 


\section{Significance of Study}

Diversity in higher education has been a highly visible topic because of Supreme Court cases including, University of California v. Bakke and Grutter v. Bollinger. These cases used social science research such as Gurin et al.'s (2002) to argue that not only is diversity in numbers important but interactions between students of difference races also support students' academic and social development. Despite the FDIP legislation being passed nearly 20 years ago and racial discrimination being outlawed over 50 years, there is still a lack of faculty diversity in higher education, specifically pertaining to URMs who represent the largest percent of the population in community colleges.

Studying the experience of faculty of color and programs that seek to expand diversity at community colleges would enable campus leaders to identify practices that impact faculty diversity (Fujimoto, 2012). However, most of the research continues to focus on student diversity and not on faculty. This study aimed to understand and broaden the topic of diversity in higher education to include faculty diversity within a community college context as well.

The significance and benefits of studying faculty diversity has equity implications because studies have shown the benefits of having faculty of color and the potential effects they have on closing the achievement gap. These benefits fall within two categories; 1) how faculty of color enhance teaching and learning by providing diverse perspectives in an increasingly interdependent world, and 2) how faculty of color serve as symbolic agents of change not only to students but as faculty leaders who can broaden the scope of scholarship within their institutions as well (Fujimoto, 2012; Nevarez \& Wood, 2010;). 
A diverse professoriate impacts teaching and learning by providing diverse perspectives and improving campus climate on diversity. Lee's (2010) study on campus climate found that non-Caucasian students are less satisfied than their Caucasian counterparts with the degree of faculty diversity as well as respect for diversity from professors. The study also revealed that both Caucasian and non-Caucasian students value a more diverse academic environment because students believe diversity enriches their educational experience.

In addition, a recent quantitative study of a community college in the California Bay Area by Fairlie, Hoffman, and Oreopoulos (2014) also revealed the significant academic gains of URM students who had faculty of color, including pass rates, grade performance and retention. This study's findings also showed a $20-50 \%$ closing of the achievement gap between White and URM students. However, the study also found that although students who interacted with faculty of the same or similar race had positive outcomes, students had negative outcomes with faculty of a different race (Fairlie et al., 2014).

Second, faculty of color may serve as role models to the growing population of students of color (Davis, 2010; Fujimoto, 2012; Umbach, 2006). Lee's (2010) study also revealed that non-Caucasian students were uncomfortable or lacked faculty members they could relate to who could serve as role models. Other studies have shown that faculty of color interact more with students, regardless of their race, than their White counterparts (Umbach, 2006). These interactions have a positive impact on improving students of color's attitude toward their education, as well as their attitude towards their academic potential and aspirations (Davis, 2010; Hagedorn, Cepeda, \& McLain, 2007; Lechuga, 
2011). These studies have shown that faculty of color improve the environment as well as interactions for students of color, both of which have a positive impact on student learning and retention.

Much of the discussion in the literature about the experience of faculty of color offer recommendations for institutions to improve the campus climate towards diversity. Recommendations include both formal and informal mentorships with senior faculty (Ponjuan et al., 2011; Diggs et al., 2009; Stanley, 2006; Dixon-Reeves, 2003; Sadao, 2003), cross-cultural training (Garrison-Wade et al., 2012; Stanley, 2006; Sadao, 2003) and assess diversity measures (Stanley, 2006). Faculty of color also reported the benefits of having mentors and affinity groups that supported their experience through the tenure track and recommend institutions to implement formal mentorship and affinity group programs (Reddick \& Saenz, 2012; Salazar, 2009). Although this research dissertation does not focus on the impact of faculty of color on student outcome, Grissom et al. (2015) also argue for more research on how representative bureaucracy in education impacts not only student outcomes but policy outputs as well.

There were limited studies found on actual faculty diversity programs/initiatives that provide successful practices that led to increased faculty diversity and only one study found on one FDIP in particular. Leveraging the importance of diversity in higher education and the increasing role of community colleges to increase access and success to low-income underrepresented students, this study will provide additional evidence to identify promising practices that can be institutionalized to improve faculty diversity in California community colleges. 
Not only is diversity a current policy issue because of California's transformation into a minority majority state, but scholarly articles address how faculty of color have an impact by 1) serving as role models, 2) serving the educational community and external community, which broadens the scope of scholarship, and 3) faculty of color expose students to differing perspectives that is needed to compete in an increasingly interdependent global economy.

In addition, the California community college system has a perfect opportunity to consider hiring practices, such as FDIPs, that would result in increased faculty diversity because approximately $44 \%$ of current tenured and tenure-track community college faculty are at or above retirement age (20\% age $55-59$ and $24 \%$ age $60+$ ), (CCCCO MIS Data Mart, Faculty \& Staff Demographics Report, 2015).

This study hopes to connect how the theories of Cultural Race Theory, Racial Identity Development, Cultural Wealth, and Representative Bureaucracy, or the "why" faculty of color are not representative of the California population in our community colleges, to "how" we can increase faculty diversity as a strategy to improve student access and success. This study aimed to do this by collecting both quantitative and data in a program evaluation of FDIPs at two community colleges in California. 


\section{Chapter Two: Literature Review}

\section{Introduction}

"I remember my entire [dissertation] committee telling me that Affirmative Action was a dead issue, that I should be steering away from that issue... and they told me to be careful - to research "controversial" 'issues would signal that I'm a Latina and I'm a person of color, and I only care about person of color issues. . . This is who I am. . . This is what I want to research (Mexican American, female)" (Zambrana et al., 2015, p. 55).

The purpose of this study is to provide evidence of the benefits of preparing faculty of color as a means to prepare and increase faculty of color in California community colleges. The purpose of this literature review is to connect theory and current research on faculty diversity to be used as the framework for this dissertation.

The quote above provides an overall illustration of the literature on faculty diversity, where current or prospective faculty of color must contend with their racial identity within an educational institution that does not value their identity and/or diversity-related experience, service and scholarship. This literature review will analyze theories and the current field of research about faculty diversity. This review will reveal that the literature focuses on the experience of faculty of color and that there is a lack of studies on how to increase faculty diversity in higher education. A synthesis of theories and the current research will also be provided to add to the body of knowledge on how theories can inform practice, specifically the implementation of FDIPs, in increasing faculty diversity in California community colleges.

\section{Structure and Scope of Review}

Literature regarding faculty diversity was framed by Critical Race Theory (CRT), Racial Identity Development Theory, Cultural Wealth Theory, and Representative Bureaucracy Theory. Other theories were covered in the literature, such as critical neo- 
institutionalism and intersectionality, but they usually stemmed from CRT, Racial Identity Development Theory and Cultural Wealth Theory. Review of the literature identified three themes: 1) the experience of faculty of color, 2) the employment practices that hinder or support faculty diversity, and 3) the impact of faculty of color on teaching and learning. Studies with an emphasis on practice fell into the second and third theme of the impact of faculty diversity and/or how to support faculty of color and diversity.

Articles collected for this literature review were from a Proquest Education Journal search using "community college" and "faculty of color" from 2000 to 2015. This search identified 53 articles. However, only 13 articles were relevant. An additional search using "faculty of color" or "faculty diversity" in journal article abstracts was conducted and identified 68 articles from 2000 to 2015 . For the purposes of this literature review, I deleted articles that were discipline specific, which included nursing, counseling, law, and kinesiology. I also deleted articles that were book reviews, focused on gender, and 2 that focused on White faculty. 49 articles remained and were included in this literature review. With consultation from my dissertation committee, I also expanded my search to public policy journals and searched "representative bureaucracy" and "policy implementation" using Google scholar and identified 10 articles about representative bureaucracy that provide a definition as well as research within an educational setting.

Through attribute coding three themes were identified (Miles, Huberman, \& Saldaña, 2014) based on a review of the article abstracts. After reviewing the articles thoroughly in my second cycle of coding, I determined that an additional 4 articles were book reviews and/or commentaries. It is also noteworthy to mention that $67 \%$ of the 
articles were published before 2010 and all three articles that specifically addressed community colleges were published within the last three years.

The Experience of Faculty of Color and How to Support Faculty Diversity

The most robust area of literature is about the experience of faculty of color. Aligned with CRT's emphasis of storytelling, much of the literature was qualitative in nature. The experience of faculty of color fell into three categories 1) identity issues, 2) mentorship issues, and 3) effect of experiences on satisfaction and retention.

Studies on faculty of color have reinforced CRT's argument that race still matters in U.S. colleges and universities. These studies have shown that faculty of color not only view their institutional environment differently than their White counterparts, but also believe they are treated differently because of their race (Chang et al., 2013; Diggs, 2009; Levin et al., 2014).

Studies show that faculty of color reported an unwelcome environment on their college campuses. Underrepresented faculty reported they are constantly reminded of both their positional and relational identities as new and/or faculty of color. These reminders come in the form of microaggressions, such as mistrust and verbal or behavioral discrimination on a day-to-day basis, both intentional and unintentional (Chang et al., 2013; Reddick \& Saenz, 2012; Salazar, 2009).

One study in particular showed a discrepancy in professional development interactions where ethnically underrepresented faculty members had an average of 14 professional development interactions fewer than their counterparts per semester. These professional development interactions included social gatherings and meetings, conversations with junior colleagues, senior faculty, administrators, chairs, and a mentor. 
The researchers suggest that professional development should intentionally take into account ethnicity in pairing mentors and in providing professional development (Hyers et al., 2012).

The literature revealed how faculty of color struggle with balancing their identity as a person of color and as a faculty member in an institution that does not value their work as a faculty of color (Diggs, 2009; Garrison-Wade et al. 2012; Levin et al. 2013). These conflicts of identity have been termed "double consciousness," "cultural dissonance," and "biculturation" (Sadao, 2003; Diggs, 2009; Garrison-Wade et al. 2012; Levin et al. 2013 \& 2014).

Much of the identity issues were framed from the experience of service work that faculty of color chose to participate, including mentoring. Faculty of color reported that their diversity-related service work provided them with a sense of value to their community as well as a support network (Reddick \& Saenz, 2012; Stanley, 2006). In addition, the institutional value that is placed on this kind of service work also had a positive correlation on faculty of color's retention and satisfaction. Thus, it is recommended that educational institutions place a higher value on service in decisions regarding tenure and promotion (Jayakumar et al., 2009; Stanley, 2006; Ponjuan et al., 2011).

Most of the literature revealed that the experience of faculty of color in balancing their identities as a person of color and a professor are challenging. Only one article focused on the success of how faculty of color balance dual identities in the professoriate. However, the author also mentions that the research was conducted at University of 
Hawaii at Manoa, located in a diverse state that historically has attracted multicultural students and faculty (Sadao, 2003).

Haley et al.'s (2014) research revealed that many graduate students of color's choice to become a professor was influenced by their socio-cultural identity. The study indicated that students' experience in graduate school did not value and/or support their aspirations to be role models, and an engaged participant and advocate in their communities and family life encouraged them to pursue a career as a professor. This research provides insight into the importance of institutions of higher education to consider how the professoriate may be perceived by some applicants, as scholars working in isolation. If institutions of higher education want to increase faculty diversity, they will have to consider people of color's cultural and social identity that plays a role in their scholarship and service.

Furthermore, this research also supports the need for induction programs to address some of the perceptions of life as a professor as being one that is insensitive to family life and service to the community. This work-life balance issue is not just important to faculty of color but all faculty.

Much of the discussion in the literature about the experience of faculty of color offer recommendations for institutions to improve the campus climate towards diversity. Recommendations include both formal and informal mentorships with senior faculty (Diggs et al., 2009; Dixon-Reeves, 2003; Ponjuan et al., 2011; Sadao, 2003; Stanley, 2006; Zambrana et al., 2015), cross-cultural training (Garrison-Wade et al., 2012; Sadao, 2003; Stanley, 2006) and assess diversity measures (Stanley, 2006). Faculty of color also reported the benefits of having mentors and affinity groups that supported their 
experience through the tenure track and recommend institutions to implement formal mentorship and affinity group programs (Reddick \& Saenz, 2012; Salazar, 2009; Zambrana et al., 2015).

Higher education is often seen as a mechanism that can bring equality among the races. Unfortunately, these studies have shown that faculty of color face very different experiences than their White counterparts and supports CRT's and Racial Identity Development Theory claims that racism and one's racial identity still influences how we are perceived and treated. The design of this program evaluation will include questions about race and seek to identify whether race influenced participation in the FDIP. As recommended by much of the studies, educational institutions are recommended to consider the racial identity of their students as well as their faculty and take an approach that values people of color's cultural wealth, as supported in Cultural Wealth Theory to provide an inclusive learning environment for both students and faculty.

The Employment Practices that Hinder or Support Faculty Diversity

Literature focused on employment practices included a broad range of articles. However, the literature fell within three categories 1) hiring, 2) retaining, and 3) monitoring faculty diversity. The overall underlying theme was focused on practices that improved campus climate that support faculty of color.

Although much of the literature cited legal cases such as Grutter v. Bollinger, which upheld affirmative action admissions policies of the University of Michigan Law School in 2003, one article in particular used a legal stance to inform policy implications for faculty diversity (Igwebuike, 2006). Igwebuike (2006) provided a brief overview of legal cases that pertained to diversity in education and offered five legal implications for 
faculty diversity including 1) quotas that seek to correct past discrimination is constitutional as found in Paradise v. United States, 1987, 2) race-based employment policies are legal as long as the benefits of diversity is well documented in the hiring process, 3) educational institutions have a right to uphold their mission towards diversity as considered in Grutter v. Bollinger, 2003, 4) race-based hiring is protected under Executive Order Number 11246 (1964-65) and Title VII of the Civil Rights Act of 1964, and 5) race-based policies should be time-restricted as policies take effect and change social reality. Igwebuike (2006) offers more policy implications including 1) the recognition that diversifying faculty to serve as role models is not the only argument, breaking down stereotypes and preparing students for a diverse workforce and society also promotes learning outcomes and 2) faculty diversity should be linked to accreditation standards and the institution's mission and goals.

Despite California's Proposition 209 being passed in 1996 that, "Prohibits the state, local governments, districts, public universities, colleges, and schools, and other government instrumentalities from discriminating against or giving preferential treatment to any individual or group in public employment, public education, or public contracting on the basis of race, sex, color, ethnicity, or national origin" (California Online Voter Guide, 1996), many articles described strategies used to address diversity in employment practices.

Smith et al.'s (2004) article researched nearly 700 hiring committees at three large public research universities and revealed that faculty of color are generally hired under two conditions: 1) the job description includes diversity factors and 2) "special hire" interventions. The article also noted that faculty of color hired as a "special hire" were 
supported and their scholarly work highly regarded, but more research is needed to determine the success of this "special hire" strategy. The authors also noted that these strategies do not violate any legal policy on affirmative action (Smith, 2004).

Two articles described programs that support faculty diversity. One program was a pilot program that included benchmarking of retention programs that promote faculty diversity, mentorships and monthly professional development for new faculty, and a college-wide diversity summit to improve campus climate (Piercy, 2005).

Another article included a program evaluation of a Faculty Diversity Internship Program at a network of community colleges in Southern California that provide graduate students an opportunity to teach a community college course and shadow a community college faculty member, the same program being evaluated in this dissertation. However, the program evaluation did not include qualitative data and did not provide data on the current faculty demographics at the research site (Jeffcoat \& Piland, 2012).

Both articles stressed the importance of providing new faculty opportunities to be mentored and a strong commitment from college administrators towards faculty diversity (Piercy, 2005; Jeffcoat \& Piland, 2012).

Finally, one article emphasized the monitoring of faculty diversity by looking at diversity from a more focused approach rather than from a broad approach (Weinberg, 2008). The article recommended analyzing faculty diversity through a "utilization analysis" because diversity happens with "clustering effects" in some majors, causing underutilization in other majors, such as STEM majors (Weinberg, 2008). Weinberg (2008) provides recommendations on both recruiting and retaining faculty of color through more targeted outreach and creating a supportive and welcoming environment. 
Recommendations on creating a supportive and inclusive environment include commitment across the educational institutions from faculty, staff, and administration (Kezar et al., 2008; Stanley, 2006; Zambrana et al., 2015). Kezar et al.'s (2008) research included interviews of 27 college presidents that revealed the impact that presidents play role in advancing a diversity agenda, particularly, prioritizing the hiring of faculty of color by working across campus and hiring deans and other administrators who shared the same diversity goals.

This study will include questions about the implementation of FDIPs. The findings may include the impact of leadership and collaboration in implementing the FDIP to improve faculty diversity. However, despite institutional commitment such as tangible resources in time and money, institutions must also recognize the cultural wealth of its current and prospective faculty of color as well. As Yosso (2005) state, institutions should recognize the cultural capital that people of color bring to their higher education experience and as the population of people of color increase, "they become empowered participants, hearing their own stories and the stories of others, listening to how the arguments against them are framed and learning to make the arguments to defend themselves" (p. 75).

The Impact of Faculty Diversity on Teaching and Learning

Few articles focused on the impact of faculty of color on teaching and learning. However, many articles cite a small group of literature that provided limited data on how faculty of color impact teaching and learning. These articles addressed how faculty of color have an impact by 1 ) serving as role models, 2) service to the educational community and external community, and 3) broadening the scope of scholarship. 
Multiple studies examined the role of faculty of color as role models and revealed the positive impact that faculty of color have on students of color, specifically (Lee, 2010; Stanely, 2006; Umbach, 2006; Zambrana, 2015).

Lee's (2010) study revealed that non-Caucasian students were uncomfortable or lacked faculty members they could relate to who could serve as role models and both Caucasian and non-Caucasian students value a more diverse academic environment. Other studies have shown that faculty of color interact more with students, regardless of their race, than their White counterparts (Umbach, 2006). These studies have shown that faculty of color improve the environment as well as interactions for students of color, both of which have a direct impact on student learning.

Other studies also showed that not only do faculty of color have an impact on students through their interactions but through teaching as well. Nelson's (2011) study revealed that although most faculty reported believing in the importance of including diversity into college courses, faculty of color scored higher in including it in course content. A recent large-scale quantitative research at a community college in Northern California revealed students who had same-race instructors, actually performed better and had positive long-term outcomes such as retention and completion (Fairlie et al., 2015).

Faculty of color are also usually called upon to serve on committees related to diversity-related initiatives (Levin et al., 2014; Diggs et al., 2007; Reddick \& Saenz, 2012). These activities enable faculty of color to serve as agents of change by collaborating across campus to deepen the dialogue about diversity (Stanley, 2006). Opportunities for faculty of color to serve in leadership positions can serve as a starting point for educational institutions to examine and support their commitment to inclusivity 
and broadening the traditional definition of scholarship (Antonio, 2002; Nelson, 2011; Stanley, 2006).

Researchers have linked the theoretical frame of representative bureaucracy to educational outcomes. Pitts (2007) research in Texas revealed that teacher representation not only was positively correlated with higher test scores but also corresponded to fewer students dropping out. Ross et al.'s (2010) research similarly looked at over 1,000 Texas school districts and revealed that the larger number of Latino/a students was positively correlated with the number of Latino/a school board members, administrators, and teachers. The research also showed that the number of Latino/a teachers was positively correlated with higher standardized test scores but not school board members or administrators (Ross et. al., 2010). These studies reinforce earlier findings from research conducted by Meier et. al. (1994, 2000, 2001, 2006). However, Meier et. al. (2006) and Owens et. al. (2012) emphasize that although programs to achieve student success matter, people matter as well. Owens et. al. (2012) study on 500 Texas school districts revealed that managers in heterogeneous districts tend to mitigate any negative effects of representative bureaucracy through networking activities.

Overall, the literature calls for more and expanded research on representative bureaucracy in education, including any negative effects of representative bureaucracy, role perception, discretion, and qualitative data (Grissom et. al. 2015; Kennedy, 2014; Meier et. al., 2001).

This program evaluation sought to identify not only if the FDIP has an impact on increasing faculty diversity, but also whether interns hired through the program were well prepared to work in a diverse community college, which include their impact both inside 
and outside of the classroom. In addition, identifying the barriers and challenges of implementing FDIPs may also reveal representative bureaucratic challenges as well. California Community Colleges and Faculty Diversity

The previous sections of this literature review provide an overview of the experience, employment practices, and impact of faculty of color in education. This next section will focus on California community colleges specifically and faculty diversity.

California community colleges are the nation's largest higher education system. It consists of 113 community colleges and enrolls over 2.3 million students who have a range of educational goals, including life-long learning, basic skills, career/technical training and development, and transfer to 4-year universities (California Community Colleges Chancellor's Office, 2016).

In 1992, California legislation passed into Education Code Title V, the ability for California community colleges to implement Faculty Diversity Internship Programs with the explicit goal to "promote inclusive efforts to locate and attract qualified graduate students who are members of monitored groups" including groups identified by gender, ethnicity, and disability (Title V, California Code of Regulations, Section 53500). Although the legislations do not identify which group should be monitored specifically, the legislation does require colleges to collect data to determine if there are any underrepresented groups based on gender, ethnicity, and disability.

Despite legislation being passed over 20 years ago, less than half of colleges in the system have implemented FDIPs, according to a CCCCO commissioned report in 1996 on Faculty Internship Programs. There has been no comprehensive report since then. However, the CCCCO also commissioned, in 2000, a study "to research and 
disseminate information about the innovative and replicable ways in which the state's community colleges are addressing diversity" (Gabriner et al., 2002, p. 13). The study, We Can Do That! A User's Guide to Diversity Practices in California Community Colleges, identified over 23 strategies to promote faculty diversity in three different categories 1) recruitment \& hiring, 2) internal climate, and 3) external relations. The study included FDIPs at Los Rios Community College District, Peralta Community College District, and San Diego Imperial Valley Community College Association, as well as two other internship programs at Cerritos College and Los Angeles Community College District.

Faculty Diversity Internship Programs provides graduate students with a faculty mentor in the same discipline, training ranging from classroom management to pedagogy, and teaching experience. The FDIP not only serves as a recruitment strategy to attract faculty of color, but also provides interns with an induction program that prepares them to teach in a community college setting, which may impact retention of faculty of color as well.

Based on the low numbers of implementation, it seems like the existence, ability, and perhaps benefits for community colleges to implement FDIPs are fairly unknown, despite the Academic Senate for California Community Colleges encouragement "to expand...college[s] participation in internship programs" (2000, Resolution 17.03) and California legislation allowing community colleges to allocate funds to increase faculty diversity (Title 5, Section 53500, California Code of Regulations).

The passing of Proposition 209 in 1996 that prohibits public institutions from giving preferential treatment based on race, sex, and ethnicity, may have been seen as a 
setback for diversity-related initiatives. However, as early as Fall 1997, the Academic Senate for California Community Colleges (ASCCC) put forth a resolution stating that "Whereas the makers and proponents of Proposition 209 deliberately deceived voters by calling Proposition 209 a "civil rights" initiative, and... Resolved that the Academic Senate urge local senates to continue to ensure that affirmative action regulations be enforced on their campuses" (ASCCC, Resolution 03.02).

Many may argue that there is a lack of qualified candidates to teach in community colleges. The minimum qualifications to teach at a community college are as follows:

- A master's degree in the discipline that the candidate intends to teach, if a master's degree is required; or

- A bachelor's or associate degree and minimum years of experience in the discipline that the candidate intends to teach, if a master's degree is not required (typically career-technical education) (CCCCO, 2012, Minimum Qualifications for Faculty and Administrators in California Community Colleges). According to the California Post-secondary Education Commission, graduate degrees conferred to URM students have gradually increased 5\% each year between 2000 and 2009 from 7,963 to 12,558 . However, across the same time period, on average only $15 \%$ of students who receive graduate degrees are URM graduates.

President Barack Obama's support of free community college is an opportunity to resurface faculty diversity into public debates. More recently and locally, the CCCCO's EEO \& Diversity Committee have organized diversity trainings and summits in the fall 2015 and continued in the spring 2016 semester. The trainings have included review of federal and state EEO legislation and implicit bias in hiring and have been limited in 
offering strategies on how to increase faculty diversity. However, the CCCCO's Institutional Effectiveness Partnership Initiative have set up Partnership Resource Teams consisting of community college faculty and staff volunteers who can provide technical assistance to any community college/district that requests assistance, one area of assistance include implementation of diversity activities, including faculty internship programs.

Fowler (2012) defines public policy as, "the dynamic and value-laden process through which a political system handles a public problem. It includes a government's "expressed intentions and official enactments, as well as its consistent patterns of activity and inactivity" (p. 5). The adoption of FDIPs in California's legislature in Title 5, California Code of Regulations, Section 53500 is a good example of the dynamic and value-laden process of California legislations that has gone through patterns of activity and inactivity, most likely, a result of the support and opposition of affirmative action, and more specifically in California Proposition 209.

The passing of FDIP in Title 5, can be seen as a policy that encompass all three types of policy, 1) distributive, 2) regulatory, and 3) redistributive and utilized in varying degrees all four policy instruments, 1) mandates, 2) inducements, 3) capacity building, and 4) system changing. This dissertation aims to provide data to promote the enactment of all policy instruments. Mandates usually include not only language regarding a desired behavior but language regarding noncompliance as well (Fowler, 2012). The Title 5 language regarding FDIP does not include prescriptions of penalty to Districts who do not implement FDIPs or who do not show equitable diversity in faculty demographics. Although Title 5 did indicate that funding in inducements and/or capacity 
building funds are available for Districts for equal employment opportunities, there were no guidelines specific to how FDIPs should be implemented. The adoption of Title 5 regarding FDIP, was a system change that gave local control to districts to implement FDIPs. However, the lack of adoption across California community colleges may indicate the weak system change since the FDIP is voluntary.

\section{Implications for Further Research}

Grissom et al. (2015) states that studying representative bureaucracy in educational settings identifies how bureaucratic systems impact underserved groups. They identified educational research that has linked representative bureaucracy to student outcomes including, discipline, gifted assignment, special education, and student achievement. However, most of the research identified was from K-12 and the authors recommend more educational research that link representative bureaucracy to policy outputs and student outcomes (Grissom et al, 2015).

Furthermore, review of the literature reveals that there is a lack of research about faculty diversity within community colleges. Most of the literature focused on the experience of faculty of color at four-year universities and representative bureaucracy at the K-12 level. For example, Victorino et al. (2013) study of nearly 30,000 faculty at 4year universities reported that female, faculty of color, and African American faculty had a less positive view on the campus racial climate and their study showed a positive relationship between perceptions of campus racial climate to job satisfaction. The need for more literature about faculty diversity at the community college level cannot be overstated not only for the diverse student population but also because of the large population of students enrolling in community colleges overall. 
The literature review also shows that there is a lack of research about the impact of diversity programs on employment practices, specifically. There is a wide range of literature about the impact of affirmative action programs on the admission and enrollment of students of color, as well as literature on diversity at the administrative level. However, there is a lack of literature about faculty diversity.

There was also a lack of literature on the impact of faculty of color on student outcomes. The current literature included limited research with a small sample and the one large-scale study was a quantitative study that did not provide insight about the types of interactions that had the most positive impact on student outcomes.

Although the literature provides recommendations on how to improve faculty diversity, very little research is conducted on the impact of some of these strategies and recommendations. The purpose of this study is to add to the body of knowledge about strategies to improve faculty diversity, particularly how FDIPs may be used as a mechanism to achieve faculty diversity in California community colleges. The dissertation aims to build on the language of the current policy, as well as leverage the current policy context surrounding California community colleges' commitment to diversity, access, and student success and argue that it is time to resurface race and consider faculty diversity in recruiting and retaining faculty of color in California community colleges, so that our faculty and student body reflect the diversity of our State, a testament to community college's commitment to diversity.

\section{Conclusions and Implications}

Overall, the studies reviewed discussed the topic of faculty diversity using the frame of Critical Race Theory, Racial Identity Theory, Cultural Wealth Theory, and 
Representative Bureaucracy. The studies showed that faculty of color have very different experiences than their White counterparts and that they also have positive influences on students of color and include diversity-related issues in their curriculum, classrooms, and service to the campus and community. However, the studies also revealed that faculty of color's racial identity and race-conscious service and scholarship are not valued in the academe, which may impact hiring and tenure decisions, thus, limiting faculty diversity in higher education.

This dissertation is informed by the theories and the studies reviewed in developing the program evaluation of FDIPs in California community colleges. The research design and questions sought to use the stories of the FDIP participants to reveal supports and challenges of using FDIP as a means to increase faculty diversity and perhaps improve campus climate. Program evaluation of two existing and long-standing FDIPs was used to understand challenges that limit policy implementation that negatively impact policy outcomes. Integrating the theories and practice of policy implementation may provide evidence for community colleges seeking to implement FDIPs as a means to increase faculty diversity. 


\section{Chapter Three: Methodology}

\section{Introduction}

"Our results suggest that the academic achievement gap between white and underrepresented minority college students would decrease by hiring more underrepresented minority instructors. However, the desirability of this policy is complicated by the finding that students appear to react positively when matched to instructors of a similar race or ethnicity but negatively when not...A more detailed understanding of heterogeneous effects from instructor assignment, therefore, is needed before drawing recommendations for improving overall outcomes. The topic is ripe for further research, especially in light of the recent debates and legislative changes over affirmative action." (Fairlie et al., 2015).

This chapter reviews the purpose of the study and research questions and describes the qualitative research design utilized to answer the research questions. The chapter will 1) explain the transformative program evaluation research design in examining the Faculty Development Internship Program at two research sites, 2) discuss the role of the researcher, 3) describe the context of the research, 4) provide details on the data collection methods, and 5) discuss the data analysis methods utilized.

The study utilized a transformative research design to develop a program evaluation to collect qualitative and some quantitative data to answer the research questions (Creswell \& Plano Clark, 2011). A transformative approach was used to develop the program evaluation with the purpose of identifying social justice challenges, specifically with this research, faculty diversity challenges (Creswell \& Plano Clark, 2011).

An online survey was designed to collect qualitative and quantitative data from current and former participants of FDIPs and additional qualitative data were collected through interviews with seven interns and seven faculty mentors (see Appendix 1). Additional quantitative data were also collected from the California Community Colleges 
Chancellor's Office MIS Datamart. The survey provided basic information regarding the participants, including demographic information and their perceptions of whether the FDIP had a positive effect on professional development and diversity-related issues. The face-to-face interviews can validate the findings from quantitative data on the demographic makeup of faculty across California as well as within campuses that implement FDIPs, as well as identify key constructs that impact the successful implementation and impact of the FDIP. While the qualitative data provided evidence of FDIP's formative impact, both the qualitative data and the quantitative data together, allowed for data analysis in answering the summative impact of the FDIP.

\section{Role of the Researcher}

I grew up low-middle class in Queens, New York, in the 1980s when diversity was referred to as a melting pot or a salad bowl. I probably would have benefited from attending a community college. However, since I went to high school abroad after my parents divorced and I was a first generation college student, I didn't know about the community college system. I attended a college fair with only 4-year university recruiters, at my international high school in Thailand and picked the college that gave me the largest scholarship and financial aid package. I ended up at a small, private liberal arts college just outside of Philadelphia and as soon as I discovered study abroad, I left as soon as I could because for the first time in my life, I felt like an outsider and a minority.

Now, as a first generation college student, person of color and a student services professional in a California community college, this research is important to me personally and professionally. I do believe that a diverse and inclusive learning environment plays a key role in preparing students for an increasingly global workforce 
and economy. I also believe that diversity and inclusivity in higher education should not only be reflected and practiced in its student body but in its faculty, staff, curriculum, and pedagogy as well.

My personal and professional commitment to my students is one where students are free to explore their world and their place in it and discover how to navigate both the barriers and facilitators to their success and the success of others. I see my role in this study as similar, to understand the barriers and facilitators that support and/or hinder faculty diversity and understand and discover my role as well as other stakeholders, who influence faculty diversity in the California community college system.

During a Flex Day student panel, a Latino student shared with faculty and staff, "In my lower level Math class, there were a lot of students who look like me and the higher I went, I wondered, where are all the Latinos?" This student's observation was simple but deeply troubling. I wondered if the lack of peers in higher level classes and the lack of a role model that look like them impact student success. I chose to focus my research on faculty because they have the most contact and visibility with students.

Although my experience may not be comparable to the URM students who represent the majority of students in California community colleges, I am aware of the potential researcher bias because of my identity as a person of color. I attempted to avoid researcher bias by designing a survey and interview protocol that was reviewed by the FDIP Coordinators that aimed to solicit information about the FDIP and its purpose of increasing faculty diversity. The survey was anonymous and face-to-face interviews were randomly solicited through the online survey. As the researcher, I had no personal or professional relationship with any of the interviewees or their respective campuses. 


\section{Research Objectives and Questions}

The percentage of URM faculty in community college has not matched the increased URM population in California and its community colleges, despite legislation protecting equal employment opportunity. The overall purpose of this study is to provide evidence, recommendations, and guidelines to any community college and/or district interested in implementing a FDIP as a means to increase faculty diversity. To this end, a program evaluation was conducted of the Faculty Diversity Internship Program (FDIP) at two sites, Peralta Community College District (four colleges) and the San Diego Imperial Valley Community College Association (ten colleges) to answer the following research questions:

1. What do FDIP participants find beneficial in participating in the program?

2. What are the barriers and challenges in implementing FDIPs?

3. What is the impact of the FDIP on faculty diversity as a recruitment and retention tool?

Although not a primary research question, this research also aimed to understand the FDIP impact in improving campus climate around diversity and serving as a recruitment and retention tool for students of color as well.

\section{Context and Participant Selection}

This study included a program evaluation of FDIPs at two California community college districts/associations; Peralta Community College District (PCCD) and San Diego and Imperial Valley Community College Association (SDICCA).

The Peralta Community College District, includes four colleges serving both urban and suburban communities in the East Bay near San Francisco. PCCD serves 
approximately 30,000 students, each college serves approximately 6,000 to 7,000 students with the exception of Laney College that serve about 11,000 students. The student population is very diverse, including 22\% African American, 26\% Asian (including Filipino and Pacific Islanders), 23\% Hispanic, and 18\% White (CCCCO Datamart, 2015). The faculty demographics at PCCD is also quite diverse $21 \%$ African American, 15\% Asian, 14\% Hispanic, and 45\% White (CCCCO MIS Datamart, 2015). Originally, the PCCD FDIP was part of a Northern California regional FDIP that originated from faculty diversity legislation co-authored by PCCD Trustee Cy Gulassa, where each college/district paid fees to be a part of the program (E. Chan, personal communication, February 22, 2016). In 1992, PCCD established their own "home grown" program, there has been nine part-time FDIP coordinators since its inception (E. Chan, personal communication, February 22, 2016; Klein \& Peralez, 1996).

SDICCA includes ten colleges located in urban, suburban and rural cities in Southern California from Oceanside to San Diego. The smallest district (Imperial) serves approximately 8,000 students and the largest district (San Diego) serves 67,000. The student ethnic diversity varies across districts and only the Latino/a population shows an ethnic disparity between students and faculty. All districts have a Hispanic student population over $33 \%$ and with the exception of $68 \%$ and $90 \%$ at Southwestern CCD and Imperial CCD respectively (CCCCO Datamart, 2015). The Hispanic full-time faculty demographics at most districts are between $14 \%$ and $19 \%$ with the exception of $26 \%$ and $24 \%$ at Southwestern CCD and Imperial CCD respectively (CCCCO Datamart, 2015). 
The SDICCA Faculty Internship Program was established in 1994 with a small grant from the California Community Colleges Chancellor's Office with the goal of preparing faculty of color in the community colleges (Jeffcoat \& Piland, 2012).

These FDIPs were selected for the study because they have been in existence for over 20 years and represent urban, suburban, and rural regions of California. In order to design the program evaluation, initial data collection about each FDIP research site was conducted to provide an overall description. The following comparison table and logic model were created. The comparison table was created through internet research and correspondences with the FDIP Coordinators. In developing the logic model to answer the research questions, first stakeholders/program participants were identified and activities and outcomes were identified to each program participant.

Table 1: Comparison of FDIPs

\begin{tabular}{|c|c|c|}
\hline & Peralta CCD & $\begin{array}{c}\text { San Diego \& Imperial Valley } \\
\text { CCCA }\end{array}$ \\
\hline Founded & 1992 & 1994 \\
\hline \# of campuses & 4 & 10 \\
\hline Staffing & 1 part-time coordinator & $\begin{array}{l}1 \text { campus coordinator each and } \\
1 \text { regional director }\end{array}$ \\
\hline Length & 1 semester & 11 months \\
\hline Goals & $\begin{array}{l}\text { The purpose of the Faculty } \\
\text { Diversity Internship Program is to } \\
\text { enhance: } \\
\text { A. the recruitment of qualified } \\
\text { persons from diverse backgrounds } \\
\text { pursuing the masters or doctoral } \\
\text { degrees, or both, into faculty } \\
\text { positions where such degrees are } \\
\text { required in the Peralta Community } \\
\text { College District, particularly for } \\
\text { disciplines for which recruitment } \\
\text { is difficult and for disciplines in } \\
\text { which a shortage of qualified } \\
\text { faculty is anticipated; } \\
\text { B. the recruitment of licensed }\end{array}$ & $\begin{array}{l}\text { - Introduce graduate students } \\
\text { and students recently } \\
\text { completing their Master's } \\
\text { degree, to the community } \\
\text { college environment and } \\
\text { student population. } \\
\text { - Arrange successful mentoring } \\
\text { relationships that support the } \\
\text { development of interns and } \\
\text { mentors as master counseling, } \\
\text { Library, or classroom faculty } \\
\text { members. } \\
\text { - Provide training for interns } \\
\text { emphasizing assessment of }\end{array}$ \\
\hline
\end{tabular}




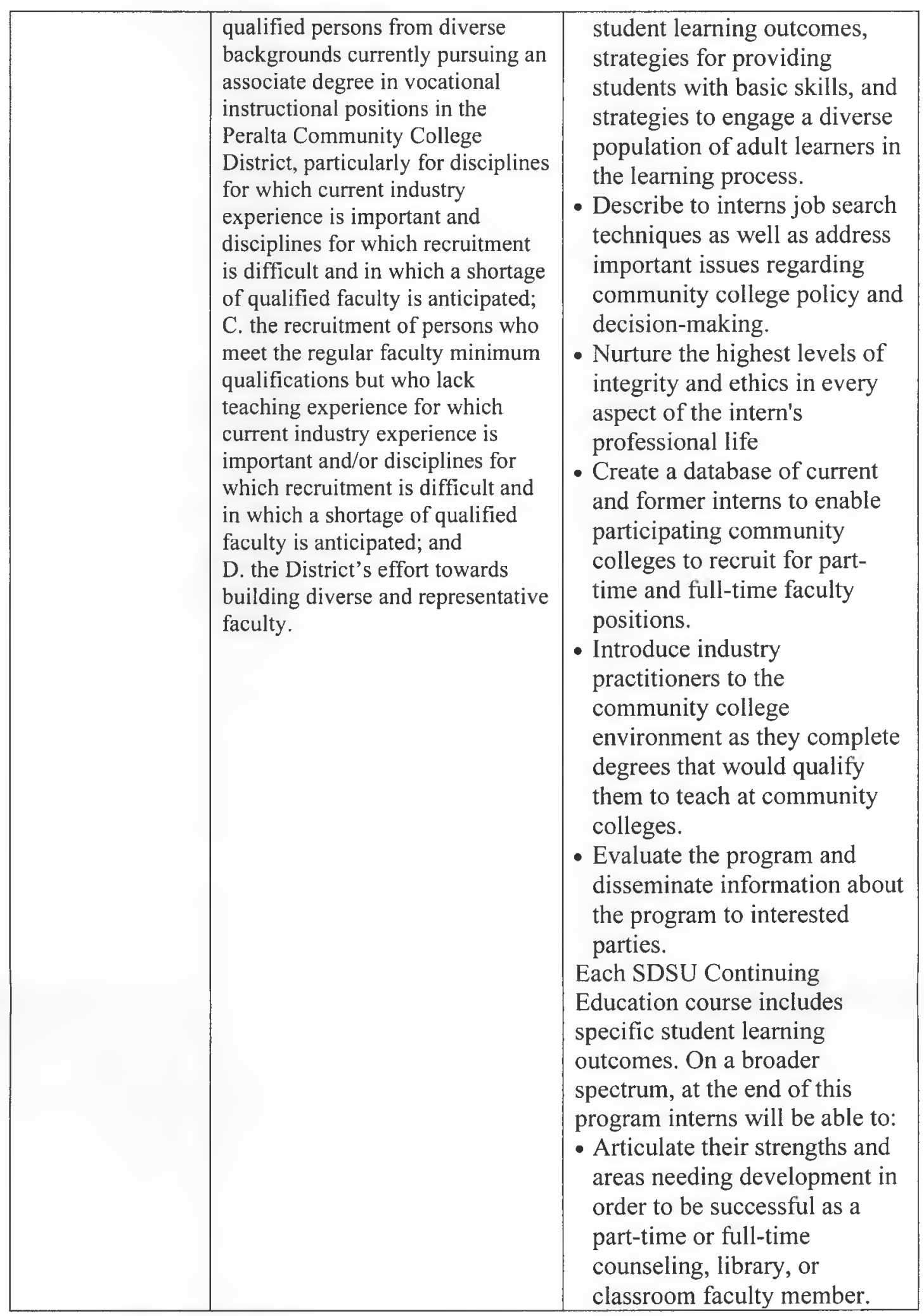




\begin{tabular}{|c|c|c|}
\hline & & $\begin{array}{l}\text { - Network professionally } \\
\text { among the local community } \\
\text { colleges. } \\
\text { - Garner working, professional } \\
\text { relationships with faculty and } \\
\text { staff in the SDICCCA region. } \\
\text { - Create a realistic, five-year } \\
\text { professional plan for } \\
\text { counseling, librarianship, or } \\
\text { classroom teaching. }\end{array}$ \\
\hline $\begin{array}{l}\text { Intern } \\
\text { Compensation }\end{array}$ & $\$ 42-50$ per hour & $-\$ 600$ \\
\hline $\begin{array}{l}\text { Mentor } \\
\text { Compensation }\end{array}$ & $\$ 500$ & $\$ 0$ \\
\hline $\begin{array}{l}\text { Intern } \\
\text { Eligibility }\end{array}$ & $\begin{array}{l}\text { Completion of half of MA or } \\
\text { Doctoral program } \\
\text { Completion of half of BA and } 4 \\
\text { yrs exp or completion of half of } \\
\text { AA and } 6 \text { yrs exp (CTE) }\end{array}$ & $\begin{array}{l}\text { MA with no experience or } \\
\text { completion of half of MA or } \\
\text { Doctoral program } \\
\text { BA and } 2 \text { yrs exp (CTE) }\end{array}$ \\
\hline $\begin{array}{l}\text { Application } \\
\text { Process }\end{array}$ & $\begin{array}{l}\text { Application; Cover Letter; } \\
\text { Resume; Transcripts }\end{array}$ & $\begin{array}{l}\text { Application; Resume; } \\
\text { Transcripts }\end{array}$ \\
\hline Deadline & Rolling & March 15 \\
\hline Selection & Approved by Academic Senate & 3 member selection committee \\
\hline Workshops & $\begin{array}{l}\text { Recommended } \\
\text { Getting Past Gatekeepers; } \\
\text { Classroom Assessment; } \\
\text { Cultural Competency }\end{array}$ & $\begin{array}{l}\text { Required } \\
\text { Teaching \& Learning Process: } \\
\text { Good Teaching Practices; CC } \\
\text { Structures \& Organization; CC } \\
\text { Hiring Process; Practice } \\
\text { Interview Techniques }\end{array}$ \\
\hline $\begin{array}{l}\text { Intern } \\
\text { Responsibilities }\end{array}$ & $\begin{array}{l}\text { A. Teach one class for one } \\
\text { semester (Intern may reapply for } \\
\text { up to three semesters); } \\
\text { B. Work closely and meet } \\
\text { regularly with a Faculty Mentor; } \\
\text { C. Prepare course syllabus } \\
\text { according to college standards; and } \\
\text { D. Participate in department } \\
\text { meeting. }\end{array}$ & $\begin{array}{l}\text { - Attend Summer institute } \\
\text { course } \\
\text { - Interns shadow mentors in the } \\
\text { fall, includes tutoring } \\
\text { students, preparing course } \\
\text { materials, teach segments of } \\
\text { class and attend institute } \\
\text { course } \\
\text { - Interns teach own section in } \\
\text { the spring and attend institute } \\
\text { course }\end{array}$ \\
\hline
\end{tabular}


Table 2: Logic Model of Faculty Diversity Internship Programs

\begin{tabular}{|c|c|c|c|c|}
\hline Inputs & Outputs/Activities & Outcome & Short-term Impact & Long-term Impact \\
\hline $\begin{array}{l}\text { FDIP } \\
\text { Coordinator }\end{array}$ & $\begin{array}{l}\text { - Recruit/outreach mentors \& } \\
\text { interns } \\
\text { o Graduate schools } \\
\text { o Information/orientation } \\
\text { sessions } \\
\text { - Coordinate application and } \\
\text { placement criteria } \\
\text { - Coordinate } \\
\text { training/professional } \\
\text { development workshops }\end{array}$ & $\begin{array}{l}\text { - Identify mentors \& } \\
\text { interns } \\
\text { - Implement } \\
\text { training/professional } \\
\text { development curriculum } \\
\text { - Program evaluation }\end{array}$ & $\begin{array}{l}\text { - Mentor/intern matches } \\
\text { - Ongoing program } \\
\text { implementation/improvement } \\
\text { - Program reporting }\end{array}$ & $\begin{array}{l}\text { - Increased faculty diversity } \\
\text { - Use FDIP to recruit and train } \\
\text { new faculty who better reflect } \\
\text { our student population; } \\
\text { - Intentionaliy develop mentoring } \\
\text { opportunities throughout } \\
\text { faculty ranks; } \\
\text { - Increase the social capital built } \\
\text { between faculty; } \\
\text { - Increase and broaden } \\
\text { participation in campus and } \\
\text { district leadership. }\end{array}$ \\
\hline Applicants & $\begin{array}{l}\text { - Participate in } \\
\text { information/orientation sessions }\end{array}$ & $\begin{array}{l}\text { - Complete application and } \\
\text { supporting materials } \\
\text { - Identify possible mentors }\end{array}$ & - Mentor match & - Participation in FDIP \\
\hline Mentors & $\begin{array}{l}\text { At least } 3 \text { meetings per term } \\
\text { w/interns } \\
\text { Shadowing/observations of } \\
\text { interns }\end{array}$ & $\begin{array}{l}\text { - Completion of learning } \\
\text { outcome rubric for } \\
\text { interns }\end{array}$ & $\begin{array}{l}\text { - Networking/research } \\
\text { collaborators }\end{array}$ & - Diversity advocate \\
\hline Interns & $\begin{array}{l}\text { At least } 3 \text { meetings per term } \\
\text { with mentor } \\
\text { - Shadowing } \\
\text { - }\end{array}$ & $\begin{array}{ll}- & \text { Teaching experience } \\
\text { - } & \text { Teaching portfolio }\end{array}$ & $\begin{array}{l}\text { Learning outcomes for } \\
\text { interns: } \\
\text { o Understanding minimum } \\
\text { qualifications/application } \\
\text { process/tenure process } \\
\text { o Curriculum development } \\
\text { o Pedagogy in diverse CC }\end{array}$ & $\begin{array}{l}\text { - Employment in CC } \\
\text { - Long-term mentor-mentee } \\
\text { relationship }\end{array}$ \\
\hline Budget & - Resource allocation & $\begin{array}{l}\text { - Stipends for mentors \& } \\
\text { interns } \\
\text { - Release time for } \\
\text { coordinator } \\
\text { - Budget for program } \\
\text { activities }\end{array}$ & - Incentivize participation & - Institutional resource allocation \\
\hline
\end{tabular}


The population for the program evaluation are former and current participants of PCCD and SDICCA FDIPs, including faculty who served as mentors and former and current graduate students and/or career changers who were interns in the program. It is expected that the majority of interns of the FDIP were persons of color, who had a career interest in teaching in a community college. The total number of participants throughout the history of the FDIP at both sites is unknown.

In order to obtain data for the FDIP program evaluation, purposeful sampling was used to collect data about FDIPs. FDIP Coordinators identified a total of 132 former and current participants. At SDICCA contact information of participants dated back to 2012 and at PCCD there was no record keeping of when the interns or mentors participated. Respondents of the survey provided contact information, if they wished to participate in an interview.

A total of 96 respondents ( $73 \%$ response rate) completed the survey and 14 participants were interviewed (seven interns and seven mentors). The interviews were conducted at a location chosen by the interviewees and interviews were between 15-45 minutes long. The interview started with an introduction of the researcher, including a statement explaining no working relationship in the community college districts where the study is being conducted and that the study is towards a dissertation towards completion of an Ed.D. from SFSU. In addition, interviewees were informed that no names or any other identifiers will be included in the findings. These statements of neutrality and confidentiality was intended to put interviewees at ease so they share freely about their experience in the FDIP. 


\section{Ethics and Protection of Human Subjects}

This program evaluation of two FDIPs in California community colleges had some ethical considerations. Any harm to participants in the program evaluation was not expected and none arose. The program evaluation was been deemed "excepted from review" on March 16, 2015 by the SFSU Institutional Review Board. In addition, PCCD's Director of Institutional Research, Nathan Pellegrin, also approved the program evaluation of the FDIP. Bridget Herrin, the Research Analyst for Student Success \& Equity at MiraCosta College and the Executive Director of SDICCA FDIP also approved the program evaluation. Measures were taken to protect the privacy of all participants.

Every effort was made to ensure that there were no identifiers in the data to prevent any issues of confidentiality. The online survey included the purpose of the program evaluation, including a confidentiality statement as follows, "Your privacy and participation will be respected and valued. You must be 18 years of age or older to participate. There are no risks or benefits to you in participating in this survey. You may choose to participate or not. You may answer only the questions you feel comfortable answering, and you may stop at any time. If you do not wish to participate, there is no penalty to yourself. If you do participate, completion and return of the survey indicates your consent to the above conditions. Your decision whether or not to participate in this program evaluation will have no influence on your present or future status at your current employment."

The survey was anonymous and only respondents who were interested in participating in an interview, provided contact information. Interviews were transcribed and recorded on a secure, personal laptop computer with limited identifying information. 
Because the online survey was anonymous, bias and ethical issues related to researcher participant relationships were significantly minimized. In addition, because the researcher has no personal or professional relationship to the interviewees and the educational institutions, unbiased data collection and analysis was possible to provide the most objective guidelines and recommendations based on the findings of the program evaluation.

\section{Data Collection}

Quantitative data about the demographics of the faculty were obtained from the California Community Colleges Chancellor's Office MIS Data Mart. Only data from 2000 was available as provided in Table 1 . However, the validity of the data is limited because only faculty demographic trends for the two FDIP research sites were included and the data of the faculty demographics across California includes all campuses, regardless of whether they have FDIPs or not. The reason for this is because a comprehensive report about faculty internships across California has not been published since 1996 and there is no list of colleges that have FDIPs and when they were established.

Before designing the research instrument and collecting data about the FDIP, an understanding and overview of FDIP and its purpose and design was required. Through internet searches, interviews with former and current FDIP Coordinators, a comparison chart and logic model of the PCCD and SDICCA FDIP was developed (see Table 1 and 2 on page 44 and 47). The logic model informed the design of the online survey and interview protocol. An online semi-structured survey with 27 questions was also constructed and reviewed by the FDIP coordinators (see Appendix 1). The survey 
included 15 questions about demographics and participation information, 9 six-point Likert (0-5) scale questions, and 3 open ended questions. The semi-structured survey provided both quantitative and qualitative data that allowed for limited statistical data analysis but the open ended questions provided more in depth responses about participants' experience in the FDIP (Cohen et. al., 2011).

The draft survey and the interview protocol were sent to FDIP Coordinators for review and included both formative and summative data, with the goal of identifying effective program elements/activities and whether or not participants report that the FDIP had an impact on both preparing them for and/or improving teaching in a diverse community college and faculty diversity. The survey and interview was piloted with a classmate who participated in a FDIP that was not part of the research site and minor adjustments were made and the final survey was set up on a Google form document.

The final online survey was emailed to 132 current and former participants by the current FDIP Coordinators in November 2015. The survey was emailed an additional two times by the FDIP Coordinators and researcher each. A total of 96 surveys were received ( $73 \%$ response rate), 83 responses from interns and 13 responses from mentors.

Face-to-face interviews were conducted with past and current interns and mentors between December and February. Interview participants were solicited through the survey and interviewees were contacted and provided with the interview questions a day before the actual interview. All interviews were face-to-face and lasted between 15-45 minutes. Most interviews were at a location chosen by the interviewees and were conducted at a coffee shop, the interviewee's workplace, or a public library. The interview questions allowed participants to elaborate on survey questions, specifically 
about their mentorship experience, as well as their participation in internship workshops/activities and interactions with other colleagues, their overall perceptions in regards to whether the internship program had an impact on preparation to teach in a community college and faculty diversity overall.

This study had some external validity issues that limit generalizability to a larger population, which may include all graduate students of color seeking faculty positions (Creswell \& Plano Clark, 2011). For example, most interns of the program were in their final year of graduate school, which is an external motivating factor to seek employment in the near future. Other factors include intern's motivation to seek part-time or full-time teaching positions and/or whether or not there are limited employment opportunities. The survey and interview protocol specifically asks participants about the impact of the FDIP and not external factors that may lead to program outcomes. In addition, this study's transferability is limited because of the small sample size of 96 respondents and 14 interviewees.

The reliability of the survey is established with multiple closed questions that ask about their participation in the FDIP, specifically, and open ended and survey questions that ask specific questions about their participation in the FDIP. These types of and specific questions limit the respondent's subjective opinions about external factors that impact their employment or preparation for teaching at a community college. 
Data Analysis

Quantitative data about the demographics of the faculty population across a 15 year period were derived from the California Community Colleges Chancellor's Office MIS Data Mart. Because data were limited to faculty demographics between 2000 and 2015 only, analysis cannot be made between faculty diversity before and after policy implementation. In addition, state-wide faculty demographic comparisons were not able to be made between campuses with FDIPs and without FDIPs, since there has been no comprehensive report on FDIPs.

Limited quantitative data from the online survey were collected and descriptive statistics provided a typical participant profile. Because the respondent rate and sample size is low, comparisons and correlative statistical significance cannot be determined.

Qualitative data were derived from two sources, 1) three open ended questions on the online survey and 2) face-to-face interviews with seven interns and seven mentors. Both data sets were coded using descriptive and process coding and in vivo coding was used to describe interest in participation in the FDIP. Codes were also assigned a positive or negative evaluative code. Descriptive coding was used to identify a label that offered an inventory of topics for indexing and categorizing and since the FDIP included many action-based activities, process coding was used to identify the observable actions that mentors and interns engaged in (Miles \& Huberman, 2014). The codes are as follows:

Table 3: Codes Identified in First and Second Cycle Coding of Survey and Interviews

\begin{tabular}{|l|l|}
\hline Descriptive coding & Application/Placement/Selection Process \\
& Orientation/Preparation/Training \\
& Mentorship \\
& Diversity \\
& Benefits/rewards \\
& Leadership \\
\hline
\end{tabular}




\begin{tabular}{|l|l|}
\hline In vivo coding & Institutional Practices \\
\hline & "foot in the door" \\
& "going home" \\
& "share knowledge" \\
& "give back" \\
\hline Process coding & Teaching/Guest lecturing \\
& Shadowing \\
& Networking \\
& Mentor observing \\
& Attend meetings \\
& Training \\
& Collaborating \\
\hline
\end{tabular}

No software was used to code the data. The first cycle coding was used in transcribing the interviews and then second cycle coding was used to analyze the transcripts that segmented the data even further and brought about more precise categories, causal relationships, and concepts (Miles \& Huberman, 2014). Upon initial analysis of the codes, the descriptive codes included program elements of the FDIP with further details provided by the process codes and the in vivo codes described the expectations of program participants.

The categorization of codes informs the research findings and the format of the following chapter about findings will be organized into five sections including a description of program and participants and a section for each research question. 


\section{Chapter Four: Report of Findings}

Introduction

A program evaluation was conducted of the Faculty Diversity Internship Program (FDIP) at two sites, Peralta Community College District (four colleges) and the San Diego Imperial Valley Community College Association (ten colleges) to provide evidence and recommendations for implementing FDIPs as a strategy to increase faculty diversity and prepare new faculty to work in a diverse community college. The research questions were:

1. What do FDIP participants find beneficial in participating in the program?;

2. What are the barriers and challenges in implementing FDIPs?

3. What is the impact of the FDIP on faculty diversity as a recruitment and retention tool?

The program evaluation took a transformative design approach to identify social justice challenges, specifically with this research, faculty diversity and representative bureaucracy challenges (Creswell \& Plano Clark, 2011). Survey and interview questions were designed to provide respondents and interviewees an opportunity to share their stories that may resurface race in their participation in FDIP. Quantitative data were collected from the California Community College Chancellor's Office MIS Data Mart on the demographic trends of faculty and students in California community colleges within the last 15 years. Additional quantitative data were collected through an online survey with 27 questions, which included nine likert-scale questions. However, most of the data were qualitative and collected through three open ended questions in the online survey and face-to-face interviews with seven interns and seven faculty mentors. 
Overall, the quantitative data revealed mixed results on the impact of FDIPs on recruiting faculty of color. The faculty demographics collected and compared across 15 years showed little increase in faculty diversity both across California and in the research sites. However, qualitative data revealed the positive impact that FDIPs have on preparing and perhaps retaining new faculty of color to teach in a diverse community college classroom. The data showed the importance of the mentorship experience, as well as a structured internship program that include teaching, professional development, and networking opportunities in recruiting and preparing new faculty for their first semester in a community college.

\section{The Findings}

This section starts with findings about the participant profiles, including their interests and expectations in the FDIP and a section to answer each research question. Each section will start by presenting quantitative data, followed by qualitative data and ending with an analysis of the findings.

Participant Profiles and Interest \& Expectations in the FDIP

"I remember when I went to my first meeting with everyone...one of the first things that I thought of was, "Wow this room is really diverse...my gosh, there's like people of all sorts of color here!" and I felt like, that 's what it's supposed to be...I remember another intern actually said, "I purposely looked for a person of color to be my mentor, " and I remember thinking that is awesome and I'm glad that there are mentors out there that are from minority groups who are looking to mentor people because sometimes that doesn't always happen" (intern interview).

An online survey was emailed to 132 former and current participants and $96(73 \%$ response rate) responses were received from 83 interns and 13 faculty mentors. Appendix 2 provides some comparative data of all survey responses. The majority of 
interns were female (70\%), while the mentors were evenly split in gender. $67 \%$ of interns were under the age of 40 , while $61 \%$ of mentors were age 50 or above. $32 \%$ of interns were URM and $15 \%$ of faculty mentors were URM. The majority of interns and mentors were in the Counseling and English disciplines, followed by Biology, Business, History, and Sociology. All other disciplines were represented by less than three interns. Three colleges had eleven or more interns and seven colleges had less than ten interns.

Table 4: Survey Participant Profile

\begin{tabular}{|c|c|c|c|c|c|c|c|c|}
\hline & Interns & $\begin{array}{l}\% \text { of } \\
\text { sub- } \\
\text { group }\end{array}$ & $\begin{array}{l}\% \text { of } \\
\text { total }\end{array}$ & Mentors & $\begin{array}{l}\% \text { of } \\
\text { sub- } \\
\text { group }\end{array}$ & $\begin{array}{l}\% \text { of } \\
\text { total }\end{array}$ & Total & $\begin{array}{l}\% \text { of } \\
\text { total }\end{array}$ \\
\hline Participant Types & 83 & $100 \%$ & 86 & 13 & $100 \%$ & 14 & 96 & 100 \\
\hline \multicolumn{9}{|l|}{ Gender } \\
\hline Female & 58 & 70 & 60 & 7 & 54 & 7 & 65 & 68 \\
\hline Male & 22 & 27 & 23 & 6 & 46 & 6 & 28 & 29 \\
\hline Decline to State & 3 & 4 & 3 & 0 & 0 & 0 & 3 & 3 \\
\hline \multicolumn{9}{|l|}{ Age } \\
\hline $20-29$ & 21 & 25 & 22 & 0 & 0 & 0 & 21 & 22 \\
\hline $30-39$ & 35 & 42 & 36 & 3 & 23 & 3 & 38 & 40 \\
\hline $40-49$ & 15 & 18 & 16 & 2 & 15 & 2 & 17 & 18 \\
\hline $50-59$ & 5 & 6 & 5 & 5 & 38 & 5 & 10 & 10 \\
\hline $60+$ & 4 & 5 & 4 & 3 & 23 & 3 & 7 & 7 \\
\hline No response & 3 & 4 & 3 & $\mathbf{0}$ & 0 & 0 & 3 & 3 \\
\hline \multicolumn{9}{|l|}{ Diversity Factors } \\
\hline African-American/Black & 10 & 12 & 10 & 0 & 0 & 0 & 10 & 10 \\
\hline Afro-Puerto Rican & 1 & 1 & 1 & 0 & 0 & 0 & 1 & 1 \\
\hline Native American Indian & 2 & 2 & 2 & 0 & 0 & 0 & 2 & 2 \\
\hline Arab & 1 & 1 & 1 & $\mathbf{0}$ & 0 & 0 & 1 & 1 \\
\hline Asian & 11 & 13 & 11 & 2 & 15 & 2 & 13 & 14 \\
\hline Chicano/Latino/Hispanic & 14 & 17 & 15 & 2 & 15 & 2 & 16 & 17 \\
\hline Middle Eastern & 1 & 1 & 1 & $\mathbf{0}$ & 0 & 0 & 1 & 1 \\
\hline Multiracial/ethnic & 10 & 12 & 10 & 1 & 8 & 1 & 11 & 11 \\
\hline Sexual Orientation & 1 & 1 & 1 & $\mathbf{0}$ & 0 & 0 & 1 & 1 \\
\hline White & 28 & 34 & 29 & 7 & 54 & 7 & 35 & 36 \\
\hline No response & 4 & 5 & 4 & 1 & 8 & $I$ & 5 & 5 \\
\hline
\end{tabular}




\begin{tabular}{|c|c|c|c|c|c|c|c|c|}
\hline \multicolumn{9}{|l|}{ Campus } \\
\hline Alameda & 11 & 13 & 11 & 4 & 31 & 4 & 15 & 16 \\
\hline Berkeley & 8 & 10 & 8 & 2 & 15 & 2 & 10 & 10 \\
\hline Cuyamaca & 4 & 5 & 4 & 2 & 15 & 2 & 6 & 6 \\
\hline Grossmont & 13 & 16 & 14 & $\mathbf{0}$ & 0 & 0 & 13 & 14 \\
\hline Laney & 10 & 12 & 10 & 2 & 15 & 2 & 12 & 13 \\
\hline Merritt & 3 & 4 & 3 & $\mathbf{0}$ & 0 & 0 & 3 & 3 \\
\hline Mira Costa & 11 & 13 & 11 & 0 & 0 & 0 & 11 & 11 \\
\hline Mt. San Jacinto & 2 & 2 & 2 & 0 & 0 & 0 & 2 & 2 \\
\hline Palomar & 4 & 5 & 4 & 0 & 0 & 0 & 4 & 4 \\
\hline SD City & 6 & 7 & 6 & 0 & 0 & 0 & 6 & 6 \\
\hline SD Mesa & 3 & 4 & 3 & 1 & 8 & 1 & 4 & 4 \\
\hline SD Miramar & 7 & 8 & 7 & 2 & 15 & 2 & 9 & 9 \\
\hline Southwestern & 1 & 1 & 1 & $\mathbf{0}$ & 0 & 0 & 1 & 1 \\
\hline \multicolumn{9}{|l|}{ Discipline } \\
\hline Accounting & 1 & 1 & 1 & 0 & 0 & 0 & 0 & 0 \\
\hline Africana Studies & 1 & 1 & 1 & 0 & 0 & 0 & 0 & 0 \\
\hline Biology & 5 & 6 & 5 & $\mathbf{0}$ & 0 & 0 & 5 & 5 \\
\hline Business & 5 & 6 & 5 & 1 & 8 & 1 & 6 & 6 \\
\hline Chemistry & 2 & 2 & 2 & 1 & 8 & 1 & 3 & 3 \\
\hline Chicano Studies & 1 & 1 & 1 & $\mathbf{0}$ & 0 & 0 & 1 & 1 \\
\hline Child Development & 3 & 4 & 3 & $\mathbf{0}$ & 0 & 0 & 3 & 3 \\
\hline Communication & 1 & 1 & 1 & $\mathbf{0}$ & 0 & 0 & 1 & 1 \\
\hline Counseling & 17 & 20 & 18 & 2 & 15 & 2 & 19 & 20 \\
\hline Economics & 1 & 1 & 1 & $\mathbf{0}$ & 0 & 0 & 1 & 1 \\
\hline Education & 1 & 1 & 1 & 0 & 0 & 0 & 1 & 1 \\
\hline English & 16 & 19 & 17 & 3 & 23 & 3 & 19 & 20 \\
\hline ESL/ESOL & 3 & 4 & 3 & 1 & 8 & 1 & 4 & 4 \\
\hline Geography & 1 & 1 & 1 & 1 & 8 & 1 & 2 & 2 \\
\hline History & 5 & 6 & 5 & $\mathbf{0}$ & 0 & 0 & 5 & 5 \\
\hline Library & 1 & 1 & $l$ & 1 & 8 & 1 & 2 & 2 \\
\hline Life Science & 1 & 1 & 1 & $\mathbf{0}$ & 0 & 0 & 1 & 1 \\
\hline Mathematics & 3 & 4 & 3 & 1 & 8 & 1 & 4 & 4 \\
\hline Middle Eastern Studies & 1 & 1 & 1 & 0 & 0 & 0 & 1 & 1 \\
\hline Political Science & 2 & 2 & 2 & 1 & 8 & 1 & 3 & 3 \\
\hline Psychology & 3 & 4 & 3 & 2 & 15 & 2 & 5 & 5 \\
\hline Sociology & 5 & 6 & 5 & 0 & 0 & 0 & 5 & 5 \\
\hline Statistics & 1 & 1 & 1 & 0 & 0 & 0 & 1 & 1 \\
\hline
\end{tabular}




\begin{tabular}{|l|l|l|l|l|l|l|l|l|}
\hline Student Affairs & $\mathbf{2}$ & 2 & 2 & $\mathbf{0}$ & 0 & 0 & $\mathbf{2}$ & 2 \\
\hline No response & $\mathbf{2}$ & 2 & 2 & $\mathbf{0}$ & 0 & 0 & $\mathbf{2}$ & 2 \\
\hline
\end{tabular}

Face-to-face interviews were also conducted with seven interns and seven mentors. Table 2 lists all the interviewees, their district and discipline. All seven interns interviewed were female, three identified as Asian, one Latina, one African American, one Middle Eastern and one Multiethnic/African American/White. All three Asian interns participated at PCCD and the others participated at the SDICCA FDIP.

The mentors included three males and four females, all but one were mentors at PCCD. Three identified as White, one African American, one Asian, one Multiethnic/Latina/White and one Multiethnic/Asian/White.

Table 4: List of Interviewees

\begin{tabular}{|l|l|l|l|l|}
\hline \multicolumn{1}{|c|}{ Type } & Gender & \multicolumn{1}{c|}{ Discipline } & \multicolumn{1}{c|}{ Diversity Factor } & FDIP Site \\
\hline Intern & Female & ESL & Asian & PCCD \\
\hline Intern & Female & Student Affairs & Latina & SDICCA \\
\hline Intern & Female & Child Development & African American & SDICCA \\
\hline Intern & Female & Library Sciences & Asian & PCCD \\
\hline Intern & Female & Sociology & Multiracial/African American/White & SDICCA \\
\hline Intern & Female & Business Administration & Asian & PCCD \\
\hline Intern & Female & Sociology & Arab & SDICCA \\
\hline Mentor & Female & ESL & Multiethnic/Asian & PCCD \\
\hline Mentor & Male & English & African American & PCCD \\
\hline Mentor & Female & Chemistry & Multiracial/Latina/White & SDDICA \\
\hline Mentor & Female & Library Sciences & White & PCCD \\
\hline Mentor & Female & Business Administration & White & PCCD \\
\hline Mentor & Male & $\begin{array}{l}\text { Political Science and } \\
\text { Psychology }\end{array}$ & White/Sexual Orientation & PCCD \\
\hline Mentor & Male & Mathematics & Asian & PCCD \\
\hline
\end{tabular}

Additional qualitative data were collected in the interviews regarding the participant's interest and expectations in participating in the FDIP. For interns, most expressed their interest in participating in the FDIP in order to get their "foot in the door." Specifically, five of the seven interns interviewed shared that they were interested 
in teaching at a community college specifically because of the student population. Additionally, some interns expressed how teaching at a community college was like going "home" or "back to their roots" as evidenced below.

- The interest came from wanting a foot in the door for the community college district... I already had the goal in mind to teach, specifically at Laney College and it was very intentional for me because both of my parents went to Laney when they first emigrated from China... but it wasn't until I actually went to Laney... and I took Asian American Studies, which was just at the time, like a filler class for my schedule ... So that was kind of my first foray into ethnic studies and I think that's probably when I shifted into wanting to teach and thought about education.

- I just never had a lot teachers who looked like me, very few...I just want to be a role model for students. I understand a lot of their backgrounds. I'm the first in my family to go to college, from a working class family,... I feel like I connect with them in a lot of ways. These experiences are similar to Reddick \& Saenz's (2012) experience as described in their study, "I began taking ethnic studies courses...I finally felt culturally validated, like I belonged. I credit my undergraduate experiences during this time with igniting my passion and motivation for pursuing graduate study and my pathway to the professoriate" (pp. 366-367). These experience emphasizes the importance of "affinity groups" that provide nurturing spaces and a stronger support network for faculty and students of color (Chang et al., 2013; Reddick \& Saenz, 2012) and recommend that these 
affinity groups work collaboratively across campus, including with the alumni association to keep track of promising students of color who continue on to graduate school, who can be recruited for future faculty positions (Reddick \& Saenz, 2012). In January 2016, the California Community Colleges Chancellor's Office's (CCCCO) EEO \& Diversity Advisory Committee launched a new initiative, "AA to MA Faculty Diversity Pathway," to encourage community college students to become qualified for employment at the community colleges. Although the $\mathrm{CCCCO}$ has provided EEO trainings and peer-reviewers, similar to the FDIP legislation, there is very little implementation guidelines for this new Faculty Diversity Pathway initiative specifically.

Similar to intern's interest, their expectations of the FDIP was primarily to gain teaching experience and knowledge through their mentor. Four of the seven interns expressed their excitement with working closely with a mentor, "Anytime I was a mentor to somebody or was a part of a mentorship program...your mentor kind of guides you and reaches out to you and gives you some of the ins and outs." In addition to this guidance, other interns also expected the shadowing aspect of working with a mentor, "not only would you be shadowing this mentor learning sort of the ropes and learning to do their job...get acquainted with the department at that campus and with the campus culture."

Understanding the expectations of interns helped to understand many of the challenges that arose between mentors and interns as evidenced below.

- It's just kind of that guiding hand and of course, I think it is the mentee's responsibility to be active and engaged with their mentor but 
not so much lead the show and, so that expectations kind of got flipped on its head when I met him.

- My expectation was to gain experience with a faculty who had qualifications, skills, experience, and advance knowledge in my field of interest and when I met with her, I was really,...very disappointed ...I really thought I was wasting my time... When you are an educator you have to stay with the trend or above the trend, you have to stay with what the research is out there, because things are changing a lot...she treated us like we were in elementary school.

Expectations of mentors varied from having no expectations to many and very high expectations. Data showed that new mentors tended to none or less expectations than mentors who previously served.

- To be honest, I didn't really have time to think about it because the semester was starting soon and I was more concerned with my classes, being a mentor was low on my priority list. But I was kind of assured, I know that (colleague name) was doing it for a really long time and I knew that I can kind of fall back and ask her questions (new mentor).

- Going in, I don't think I had any expectations at all, now I know a lot more about it and kind of what it's geared towards and what I think I can do to help people (veteran mentor).

- My expectations are fairly high of the mentees...I ask an awful lot but...I think they get an awful lot in return...you will shadow me for one course for a whole semester and before you get a course...I will 
usually come to every class for the first month or so and then if I feel things are going ok, I'll do an evaluation... Whereas when they shadow me, they walk with me to class and I talk about what we're doing...I also require that they take a set of notes...so my very first mentee is interesting she is an adjunct in our department on a regular basis now. The first semester her set of notes and her syllabus completely paralleled mine but now 6-7 years later, she put her own stamp on everything and it's just fun to watch (veteran mentor).

This testimonial from a veteran mentor had three interns and two are currently employed at the college and the other intern was not given a class to teach because the department did not feel she was ready to teach. The mentor spoke highly of the two interns that were hired and saw them as "respected colleagues." This finding is similar to a key finding in Davis' (2010) study that showed that having high expectations of interns may lead to a more positive internship experience and positive long-term outcomes.

These findings also validates Lumpkin's (2011) article stating the importance of establishing an understanding among mentorship participants, the scope of their involvement and the benefits of participating. Although efforts to limit mismatch of mentors and interns should be taken, these mismatch relationships can provide interns with examples of different styles that they would not want to emulate (Chang et al, 2013). These challenges may also be consistent with findings from Zambrana et al.'s study (2015) that described "benign neglect" where mentors were non-responsive and/or supervisory rather than advisory, when they participated in a formal mentorship program. 
Other interests and expectations of mentors included their desire to share their knowledge or developing new faculty as well as learn from interns as well. Four of the seven mentors also indicated that they also had positive mentors in their earlier career path and that experience gave them a sense of wanting to "give back," a recurring finding in the literature on why faculty serve as mentors (Chang et al., 2013; Reddick \& Saenz, 2012).

- So my expectations were to... as a chance to give back and also most of the students who were serving as interns were coming from programs where they have some theoretical training and so, it was also a chance for me to just to keep up with what they were studying and learn myself (current mentor and former intern).

- When I first got into higher ed, which was in the community college system, I had people really help me out, nothing direct one-on-one like, "Hey we're going to meet every week." or "Hey, let me take you under my wing," or anything like that but I felt really, really supported when I first came on and as I gained knowledge about new teaching methods and cool things that you can introduce to the classroom or resources that would help my students in the classroom, I found myself wanting to share that knowledge the same way that others had shared with me (current new mentor).

- I kind of kept my eyes and ears open for those opportunities to be a mentor because every experience I had was so great, I always learned a lot and I always felt like it's important to give back (current mentor). 
Overall, the interest and expectations of both interns and mentors was influenced by their identity as an educator and/or person of color and their desire to give back to their community. Nearly all of the mentors reported their past experience in positive mentorship relationships that also prompted them to serve as mentors, which assumes that they developed the cultural capital needed to navigate becoming a professor and wanted to do the same for new faculty.

\section{Benefits of Participating in the FDIP}

Based on descriptive and process coding of both the open ended questions in the survey and interviews, the study identified multiple benefits of participating in an FDIP, including 1) mentorship, 2) teaching experience 3), professional development and 4) networking and collaboration. These benefits include key elements or activities that the literature reviewed recommended in supporting and preparing new faculty of color.

\section{Benefit \#l: Mentorship: More than just shadowing}

"I can't imagine trying to learn how to teach without the support and regular feedback from my mentors. I think it should be something done for all new faculty in community colleges, especially if we hope to change the achievement of students who are not persisting through the system. Without an expert teacher to really point out what's not working, most faculty will blame the students or the system and not understand their role in creating an inclusive, rigorous, and engaging classroom" (intern survey response).

A major component of the FDIP is mentorship with a full-time faculty member within the same discipline. One of the program goals of the SDICCA FDIP is to "arrange successful mentoring relationships that support the development of interns and mentors as master counseling, Library, or classroom faculty members" (SDICCA, n.d.). The 
Peralta FDIP promises interns to "work closely and meet regularly with a Faculty Mentor: (PCCD FDIP, n.d.).

Survey results revealed that $41 \%$ of participants were matched with a mentor/intern of the same race and $83 \%$ continue to have a relationship with their mentor/intern. On a likert-scale question with 0 being not applicable/not sure and 5 being strongly agree, interns and mentors indicated that their mentor/intern was a good match on average 4.09 and 4.33 , respectively. Qualitative data also revealed the mentorship component of the FDIP as a major factor that influenced participant's experience and provided a deeper understanding of the important role that mentors play. These experiences can be influenced by the expectations that the mentor and intern have of the FDIP, as described in the previous section. However, the engagement or lack of engagement between mentors and interns also influenced interns experience in the FDIP as well.

One way that interns were engaged with mentors was through shadowing, most of which entailed classroom observations. These opportunities were beneficial in providing interns with exposure to the community college classroom, as described in one intern survey response, "I also spent a lot of time observing classrooms of my mentor's colleagues to observe a variety of teaching styles... it was a great idea that my mentor had and was extremely helpful for me in building my own idea about pedagogy and curriculum development."

In conjunction with classroom observations, mentors who engaged their interns in discussions regarding teaching, also received positive feedback such as this survey response from an intern, "By far, the most lasting, impactful, and important part of the 
FDIP was the intensive mentoring that I received. [Mentor name] met with me regularly for long, individual meetings where we would talk in-depth about what I was doing in the classroom, his experiences in the classroom, suggestions, advice, etc. He also came in and observed me teach, and he provided me with very thorough written and oral feedback. He shared so much curriculum with me, as well as discipline-specific pedagogy...He continues to be an influence on who $I$ am as an educator and administrator".

The data revealed that a higher level of engagement indicated a higher level of satisfaction in the FDIP. However, this also depended on the intern's expectation as well. For example, one intern expressed that she didn't want a mentor who was too hands-on because she wanted to find her own way but she was happy with her mentor's level of availability.

A few survey respondents indicated that although they had a good internship experience, the mentorship experience was a bit challenging, some expressing that they wished that their mentor was invested in their "growth." One intern survey response suggested, "creat[ing] a culture of good communication between mentors and mentees so that the teams are sure that they are working towards mutually beneficial goals. It's important for mentors and mentees to both feel like they are learning and growing as well as participating in a meaningful way."

Other interns shared that some mentors seem to have "lost their passion" and that mentors should be selected carefully to ensure that interns have a positive experience. In fact, even one mentor commented when asked about how to encourage more faculty to consider mentoring that faculty who have been teaching the longest seem "disenchanted" 
and perhaps may be afraid of passing that down to new faculty. One student affairs intern adamantly shared, "it is really important to find those faculty, not that they just want to volunteer, but those who can really inspire and can transfer the knowledge... and really motivate those people to make an impact on student's lives and what I have seen or what I have observed and I don't know if I'm wrong is that a lot of the mentors or faculty that are mentoring, are no longer motivated with their jobs, so their just doing their jobs, so how are you going to motivate a new person whose coming on board, if you're not even motivated yourself?"

Qualitative data from the survey and interviews provided more positive insight to the mentorship experience from the mentor's perspective. Five of the seven mentors interviewed reported that their involvement as a mentor in FDIP improved their teaching and learning in the classroom, which included a more intentional or focused teaching, improving or adopting new teaching/grading methods, and learning about current theoretical and practical trends in the field from their interns, as described below.

- Absolutely, there's a couple areas where we worked together very closely. So she helped me craft some of our assessments and I feel like my approach to assessment then changed and became a lot more rigorous, so that was very helpful and then we co-taught some library classes or library orientations together and I also let her be an observer in my class and in my online class, so kind of based on her presence it made me try to focus a little bit more.

- She knew a lot about instruments and stuff because she had recently finished or was finishing her Master's at UCSD and... you know I've 
been out of it from lab work for awhile, except for just teaching lab and so I remember thinking, 'Oh wow, I need to remember that for when I teach lab,'... I do have a lot of discussions with interns about teaching methods and grading and they had ideas, and of course, I would be complaining about how many labs I had to grade and sometimes they'd have some ideas, like, 'Oh what if you just graded every other assignment and the others just check them off and give them credit for doing it,'... so I felt like I learned a lot and it did help me improve too because of the things I did begin to do and found them to be effective and of course it keeps you on your toes when you know someone is observing you, you always want to put your best foot forward.

The overall qualitative and quantitative data reveal the importance that the mentorship has on the FDIP experience. Challenges in the mentorship included differing expectations, the lack of engagement of mentors, and the mentor's passion towards their role as a faculty and/or mentor. Both interns and mentors provided suggestions on how to improve the mentorship experience. All mentors interviewed suggested providing mentor training that includes 1) a model for mentoring that provides guidance on different components of effective mentorship, 2) a handbook and resources that assist mentors with logistical information and how to prepare interns to teach in a classroom, and 3) background information about the FDIP that outline expectations for both interns and mentors. 
A final note about the mentorship component of the FDIP, is that through shadowing and guidance, mentors do serve as role models for new faculty and sometimes even reveal intern's hidden potential as one intern described the rewarding aspects of her participation, "I would say [my mentor's] positive attitude towards everything, whenever I had a problem, she knew how to solve it. Even if she didn't have the solution, she was very positive about it, she motivated me to do better and definitely boosted my confidence a lot... my expectations were very low because I was not prepared at all but the way they dealt with it, [the FDIP Coordinator and my mentor], automatically motivated me to prepare a syllabus, a course outline, the assessment, I prepared a couple of case studies, tests, so I did some studying regarding the diversity within a classroom and how I can connect with, so their positivity... actually was very rewarding for me."

This sentiment was also an important finding in Reddick \& Saenz's (2012) study, "Ultimately, if our stories are at all instructive, supporting young scholars of color seems to hinge on relationships. Our mentors clearly saw potential in us at early stages of our careers and invested in us. It was their sense of the possible that sustained us at times when we doubted ourselves, and it is this very personal, deep care that we take to heart with our own students, both graduate and undergraduate... Beyond these initial contacts, however, we found that these caring individuals were known as role models in our peer community; took the time to open their schedules and lives with us on an individual basis; granted us greater, positive visibility through feedback and recognition of our work; and were willing to serve in key advising roles related to our development. Indeed, we might label these individuals "mentoring magnets," who in their lived example of being successful professionals of color at a PWI attracted our interest. Their reciprocation 
assisted and guided us to opportunities that ultimately have brought us home." (p. 375376).

\section{Benefit \#2: Teaching Experiences}

"During the fall, my mentor visited my classes once a week and provided detailed feedback that really helped me understand where I needed to improve as a teacher, that coaching was invaluable. During my summer internship, my mentor was much more hands off, and I could have used more support as I tried to figure out how to manage the classroom every day. In some ways, this was a great way for me to explore the class, but I think a combination of the two methods works" (intern survey response).

The second benefit in participating in FDIPs identified was providing interns with teaching experience, which nearly all interns expected. However, not all interns were provided with opportunities to teach, which was dependent on whether the mentor believed they were ready to teach or whether there were available classes.

For one intern, her experience in the FDIP actually rekindled her love of teaching, "So after I quit teaching English, I thought I was going to become a public librarian and work with kids... because I felt like I had burnt by academia and then I was like 'Wow, I really miss teaching...I don't want to give it up.' So I feel like as a teacher you do something and it fails horrible but then sometimes you do something and it works really well, students are really engaged and then it's super rewarding...I gave out surveys...sometimes I'll have a quiet class and they won't say anything but then I'll read their feedback and then they loved it or they thought it was really cool. I remember seeing this comment that said, "Why are librarians so cool?" and that made me feel so good." 
Both mentors and interns shared that it is a combination of luck and timing as to whether interns have the opportunity to teach their own class and see it as one of the challenges of the FDIP. One Business intern shared that some disciplines tend to have more classes than other, "I would say, I was lucky enough to land this position, but there are certain disciplines that don't have enough classes, even Business, we don't have enough classes but disciplines such as Education, Political Science, their number of classes are very limited,... I remember a couple of people were very frustrated." A mentor that teaches Psychology and Political Science shared, "if I had one regret about the design is that we can't absorb the number of people I'd like to train, so I would love to train more people but we can't absorb them."

Two interns provided examples of why a structured internship program is crucial in preparing interns to teach. Both interns participated when there was a change in FDIP Coordinators and were provided with limited training/preparation and support in finding a mentor. One intern ended up not completing the internship and the other was assigned a mentor and a class a few days before the start of the semester. "The more time you have...the more prepared you can be... before you actually step into a class...the other workshop that I went to was creating a student-centered syllabus. I would have liked something like that for the orientation for interns but also anything like first day activities on getting to know your students, breaking the ice, setting the community atmosphere you want in your classroom but also the little logistical things like how to get a parking permit, how do you get a classroom key, how do get paid, also SLOs...I didn't have time to plan the course. I was going day-by-day, planning the lesson day-by-day, instead of 
looking at the whole broad scope and doing backward planning and it influences student's success too."

Interns also mentioned that teaching experience not only helped them develop their teaching but also provided them with experiences to connect with students as well, particularly their ability to connect with students of the same race as them.

- My mentor has also given me several chances to teach class as a guest speaker, and those experiences not only helped me to alleviate nervousness of teaching in front of students but also guided me to teach by student-centered learning (intern survey response).

- After all of the students have left, a couple of them had come in...because they're always late, so I kind of remembered their name... and they were talking to each other in Hindi, I do not speak Hindi but I understand a little bit, so one was saying to the other, "Oh you're always late, so she remembers your name," I smiled at them and then they understood that I understand their language and I could see the expression, it gave them a moment of relief I would say. They can connect to me more compared to the other days when they would have a feeling of guilt on their face... so just like that, I also feel a connection...because they face certain challenges that I do on a regular basis (intern interview).

- I have an African American woman that I'm mentoring this semester...she told me later, "One of your students was out in the hallway, he didn't come to class," and...she walked up to him and 
said, "How come you weren't in class today?" and he said, "Oh I don't have my textbook yet." And she said, "Well, she gave away two textbooks today, you should have been there,"... and he goes "Oh well, you know I'm not in high school anymore so I don't have to go anymore," so she kind of like had a discussion with him... and then I asked her, "Don't be offended at this and asked her if he was African American?" and she said "Yes he was," and I said, "So you can do that, I don't know if I could have been as confronting," because it sounded like she was confronting him a little bit, not angry or anything and so she said, "Yeah maybe not but I talked to him about it," So again the mentor, the roles, people who you can look up to who are like you, who have succeeded and haven't failed just because of who they are or because of what people perceive of them, so that was kind of interesting (mentor interview).

This interaction reinforces research that showed the impact that faculty of color have on students because they serve as role models to underrepresented students (Davis, 2010; Lee 2010; Umbach, 2006). Fairlie et al.'s (2014) recent quantitative study at a large community college also showed that students who had same-race instructors, actually performed better and had positive long-term outcomes such as retention and completion. Teaching opportunities expose interns and new faculty to the diversity in a community college. More importantly, teaching under the supervision of a mentor provides interns and new faculty with different approaches and perspectives in serving students in a complex community college environment. 
Benefit \#3: Professional Development

"The workshops in the community college circuit were very informative, engaging and offered valuable resources. I liked the structure of the program in that the workshops were held at different locations in order to give us a sense of each campus community in their working environment" (intern survey response).

Both research sites organized monthly workshops that covered various professional development topics. The online survey included two likert-scale questions about whether the FDIP helped in professional development in curriculum development and pedagogy. Interns responded with an average score of 3.59 and mentors responded with an average score of 2.30. All interns who were interviewed attended most of the FDIP workshops and reported that they were beneficial. One intern who had no teaching experience at all expressed, "the workshops have been so helpful and so informative. The topics range anywhere from the interview process, campus diversity, student support services, counseling...we've had teaching workshops."

Interns did provide suggestions for improvement in regards to the workshops. One suggestion that came up multiple times in the survey was that the workshops were specific to instructional faculty and counseling interns suggested workshops specific to counselors, as well as providing more focused workshops for part-time faculty, since most interns would start out as part-time faculty. Also, survey results included that it was challenging to attend all the workshops because of time conflicts with school work, the internship, and at times work as well. Other suggestions included meeting with hiring managers who can provide insight into what they look for in job candidates. 
Mentors were aware of the workshops but most did not attend. One Business faculty mentor reported that she was invited to present at one of the workshops and found it helpful for both interns and mentors, "I was asked to speak... and that was useful in seeing who was there and how long they'd been looking... even the ones that weren't going to be my mentees. This one was on lesson planning and syllabi and so there were three of us and so, I gave my ideas and the two other instructors gave their ideas and so again I learned from that but then again, I think it was good for the mentees to see that, you know there's more than one way to do it."

Hyers et al.'s (2012) recommendation and study revealed that faculty of color had less professional development and mentoring interactions than their White counterparts. Thus, having professional development opportunities in the early stages of teaching, may have an impact on increasing and improving professional development opportunities among faculty of color. Dancy \& Brown (2011) also recommended that induction programs should include professional development opportunities where mentoring socializes new faculty to the campus community, conversely, professional development build professional capacities.

Benefit \#4: Networking and Collaboration

"I am currently having a really positive experience because everything I have learned is applicable and relevant. The exposure and collaboration with the faculty and staff is a unique opportunity, the benefits have been experience and knowledge of what is expected of a prospective community college applicant" (intern survey response).

The workshops not only provided interns and mentors with professional development opportunities, but the study also revealed participant's value of the FDIP as 
networking opportunities as well. The online survey included two likert-scale questions about whether the FDIP helped in networking both within the college and within their discipline. Interns responded with an average score or 3.52 and mentors responded with an average score of 1.77 . The qualitative data showed interns' appreciation for both networking and collaborating opportunities with other interns, faculty, and staff.

One intern talked about her experience in the monthly workshops, "I feel like I only have positive things to say about it, it's been great to see all the different community colleges as well, since they host them at different places to kind of get a feel for the... different campuses and...meet some of the faculty members. I think all but one...the Presidents came to greet us."

All of the interns interviewed shared that networking with other interns was a good experience, "it was a great time to mingle with the other interns and talk about experiences and...exchange, little tidbits of information, things that are important...I also think we also learned from each other so I love the cohort system."

Diggs et al.'s (2009) study which found that networking has both a professional and social benefits and state that faculty of color benefit from having a safe space where they can share experiences that their White counterparts do not face.

Interns also valued the opportunities to collaborate in the wider campus community, which helped to better understand the community college system, "[My mentor] encouraged me to go to see what it would be like to be a full-timer, I went to the faculty senate meeting,...the union meeting this semester... and it was very helpful to get a glimpse of what they do when they're not teaching or planning in their office...I think teaching or sharing teaching ideas or collaborating with my colleagues and meeting 
different people in the department whether they're part-timers or full-timers or new fulltimers, it's a great department, it's very supportive."

Other interns in disciplines that require more collaboration, such as counseling, library studies, and student services, also expressed their value of collaboration across the college, "I think building community here is really important, that's how I've been able to do things outside of the library or teach in other people's classes, like by meeting other people outside of my discipline, they ask me to come and work with them."

A student affairs intern, expressed her appreciation for her mentor in encouraging her to participate in committee meetings, "My mentor, she pretty much knows everything. So I've been able to be a part of the committees, I've been able to participate in the changes in the assessment in the new implementation for the Math and English requirements and the SLOs and how research works, so I pretty much feel lucky to have the mentor that I have because I feel like I'm learning a ton... because I'm getting known, I now have more voice and now I can contribute more."

This reinforced Ortlieb et al.'s (2010) study that revealed that new faculty who developed a support network among peers 1) were eager to contribute to institutional discussions regardless of existing institutional bureaucracy, 2) wanted to improve curriculum, and 3) believed that new faculty can make a greater impact on the institution. Barriers and Challenges in Implementing FDIPs

The study answered the second research question regarding the barriers and challenges of implementing FDIPs and identified the following four issues of implementation, 1) mentor matching, 2) class placement, 3) mentor training, and 4) FDIP coordination. 


\section{Barriers \& Challenges \#1: Mentor Matching}

"Honestly a year is too long of a time to waste with someone that you don't like frankly,... I mean this program really has two parts to it right, the mentor at your campus and it's also the workshops with the cohort all over the region, right? So you're basically throwing half of your internship and a great experiences that you can have from this internship if you don't have a good mentor or if you are with someone that isn't a good match for you and that's just such a shame, it could be fixed" (intern interview).

Although interns and mentors showed an average likert-scale score of 4.09 and 4.33, respectively, indicating that the mentor/intern match was a positive match, qualitative data revealed challenges in matching interns and mentors. There were many different ways that interns were matched with mentors as well as the time frame between the time of application and the time of mentor matching. The key factor that influenced interns experience was timing. However, if interns had a positive experience with their mentor, the challenges they faced through the matching process was "worth it."

On the SDICCA application, prospective interns are asked to list their top three campuses where they would like to be placed. However, one way that interns were matched with a mentor was by reaching out to a faculty to request that they serve as their mentor. This method was reported by interns as being highly effective in being matched with a good mentor. However, whether or not interns "select" their own mentors, if there were time conflicts then, a mentor match cannot be made.

- I looked at all the faculty members [in the directory] and looked at what they were doing and what they were teaching and if they had any teaching philosophies on their website,... I really wanted a good mentor...email them and say, "Hey so I'm really interested in or I'm 
thinking about doing SDICCA and I'd love for you to be my mentor, have you have been a SDICCA mentor before, do you want to meet up and talk about it, are you interested in having an intern?" because you have to remember that all of these faculty members are also doing this, from what I know for free, so they are taking time from their schedule to mentor someone... I narrowed it down to a few professors that I really like and I was willing to go anywhere in the region... The first person I met with I immediately loved her and so she became my first choice and the second person emailed me back and she said, "Yes, I'd love to work with you...".

- I feel like it required a lot of footwork on my part, we have the Coordinator for FDIP but I think in terms of getting a mentor and securing a class, it's limited what they can do because at the end of the day it depends on the Department Chair and what class they have available, but it also depends on you on contacting full-time faculty and asking them to be your mentor, so I felt like there was a lot of footwork involved but it was worth because it worked out. I emailed potential mentors... another full-timer, different from the mentor I was actually placed with he had agreed to be my mentor but it didn't work out last minute because our class times conflicted... matched just based on convenience and availability of schedule but my mentor was great, she was very open and willing to answer any questions. 
Some interns were matched with mentors in more indirect ways, with the case of two interns, they had reached out to their potential mentors through informational interviews or other graduate program internships and then the mentors made inquiries about having interns and then learned about the FDIP and had the interns apply to be a part of the FDIP. These mentorship matches that were also initiated by interns, proved to be good mentor matches.

There were multiple survey responses that expressed the challenges that interns faced in being matched with a mentor.

- Originally it was simply challenging to make contact. Once I submitted my application, the process was blurry for math people. Once I made contact with someone directly at a campus things went more smoothly.

- The challenges of this program was the scarcity of mentors. I was on the list for 3 or 4 years before receiving a call. The benefit was that I was matched with a phenomenal mentor,...that provided me with an invaluable experience through his great example of what an instructor should be.

- I think my internship program was an excellent learning experiences. Even though it was extremely challenging to work with my mentors at certain points, it did teach me a lot about the community college environment.

One mentor who was interviewed also expressed that there should be more diverse mentors and interns and there were two responses in the survey that mentors and 
interns should be matched by race and gender. Another mentor who was interviewed suggested that her intern change to another mentor who had a better schedule, but the intern did not want to change mentors because the faculty was of a different race and gender.

The matching process also effects mentors as well, as shared by one mentor in the survey, "I was assigned an intern just days before the start of the semester, had no training and no time to think about the approach I would like to take with her. I also was not in on the hiring/interviewing, so did not have a chance to find out about the intern's background before starting. Instead, we had to dive in with logistics etc. and only slowly began to discover the intern's qualities and experiences."

As found in Davis' (2010) study showing that mentors have an influence on student's academic progress, engagement, and skills, it is important for internship programs to be intentional about the mentor and intern matching process. The findings of this study also validates Lumpkin's (2011) article that identified key studies that found that when both interns and mentors play an active role in the selection process, both feel a stronger sense of ownership and connection from the start of the mentorship relationship.

Based on the previous research and data collected, solutions suggested in matching interns and mentors include 1) matching by race and gender, 2) recommending that interns research possible mentors, and 3) have mentors review interns before a match is made. In addition to these suggestions, mentor training and/or preparation can also help in developing positive mentorship experiences, as discussed in the next section. 


\section{Barriers \& Challenges \#2: Mentor Training}

"I was not provided with any training. I highly recommend training...part of what is required is to begin with,... mentees are really going to lean on their mentors for so many things outside of the classroom ... keys, passcodes, way to access student information online, when will they get paid, human resources, all those things that are overwhelming for any new faculty member are going to be especially overwhelming for a mentee because, if they're in the program, they are most likely still in a grad program, so their busy, they don't have much time, so they are really going to rely on the mentors for that, um, I think, the other one is training on how to... suggest goals for the mentees and also how to just take their goals and really work with them to ensure that their goals are met and then the other thing I think, the mentors need to be privy to is...the professional development offerings at the college that they can or online where ever that they can immediately refer the mentee to" (mentor interview).

As previously discussed, expectations influenced the experience of participants in the FDIP. Suggestions were made by both mentors and interns and in the survey as well as the interviews to provide mentors with more training and resources for a more positive internship experience. However, the eligibility of being a mentor should also be clarified. One mentor shared that as soon as he was hired as a tenure-track faculty, he inquired about being a mentor, since he developed a mentorship program in his previous institution and was told that he should not be a mentor until he had more experience and was tenured. He shared that he wanted to increase the diversity of Math faculty, since there were no Math interns and was able to be approved to serve as a mentor by his Dean eventually, "This is something I'm very passionate about and I wasn't going to take no until I really got to somewhere, so I kept prodding." The same mentor suggested that mentor training should, "fit the context of the [specific] community college system, because if you have something like this at [another district] it has to fit, I guess, what's needed to address what's happening there." 
Both surveys and interviews included several comments about interns' desire to have a mentor who is committed to their professional growth.

- My experience was positive. One thing that I think the program could improve on is making mentor responsibilities more consistent. I spent many hours with my mentor through both semesters but I hear some interns had little interaction with their mentors especially during their final semester (intern survey response).

- The overall internship was a rewarding experience. I wish my mentor was more invested in my personal growth as a professional (intern survey response).

- Perhaps it would be beneficial to orient the mentors on how they may assist their interns, especially if they have not mentored before (intern survey response).

- More clarity on the time commitment for both mentors and interns. Initially I was a bit overwhelmed with the number of hours, although I hear that wasn't typical of all interns, but in the end I feel like it paid off quite a bit (intern survey response).

- Ensure each college that is participating in the program is invested in their mentees personal development (intern survey response).

- Mentors must be committed to mentees and provide proper learning opportunities (intern survey response).

- One challenge that occurred was being matched with a mentor that was of a different gender and different race. It was a struggle to 
connect with him and understand his mentorship style. Wish my mentor could have been more invested in my personal growth. The other counselors in the department were helpful in my growth and I was exposed to a lot of community college programs that will help me in the future (intern survey response).

There were a few suggestions from both the surveys and interviews on the format of the mentor training to include an initial meeting where both interns and mentors come together and learn about the goals of the FDIP and guidelines for a successful internship experience, "An introductory group meeting with Mentor and Mentees led by the program facilitator, to establish goals, guidelines and answer questions" (survey response). Overall, this study revealed that trainings should include, 1) an overview of the FDIP and its purpose, 2) logistical information about how to prepare interns for their first semester teaching, and 3) mentor guidelines or framework for mentorship.

In integrating theory and practice in implementing FDIPs, both mentor training and mentor matching should consider the interest, expectations, and identity of both interns and mentors. The internship experience should draw on both the interns' and mentors' social and cultural capital with the shared goals and values of creating a supportive network with an ultimate goal of improving student learning. 


\section{Barriers \& Challenges \#3: Class Assignment}

"The SDICCCA program is a highly respected program. I have noticed a difference in how I am treated when I say I am an intern versus a SDICCCA intern. I can also see the reasoning as to why because the program is very unique and the exposurelexperience and workshops are incredibly valuable. The only challenge is there is never a guarantee you will find employment, but there are many former SDICCCA interns that are current counselors. It's a nice community that is willing to help one another and despite the uncertainty of employment I would still recommended the program. It's an amazing experience" (intern survey response).

The issue of interns being assigned a class came up in both surveys and interviews and from both interns and mentors. One issue as noted in the survey response above, is the availability of classes and/or employment.

In addition, one survey response from a mentor revealed inconsistent or unclear policy about whether interns are able to teach their own class or not, "I love the idea of the SDICCCA Internship. Graduate students have an ideal chance to learn about community college teaching and to be mentored while they do it. The challenge this time seems to be around who has permission to teach a course and be paid for it the semester after interning with a mentor. My intern hasn't finished her Master's, but is close. My dean says she can't teach her own class (she can teach mine, but I need to be there and she doesn't get paid). My union rep says she *can* teach her own class. My scheduling chair says he cannot hire her, as he is obligated to hire adjunct faculty who have taught here previously, before he hires here. It seems other interns who have not completed their graduate degrees have been able to teach courses (it's what I did in graduate school, for heaven's sake!). What really feels awful is that my intern is low-income. She and her family (she's married to a veteran and has two children) are on Medical. Right now, she's 
trying to work out how to pay for a root canal. I imagine many interns are in a similar place. She's interviewing for paralegal jobs (her earlier career) to help make ends meet."

The PCCD FDIP addresses the availability of class assignment on their website, "Unfortunately, while the program intends to place all selected applicants, final placements are determined by a variety of factors, including: availability of classes in your discipline, enrollment, and the intern's demonstration of their readiness" (PCCD FDIP, n.d.).

The SDICCA Coordinator shared that class assignment practices varied by district and are influenced by each campus' human resources interpretations of the minimum qualifications, which states that faculty can be employed with a Master's or equivalent experience within the discipline and that interns still in graduate programs may be employed as long as they have "direct monitoring and systematic with the intern" (email correspondence).

One mentor, who served as the President of the Academic Senate, suggested as an institutional practice that Deans and Department Chairs reach out to the FDIP when there are vacancies, not only to fill the positions with interns but so that the FDIP can do focused recruiting on disciplines that have vacancies.

In implementing FDIPs, colleges can show a greater institutional commitment to faculty diversity by setting policy and procedures that support the class assignment for qualified interns. FDIP policy should consider 1) hiring policy and procedures, 2) pay structure for both interns and mentors, 3) union regulations, and 4) minimum qualifications. 


\section{Barriers \& Challenges \#4: FDIP Coordination Transition}

"Well, I think in the beginning, it was not very organized and people weren't very knowledgeable, even the people who were running it. So that was huge, in the beginning and it made me not participate, which is bad. Once it got a little bit more structure, I got a little more communication about what was going on and that was mostly from [FDIP Coordinator], I have to say, he's really moved forward with it, he's a great guy, we're really lucky to have him as a teacher and as this coordinator. So that helped" (mentor interview).

It is important to mention that some of the challenges that both mentors and interns experienced occurred when the FDIP Coordinator changed. Some of the challenges included the lack of communication or information about FDIP when interns and mentors inquired about participation during the transition between FDIP Coordinators. Other challenges included the lack of a structured internship program, including the lack of or poorly organized professional development workshops. This finding is important for colleges to consider when implementing FDIPs and/or changing coordinators.

- There may be other things that I didn't know about but just trying to get Math people, because when I inquired there was no Math people. In fact, I don't recall, I don't think there were many Math people ever...[former FDIP Coordinator]...communication wasn't responsive because of that I wasn't able to get my questions answered and I find that as a challenge to participation...so I kept prodding, so I asked someone about what their experiences were and how they got it, I found somebody who just recently got an intern and I didn't get very 
far with that either...but once I found out, we got someone new, I was all over that because I saw it as an opportunity (mentor interview).

- $\quad$ [FDIP Coordinator]...she couldn't answer any questions, she never got back with you,... she did not meet with the Dean, with me to find out, because I didn't have a coordinator at the [college campus],... I called her, I emailed her, I did all that, never showed up, never was there to support, never said, "You have a problem, let me know," never, none of that (intern interview).

- More structure in the program, especially when interns are applying would be good and I think FDIP...is working towards that because I think the Coordinator is changing a structure and they're really trying to make it a cohort based program and then I think the only drawback I see with that is just a little bit rigid in terms of oh, you're applying one semester, you're going to workshops and preparing your portfolio one semester, then you're getting paid the next semester. It's opposite from my experience, because whereas, I had to do a lot of work by myself, I was able to get it without so much of the help with the Coordinator stepping in, I think when they move to a cohort base program, there's less room for the intern or the applicant to make their own way. I felt like I was probably one of the last intern classes to sneak in there and make their own way and do it by myself, so once it becomes more structured, it will probably be easier in terms of finding a mentor and having classes because the Coordinator can then say to 
Department Chairs, "Ok we have this amount of interns, can you save a class for these interns," and they can work out the details ahead of time, so even though my experience with getting in was free form and hectic, that free form and hecticness probably allowed me to get into the internship program (intern interview).

Even during my initial research on FDIPs, my communication with FDIP Coordinators was limited and one FDIP Coordinator mentioned that they are transitioning out of the FDIP Coordinator position. In addition, my interviews with FDIP Coordinators revealed the lack of knowledge of the history of the FDIP, as well as procedures pertaining to human resources policies and procedures, and other activities pertaining to implementing an FDIP. FDIP Impact on Faculty Diversity as a Recruitment and Retention Tool "I think the most rewarding thing was knowing that I was mentoring a person of color and she was Chinese-American and she spoke Cantonese fluently and I was so happy that we finally got someone in ESL department with that kind of background because that's a huge chunk of our student body" (mentor interview response).

In answering research question \#3, what is the impact of the FDIP on faculty diversity as a recruitment and retention tool, quantitative data collection was limited for various reasons. First, faculty demographic trends prior to 2000 was unattainable, so a baseline comparison before the legislation was adopted was not able to be determined. Second, a comprehensive report on campuses with FDIPs was not available. Thus, comparisons were not able to be made between campuses with FDIPs and campuses without an FDIP. 
However, faculty demographic trends since 2000 across 15 years was collected for all California community colleges and within the two FDIP research sites as provided in the following Table 6. The quantitative data showed that full-time URM faculty demographics across California and at the research sites (PCCD and SDICCA colleges) were relatively the same across 15 years from $18 \%$ to $24 \%$, with the research sites approximately $2 \%$ higher than the state wide average, part-time faculty demographics showed similar trends (CCCCO Datamart, 2015).

This table is not a valid indication as to whether the FDIP has an impact on faculty diversity, since the state wide trend includes colleges that have FDIPs as well but since a comprehensive report and list of which colleges have an FDIP or not is not available, comparisons cannot be made. The last report of faculty interns in California community colleges was published in 1996 and limited data exists on colleges that have implemented FDIPs since the last report. However, student and faculty demographics at the research sites was attainable. Between 2000 and 2015, the URM student population at the research sites increased from $38 \%$ to $54 \%$ and the URM faculty population increased from $19 \%$ to $22 \%$ (CCCCO MIS Datamart, 2015). 
Table 6: California Community College Faculty by Ethnicity from 2000 to 2015

\begin{tabular}{|c|c|c|c|c|c|c|c|c|c|c|c|c|c|c|c|c|}
\hline & \multicolumn{4}{|c|}{ Fall 2000 Faculty } & \multicolumn{4}{|c|}{ Fall 2005 Faculty } & \multicolumn{4}{|c|}{ Fall 2010 Faculty } & \multicolumn{4}{|c|}{ Fall 2015 Faculty } \\
\hline & $\begin{array}{c}\mathrm{CA} \\
\text { Count } \\
\end{array}$ & $\begin{array}{l}\mathrm{CA} \\
\% \\
\end{array}$ & $\begin{array}{c}\text { Site } \\
\text { Count }\end{array}$ & $\begin{array}{l}\text { Site } \\
\%\end{array}$ & $\begin{array}{c}\mathrm{CA} \\
\text { Count } \\
\end{array}$ & $\begin{array}{l}\mathrm{CA} \\
\% \\
\end{array}$ & $\begin{array}{c}\text { Site } \\
\text { Count }\end{array}$ & $\begin{array}{c}\text { Site } \\
\%\end{array}$ & $\begin{array}{c}\mathrm{CA} \\
\text { Count } \\
\end{array}$ & $\begin{array}{l}\mathrm{CA} \\
\% \\
\end{array}$ & $\begin{array}{c}\text { Site } \\
\text { Count } \\
\end{array}$ & $\begin{array}{c}\text { Site } \\
\% \\
\end{array}$ & $\begin{array}{c}\mathrm{CA} \\
\text { Count } \\
\end{array}$ & $\begin{array}{l}\mathrm{CA} \\
\% \\
\end{array}$ & $\begin{array}{c}\text { Site } \\
\text { Count }\end{array}$ & $\begin{array}{c}\text { Site } \\
\% \\
\end{array}$ \\
\hline \multicolumn{17}{|l|}{ Full-time Faculty } \\
\hline African-American & 1,072 & 6.4 & 167 & 7.5 & 1,100 & 6.3 & 176 & 7.2 & 1,110 & 6.1 & 167 & 6.3 & 863 & 6.0 & 142 & 8.1 \\
\hline American Indian & 183 & 1.1 & 26 & 1.2 & 199 & 1.1 & 21 & 0.9 & 167 & 0.9 & 43 & 1.6 & 99 & 0.7 & 43 & 2.5 \\
\hline Asian & 1,184 & 7.1 & 119 & 5.4 & 1,412 & 8.0 & 140 & 5.7 & 1,502 & 8.3 & 179 & 6.8 & 1,397 & 9.7 & 188 & 10.8 \\
\hline Hispanic & 1,742 & 10.4 & 228 & 10.3 & 2,009 & 11.4 & 279 & 11.4 & 2,319 & 12.8 & 309 & 11.7 & 2,146 & 15.0 & 283 & 16.2 \\
\hline Multi-Ethnic & 0 & 0.0 & 0 & 0.0 & 0 & 0.0 & 0 & 0.0 & 96 & 0.5 & 0 & 0.0 & 149 & 1.0 & 14 & 0.8 \\
\hline Pacific Islander & 29 & 0.2 & 5 & 0.2 & 37 & 0.2 & 7 & 0.3 & 99 & 0.5 & 7 & 0.3 & 30 & 0.2 & 10 & 0.6 \\
\hline Unknown & 265 & 1.6 & 46 & 2.1 & 434 & 2.5 & 99 & 4.0 & 1,004 & 5.6 & 99 & 3.8 & 997 & 6.9 & & 0.0 \\
\hline $\begin{array}{l}\text { White Non- } \\
\text { Hispanic }\end{array}$ & 12,214 & 73.2 & 1,627 & 73.4 & 12,403 & 70.5 & 1,726 & 70.5 & 11,789 & 65.2 & 1,830 & 69.5 & 8,671 & 60.4 & 1,066 & 61.1 \\
\hline Total & 16,689 & 100.0 & 2,218 & 100.0 & 17,594 & 100.0 & 2,448 & 100.0 & 18,086 & 100.0 & 2,634 & 100.0 & 14,352 & 100.0 & 1,746 & 100.0 \\
\hline \multicolumn{17}{|l|}{ Part-time Faculty } \\
\hline African-American & 1,762 & 4.8 & 295 & 5.8 & 1,930 & 4.8 & 320 & 5.7 & 1,996 & 4.9 & 338 & 5.5 & 1,749 & 5.2 & 333 & 6.3 \\
\hline American Indian & 321 & 0.9 & 33 & 0.6 & 317 & 0.8 & 45 & 0.8 & 293 & 0.7 & 52. & 0.9 & 198 & 0.6 & 40 & 0.8 \\
\hline Asian & 2,363 & 6.5 & 265 & 5.2 & 3,158 & 7.9 & 395 & 7.0 & 3,451 & 8.4 & 424 & 6.9 & 3,456 & 10.2 & 434 & 8.2 \\
\hline Hispanic & 2,994 & 8.2 & 564 & 11.1 & 3,815 & 9.5 & 696 & 12.4 & 4,404 & 10.7 & 776 & 12.7 & 4,321 & 12.7 & 712 & 13.4 \\
\hline Multi-Ethnic & 0 & 0.0 & 0 & 0.0 & 0 & 0.0 & 0 & 0.0 & 123 & 0.3 & 7 & 0.1 & 337 & 1.0 & 47 & 0.9 \\
\hline Pacific Islander & 82 & 0.2 & 17 & 0.3 & 114 & 0.3 & 18 & 0.3 & 209 & 0.5 & 41 & 0.7 & 130 & 0.4 & 49 & 0.9 \\
\hline Unknown & 1,682 & 4.6 & 181 & 3.6 & 1,979 & 4.9 & 237 & 4.2 & 3,228 & 7.9 & 386 & 6.3 & 2,939 & 8.7 & 401 & 7.5 \\
\hline $\begin{array}{l}\text { White Non- } \\
\text { Hispanic }\end{array}$ & 27,131 & 74.7 & 3,725 & 73.3 & 28,809 & 71.8 & 3,906 & 69.5 & 27,303 & 66.6 & 4,091 & 66.9 & 20,805 & 61.3 & 3,302 & 62.1 \\
\hline Total & 36,335 & 100.0 & 5,080 & 100.0 & 40,122 & 100.0 & 5,617 & 100.0 & 41,007 & 100.0 & 6,114 & 100.0 & 33,935 & 100.0 & 5,318 & 100.0 \\
\hline
\end{tabular}

Source: California Community Colleges Chancellor's Office Datamart. Report Run Date As Of: 1/25/2016 
The program evaluation showed more positive data, as indicated in Table 7:

Demographics of Intern Survey Response, interns included 13\%, 2\% and 17\% AfricanAmerican, Native American and Hispanic, respectively (32\% URM interns total). In addition, $33 \%$ of interns reported obtaining a position within three years of completing the FDIP. This finding may indicate the FDIPs potential in recruiting faculty of color in California community colleges. However, the sample size was limited and cannot be generalized to the total population.

Table 7: Demographics of Intern Survey Responses

\begin{tabular}{|l|c|c|c|}
\hline & Interns & $\begin{array}{c}\text { \% of sub- } \\
\text { group }\end{array}$ & $\begin{array}{c}\% \text { of } \\
\text { total }\end{array}$ \\
\hline Participant Types & $\mathbf{8 3}$ & $100 \%$ & 86 \\
\hline Gender & $\mathbf{5 8}$ & 70 & 60 \\
\hline Female & $\mathbf{2 2}$ & 27 & 23 \\
\hline Male & $\mathbf{3}$ & 4 & 3 \\
\hline Decline to State & & & \\
\hline Diversity Factors & $\mathbf{1 0}$ & 12 & 10 \\
\hline African-American/Black & $\mathbf{1}$ & 1 & 1 \\
\hline Afro-Puerto Rican & $\mathbf{2}$ & 2 & 2 \\
\hline Native American Indian & $\mathbf{1}$ & 1 & 1 \\
\hline Arab & $\mathbf{1 1}$ & 13 & 11 \\
\hline Asian & $\mathbf{1 4}$ & 17 & 15 \\
\hline Chicano/Latino/Hispanic & $\mathbf{1}$ & 1 & 1 \\
\hline Middle Eastern & $\mathbf{1 0}$ & 12 & 10 \\
\hline Multiracial/ethnic & $\mathbf{1}$ & 1 & 1 \\
\hline Sexual Orientation & $\mathbf{2 8}$ & 34 & 29 \\
\hline White & $\mathbf{4}$ & 5 & 4 \\
\hline No response & & & \\
\hline
\end{tabular}

There were two likert-scale ( 0 for not sure, 1 for strongly disagree, and 5 for strongly agree) questions on the survey about diversity 1) My participation in the FDIP 
increased my aware and sensitive to diversity-related issue, and 2) My participation in the FDIP prepared or improved my work in a diverse classroom/community college. Interns average scores were 3.87 and 4.09 respectively and mentors scores were 3.23 and 2.77 , respectively.

Not only is it important to look at the impact of the FDIP on faculty diversity from a quantitative perspective but from a qualitative perspective as well. The qualitative data collected provided rich insight on the impact of FDIP on preparing faculty for employment at a diverse community college. Responses to the interview question, "Do you think the FDIP prepared you to work in a diverse community college?" most interns responded about the diversity of the classroom and student population.

- The students, I felt like I was looking out into a sea of aunts and uncles and friends of my parents,...the classroom demographics was everything that I expected and wanted it to be, so it was very comfortable for me,...it's interesting to have been a student there in 2008 and then now I walk around campus but I walk around as an instructor, like a totally different feeling but it feels like I'm going home, so it's very special, it's not really just a job, it's something I really enjoy doing.

- Absolutely, we talked about diversity and student success and the difference between quality and equity and in a sense, I feel like it did because it showed how important that is.

However, there were some comments about the limitations of the FDIP or any other program on its impact on preparing faculty to teach in a diverse classroom. 
- To me that is not something you can just learn in one sitting or even in a program, it is something that needs to be worked at all the,... so I don't know if they prepared me to, I think that they provided some of that but...kind of open the network for you and to give you some experience in which hopefully,...you can see where your weak spots are and see where to work on...I feel like doing that consistently in your career is going to prepare you to work in a diverse community college and I'm saying this not to be unfair to SDICCA, I feel like they did their part, I just don't think one workshop or even a year long thing... [can] prepare me to work in a diverse community college, it prepared me to better work with diverse population...I think that any FDIP program the goal I think other than the other goals is to instill in their interns the sense of life long learning (intern interview).

Interns did provide suggestions on how FDIP can address diversity-related issues by engaging interns in dialogue.

- How do you prepare someone to work in a diverse environment, unless you have those conversations and I don't know if we've had those types of conversations yet (intern interview).

- If you want to talk about diversity...you have the group talk about... diverse,... you let the group come back with feedback,...give them scenarios, maybe someone will say, so what are some of the challenges you've had in a diverse group and what are some of the strengths and the benefits of having that, let the group bring their 
experiences to the table so that everyone can see what's going on, some of the strategies to overcome working with students, are you involved in the community, how resourceful are you when a student comes to you and says something to you like, you know my boyfriend is assaulting me, what do you do? As a teacher what do you do, the campus may have it but how you gonna help this student? (intern interview).

Moreover, there were comments questioning the definition of diversity and how it is integrated into the FDIP.

- When I look at the website it says diversity but I think people have different interpretations of diversity,... for me diversity means ethnic diversity, so I see other people have very open interpretations of diversity,... how come we don't say explicitly what type of diversity are we looking for, which I think is weird because librarianship it does talk about this because these residency programs say ethnic minorities or these scholarships say explicitly, so I think it's interesting that they don't say that (intern interview).

In answering the interview question, Do you think the FDIP has an impact on faculty diversity and/or an impact on the campus climate around diversity?, there were mixed responses from mentors but most mentioned that FDIP has the potential to increase faculty diversity and the climate. However, one mentor did share that he did not think the FDIP had an impact on faculty diversity because the district was already diverse. 
- We need more diversity of race. As far as I know, all the interns in our department except for my current intern have been white women. While I think it's important to hire women, it's more important to hire people of color...I think the most rewarding thing was knowing that I was mentoring a person of color and she was Chinese-American and she spoke Cantonese fluently and I was so happy that we finally got someone in ESL department with that kind of background because that's a huge chunk of our student body.

- I think it does and I really like to look at diversity, very broadly,... in addition to just ethnic background or cultural background, that they're thinking about gender, they're thinking about LGBT, they're thinking about disability, they're thinking about age, socioeconomic background, first generation college, you know and there's just so many things that I think fall under the umbrella of diversity and so, I mean when I think about the interns I've had,... first woman, she was Latina and so was [intern name] but she was also half Asian, she could probably check lots of boxes on the ethnic thing but she was also first generation college, grew up in LA.... and then the woman that I mentioned who couldn't finish, she was Asian-American, I think Chinese American and you know also older, interested in changing professions and the man [intern name] that I'm working with now.

- Is it diversity in ages, learning abilities, I don't know?...I do believe that the faculty should represent the student population not just on 
ethnic background but also on class... Now, I think it has the potential to impact, I haven't been working here long enough to see the impact but I do see the potential.

- I think if it is run well it does and especially around the campus climate around diversity... because there is so much professional development involved in the internship program,... I think it's limited to the point of how much a department really want faculty diversity, so because the FDIP can't place a students, at least in Peralta, they can't place an intern in a class... So the students that I've been working with you know are rather diverse, a lot of different backgrounds, a lot of different experiences, ages, and the like and like I said before most of the interns I've been working with have either gotten full-time positions or really super involved as a part-time instructor.

In both surveys and interviews, interns mentioned that the campus' value of the FDIP was demonstrated by administrators participating in the professional development workshops and interns being recognized during Flex Day activities before the start of their first semester teaching. These acknowledgements may demonstrate the campus' climate on diversity, which may support the FDIP as a retention tool. As revealed in Victorino et al.'s (2013) study on nearly 30,000 faculty at 4-year universities that showed a statistically significant positive relationship between campus racial climate and job satisfaction with female, faculty of color, and African American reporting less positive perceptions on campus racial climate than other faculty. 


\section{Summary and Synthesis}

Overall, the findings of this study shows that although the FDIP may not have a direct impact on increasing faculty diversity, the program does have an impact on preparing faculty for employment in community colleges. The FDIP provides mentorship that not only provides practical skills and knowledge, including but limited to curriculum development, pedagogy, and the hiring process, but the mentor/intern relationship provide a supportive relationship that socializes new faculty into the campus culture and bureaucracy that many new faculty, particularly faculty of color find difficult to navigate (Dancy \& Brown, 2011; Dixon-Reeves, 2003; Reddick \& Saenz, 2012; Zambrana et al,, 2015).

In addition, the professional development and networking opportunities included in the FDIP have similar benefits of a mentorship, as well as a safe launching point for new faculty to have an impact on students and the campus climate on diversity, particularly student equity issues (Chang et al., 2013; Dancy \& Brown, 2011; DixonReeves, 2003; Levin et al., 2014; Nelson, 2011; and Ortlieb et al., 2010).

This study also found barriers and challenges in implementing FDIPs, including 1) mentor matching, 2) mentor training, 3) class assignment, and 4) FDIP coordinator transition. The study revealed that interns expected mentors to be interested in their professional growth and data indicated a preference for matching mentors and interns with the same gender and ethnicity. Suggestions to improve mentor matching included having interns research potential mentors and having an initial informational interview. The second challenge, also related to mentor matching was the inconsistent mentorship experiences. Suggestions to improve internship experience included training mentors by 
providing an overview of the FDIP, including its main purpose, as well as logistical information needed to prepare interns for their first semester, and a framework or guidelines for mentorship.

Another challenge included the uncertainty of whether interns will have a class assignment or teaching experience during the internship program. This challenge was dependent on each campus' policy on hiring interns and their interpretation of the minimum qualifications. Colleges and districts interested in implementing FDIPs should clarify their hiring policy in regards to interns and perhaps set up policy on available classes for interns.

The final challenge that was identified through this study was in regards to the FDIP coordinator. Most of the negative experiences identified in the study related to the transition of FDIP coordinators, which provides evidence for districts to plan for changes in staffing.

Finally, this study examined the FDIPs impact on faculty diversity as a recruitment and retention tool. The quantitative data did not show FDIPs impact on increasing faculty diversity in the long-term, despite the majority of its participants being persons of color. However, the study did provide qualitative evidence showing its impact on preparing faculty for employment in a diverse community college.

Overall, the findings of this study support CRT, Racial Identity Development, Cultural Wealth, and Representative Bureaucracy theories and reflect the findings of the current scholarship on multiple aspects. First, interns expressed their interest in working at community colleges, specifically because of the diverse student population, and mentors desire to increase faculty diversity. Second, participation in FDIP was 
instrumental in helping interns develop their identity as educators and understanding the dynamic between teaching and learning and diversity. Third, both interns and mentors attributed the FDIP in preparing new faculty to not only work in a diverse community college but also in preparing future leaders committed to providing a more inclusive learning environment for all students. Finally, this study emphasized the value of institutions in making a commitment in time and resources to increase faculty diversity in recognition of our changing student population. 
Chapter Five: Discussion and Recommendations Introduction

"I have continued to teach at the college level since then, both as adjunct and as full-time core faculty. I also served as a founding director and mentor in a teaching fellowship program for graduate students who are interested in teaching at the college level. I am currently a full-time college administrator and also teach as an adjunct. This is all to say that I feel I got my roots in the FDIP, and I have definitely continued to build on that foundation. There should be more programs like FDIP, especially in an effort to diversify faculty in general" (survey response from former intern and mentor).

This chapter will provide a brief overview of the purpose of the study, the research methodology and findings, followed by a discussion of the implications of these findings for policy and practice. The chapter will conclude with the study's limitations and recommendations for action and future research.

The purpose of this study was to examine whether the Faculty Diversity Internship Program (FDIP) is an effective recruitment and retention tool for faculty of color in California community colleges. Thus, a program evaluation of the FDIP was conducted at two research sites to answer the following research questions:

1. What do FDIP participants find beneficial in participating in the program?

2. What are the barriers and challenges in implementing FDIPs?

3. What is the impact of the FDIP on faculty diversity as a recruitment and retention tool?

The program evaluation utilized a transformative research approach to examine social justice issues, specifically representative bureaucracy and faculty diversity challenges. Quantitative data was collected from the California Community Colleges Chancellor's Office Datamart on the ethnic makeup of the student population and faculty 
as well as from an online survey that was distributed to current and former FDIP interns and faculty mentors. Qualitative data was collected from three open-ended questions on the online survey and interviews with seven interns and seven faculty mentors.

Overall, the quantitative data did not show a strong impact on increasing faculty diversity at the research sites. However, qualitative data provided rich information about how participation in FDIP prepared new faculty for employment in a diverse community college that may be used as evidence to inform implementation practices.

\section{Interpretation of Findings}

This study provided an overview of the FDIPs including the purpose, structure, and benefits of participation at two FDIP sites, Peralta Community College District and the San Diego Imperial Valley Community College Association. FDIPs allow graduate students nearing completion of their program, mentorship with a faculty and teaching, professional development, and networking opportunities at a community college.

The key findings of this study identified the following benefits of participation 1) mentorship with a faculty, 2) teaching experience, 3) professional development workshops, and 4) networking and collaboration opportunities.

This study's findings reinforces much of the recommendations identified in the literature reviewed regarding the experience of faculty of color both inside and outside of the classroom. First and most impactful, the mentorship experience was found beneficial to both interns and mentors. Faculty mentors not only provided interns with coaching and support in regards to teaching and learning in the classroom but also as a guide and advocate in navigating institutional bureaucracy. Mentors expressed how their 
mentorship experience kept them abreast of new trends in the field, improved their student assessment techniques, and overall teaching and learning strategies.

Second, this study's finding that interns serve as potential role models for community college students because they can connect with students either because they are of the same ethnic and socioeconomic background and they were also alumni of community college themselves (Davis, 2010; Lee, 2010; Umbach, 2006).

Finally, as cited in the literature reviewed many faculty of color lack professional development and networking opportunities but interns reported these opportunities as key benefits in participating in FDIP (Hyers et al., 2012). These opportunities provide a support network to new faculty of color to share and provide support for experiences that only faculty of color face (Reddick \& Saenz, 2012; Zambrana et al., 2015).

Overall, the benefits of the FDIP emphasize the importance of relationships in helping interns and new faculty members prepare to serve in a diverse community college. A number of suggestions were made in the survey and interviews to provide similar inductions programs to new faculty as well. The findings show that these relationships are long-lasting and have both short-term and long-term impact in helping faculty build professional capacities as well a support network and opportunities to collaborate.

This study also found the following barriers and challenges of implementing FDIPs, including 1) mentor matching, 2) mentor training, 3) class assignment, and 4) FDIP Coordinator transition. The barriers and challenges identified in this study aligns with the recommendations provided in the literature reviewed that include institutional commitments in time, resources, and recognition in the importance of faculty diversity in 
creating an inclusive learning environment that prepares our students for a diverse workforce (Gurin et al., 2002; Dixon-Reeves, 2003; Fujimoto, 2012; Nevarez \& Wood, 2010; Reddick \& Saenz, 2012; Smith et al., 2004). Institutions that are committed to increasing faculty diversity through an FDIP should consider race, particularly in mentor matching, but should also commit time and resources in coordinating the program and providing class assignments for interns to have teaching experiences that would also provide evidence of the impact of the FDIP in preparing new faculty to serve in community colleges.

Overall, this study identified barriers and challenges from the perspective of the program participants and did not address institutional challenges. Nearly all participants recommended FDIP and shared their opinion that institutions should continue the program, and that more institutions across the State should implement the program. Some also indicated that the program should become more institutionalized because there seemed to be a lack of knowledge of the existence of the program.

In regards to whether the FDIP increases faculty diversity, the quantitative findings found that the FDIP does not have a strong impact on increasing faculty diversity, but it does have a significant impact on preparing new faculty for employment in a diverse community college and serving as agents of change in promoting an inclusive learning environment for all. Mentors reported that the interns that they have mentored have not only been hired as faculty but have also become active members in the campus community, serving in committees and also connecting to students who are of the same race or share similar traits. 
Overall, these findings support the representative bureaucracy theory that argue for bureaucracies that reflect the population served so that policies and practices also reflect the values shared by policy makers, implementers and the population they serve. The FDIP interns not only reflected the student population, but their experience and desire to work or return to their community college "roots" reflect the cultural capital they bring into the community college classroom and community.

\section{Implications for Policy and Practice}

Education has been seen as one of the key mechanism for the U.S. to prepare its workforce and maintain its competitive advantage in the global economy (DarlingHammond, 2010). As the largest higher education system in the U.S. and the URM student population expected to increase, it is important for the California community college system to consider the dynamic of these demographic trends with its policies and practices. The recommendations and implications of this study are based on the findings of this program evaluation, as well as the theories and literature presented.

Although the quantitative data from this program evaluation do not reveal strong evidence of the FDIP in achieving the goal of increasing faculty diversity, the demographics of the participant interns and the qualitative data supports the FDIPs achievement in preparing new faculty to work in a diverse community college. The program evaluation provides insight regarding the dynamic between race and teaching and learning that should be considered in implementing FDIPs. CRT emphasizes the use of storytelling or testimonials in resurfacing how race plays a role in how people of color are perceived and treated. This study shares the stories of participants in the FDIP that 
reveal how race was a contributing factor in their interest in participating in a program that aims to increase faculty diversity.

As argued in CRT and cited in the literature reviewed, faculty of color contend with legitimizing their identity in educational institutions that do not value their racial identity and their cultural wealth, which negatively impacts their experience and opportunities as an educator (Chang et al., 2013; Cuyjet, 2008; Dancy \& Brown, 2011; Diggs et al., 2009; Dixon-Reeves, 2003; Garrison-Wade et al., 2012; Hyers et al., 2012; Levin et al., 2013; Zambrana et al., 2015). Representative bureaucracy theory also argues that bureaucracies that do not reflect the populations they serve are challenged in establishing policies and practices that reflect the values of the population. Literature surveyed revealed that faculty of color serve as role models and positively impact the educational outcomes of students of color (Dancy \& Brown, 2011; Davis, 2010; Fairlie et al., 2015; Haley et al., 2014; Lee, 2010; Levin et al., 2014; Umbach, 2006).

The findings of this study align with the findings of the literature reviewed providing evidence of the reported benefits of participating in the FDIP, including mentorship, teaching, professional development, networking and collaboration opportunities in preparing to work in a diverse community college.

The study identified the mentorship experience as most influential on participants experience and impacted the development of new faculty identity pertaining to improving teaching and learning in the classroom, but more importantly, providing a support network to new faculty. The study revealed that mentors felt that helping new faculty who were persons of color was especially rewarding. Mentorships were cited in the literature as recommendations that institutions can undertake to support new faculty of 
color. Based on the literature and the findings of this study, institutions interested in implementing FDIPs, should develop mentorship components that 1) has clearly defined intern and mentor responsibilities, 2) provide mentors with training and support, and 3) a safe space to discuss any challenges that arise with mentors.

This study also revealed that interns of color were also able to connect with their students in ways that their White counterparts or mentors were not be able to, including relate and connect with the students based on their race, experience as a first-generation college student and even language. The findings of this study provide qualitative evidence for community college leaders to consider FDIPs as a means to not only recruit more faculty of color but as a means to prepare and acculturate new faculty and develop leaders committed to an inclusive learning environment as well. Thus, the implementation of FDIPs should consider professional development workshops that develop teaching methods that specifically help new faculty work in diverse community colleges, such as culturally relevant pedagogy and race-conscious topics such as implicit bias and stereotype threat.

Despite the overwhelming positive feedback from program participants, it is unfortunate that there were also findings about the FDIP's lack of strong institutional presence. Some mentors described that they were interested in serving as mentors but were unaware or were unable to find information about how to serve. Other interns expressed that they only found out about the FDIP after an informational interview with a prospective mentor. These findings beg to question the commitment of colleges/districts to faculty diversity and whether having a part-time FDIP Coordinator is enough in demonstrating the institution's commitment to faculty diversity. The findings suggest 
that the FDIPs have worked in isolation and sustained itself by the faculty mentors and FDIP Coordinators who believe in the value and impact of the program in preparing and increasing faculty of color.

Furthermore, the findings did not include any mention of the Board of Directors' role in faculty diversity. Overall, the findings specific to the lack of institutional support points to the lack of leadership in championing faculty diversity. As Fujimoto (2012) state, "It is increasingly clear that the necessary changes in diversification of faculty are greatly aided when there is race-conscious ethical leadership and commitment from the top levels of the organization. In the absence of such leadership and commitment, the types of problems... have the potential to persist and multiply."

From a system-wide standpoint, the findings also point to a lack of leadership as well. FDIP legislation was passed in 1992 and four years later in 1996, a comprehensive report was published about faculty diversity internships. I was unable to locate a comprehensive within the last 20 years. It is encouraging that the CCCCO EEO \& Diversity Sub-committee has initiated diversity trainings and summits in this academic year. These trainings/summits include information regarding legislation and programs and strategies, including FDIP about diversifying faculty and staff. The trainings/summits also highlight the window of opportunity that the State has to hire more faculty, including over $40 \%$ of current faculty at or above retirement age and the CCCCO's commitment of $\$ 60$ million towards hiring full-time faculty over the next 10 years. Although encouraging, I hope these initiatives do not follow the historic trend of the FDIP when interest seemed to ebb after initial commitments of funding. 


\section{Recommendations for Action}

It is an opportune time to share the findings of this study for two reasons. First, the researcher is employed at a district that has assembled a work group to propose the implementation of an FDIP on its college campuses. The researcher is a part of this work group and will have first-hand experience implementing an FDIP.

Second, at the state wide level, the California Community Colleges Chancellor's Office's EEO \& Diversity Advisory Sub-committee launched initiatives aimed at increasing faculty diversity in the Fall 2015 and have and are currently offering multiple trainings in California to address EEO policies and practices. Leveraging the CCCCO's current diversity initiatives will be a key strategy in sharing the findings from this study. The results of this study will be shared with the co-chairs of the EEO \& Diversity Advisory Sub-committee with the recommendation that FDIP implementation be included as one of the topics for the trainings. In addition, the researcher has submitted an application to be a part of a Professional Resource Team to provide technical assistance to any college/district requesting assistance with any of the EEO initiatives.

In addition, in fulfilling the purpose of providing evidence and guidelines for colleges interested in implementing FDIPs, the researcher has also submitted a session proposal to share findings of this study at the Student Success Conference in October 2016 sponsored by the RP Group.

As California community colleges recognize their role and obligation in increasing faculty diversity, through the CCCCO's diversity initiatives and trainings, more community colleges will seek resources on strategies to fulfill their obligation, including the FDIP as a means to recruit and prepare more faculty of color. The findings 
of this study will provide evidence for colleges in designing and implementing FDIPs that fit their specific population.

\section{Recommendations for Further Study}

This program evaluation examined two FDIPs in California that only covered 14 colleges. Because of the small sample size, the findings, particularly the quantitative findings cannot be generalized to the entire population. It is recommended that the CCCCO commission another study to examine FDIPs state wide. A comprehensive study may yield more reliable and valid research findings to understand the impact of FDIPs on faculty diversity across California. The last comprehensive study collected data from colleges/districts about their FDIP, not to current and former FDIP participants. A determination must be made as to whether data should be collected by the colleges/districts and/or FDIP participants. Data may be collected on not only the impact on faculty diversity in regards to the number of interns hired for teaching/counseling positions but also their participation in the larger college community including but not limited to committee work and other professional development and leadership activities.

This program evaluation also, did not provide evidence on the impact of the FDIP on the retention of faculty hired through the FDIP. Studying retention rates is important in determining the long-term impact of FDIPs in regards to faculty diversity. Additional research may also be conducted to determine whether there is a difference between faculty who completed the program and faculty who did not go through the program. Comparing faculty hired through the FDIP may yield results that provides evidence that supports FDIP as an effective induction program in preparing new faculty to teach and become active members in the campus community. 
Long-term research may also produce evidence of the impact of FDIP and its current and former participants on the campus climate and other diversity issues, such as professional development and/or programs focused on student equity.

Although important, increasing faculty diversity is not the end goal of FDIPs, but rather improving teaching and learning so that all students achieve success. Additional research should be conducted to examine the impact of interns who were hired and their impact on student learning both inside and outside of the classroom, and their service and scholarly activities focused on improving educational outcomes of URM students.

\section{Reflections on the Research Process}

Four years ago, I was working in a large, private university in New York City wondering, "What's next?" Even after being the first in my family to go to college and obtain a Master's degree, I still felt like an outsider working in higher education and felt very disconnected to the international students I was pushing immigration papers for in order for them to take advantage of a U.S. higher education.

I came across a job posting and the challenge of recruiting international students for a community college was appealing and fortunately, I was hired by a community college in California. When I started working at a community college, I was overwhelmed with a sense of "coming home," even though I had never stepped foot in a community college and barely knew about the system, I connected with the students so well because I saw myself in them. I found my professional home and realized that I needed to learn as much as possible about the California community college system and public education in general, so I discovered the Ed.D. program at SFSU. 
Although I never saw myself as an intellectual, I knew, I had to at least apply. Once I started the Ed.D. program, I knew that as challenging as it was, I couldn't give up, especially when I started researching the topic of faculty diversity and saw how much work that needed to be done to decrease the achievement gap, the opportunity gap and the demographic gap not only between URM students and Asian and White students but between students and faculty. Another world opened up to me and I was exposed to the works of Paolo Friere and immersed in California's rich history and leadership in social justice movements.

My experience in the Ed.D. made me reflect on my own experience of always feeling like an outsider in higher education. I never felt like I was good enough, smart enough, or even looked the part enough.

As I developed my identity as a student, an educator and a researcher, I realized that the work and learning never ends and that this dissertation is just the first step towards my continued work in resurfacing race to improve teaching and learning for all.

\section{Conclusion}

As the largest higher education system in the nation and the gateway to higher education for thousands of URM students, the California community college system should be a leader in preparing our workforce for an increasingly global and interdependent economy. Aligning our faculty with the values and population trends of the students we serve is one strategy that colleges can do to prepare our students for this shifting diversity and global interdependence. The way that we serve and teach our students can be better matched to their values, goals, and aspirations by increasing faculty 
diversity. Through the diversification of faculty, institutions can serve as leadership and scholarly role models in shaping inclusive learning and working environments.

This program evaluation provides much evidence of the impact of the Faculty Diversity Internship program in recruiting new faculty who have a focused interest in working at a diverse community college. Many of the interns were people of color who also started at a community college and felt a connection to community college students. Mentors understood how students of color might benefit from a role model who looked like them or can relate to them from a shared sociocultural background.

The mentorship experience provided interns with a supportive mentor who shared their sociocultural capital with interns that would in turn help them navigate a bureaucratic educational system. The teaching, professional development and networking opportunities also gave interns first-hand experience working at a diverse community college, an induction experience that many new faculty find challenging.

Anyone working in education would know that implementing policy is a huge undertaking. The California community college system has been strategic in assisting colleges with understanding new policy and providing funding for colleges to implement policy. However, these efforts are futile if implementers are not provided with guidelines and recommendations on promising practices in policy implementation and continued commitment towards faculty diversity.

With the CCCCO's commitment of $\$ 60$ million towards hiring full-time faculty and $40 \%$ of current faculty at or above retirement age, now is the time for the CCCCO and colleges/districts to take leadership and action on increasing faculty diversity. My hope is that this dissertation provides sufficient evidence, recommendations, and 
considerations needed to be taken in designing and implementing a Faculty Diversity Internship Program as a means to increase faculty of color and prepare them for service in a community college so that our students are prepared for our increasingly diverse global economy. 


\section{REFERENCES}

Academic Senate for California Community Colleges (2001). Resolution Number 03.02.

Retrieved on 02/24/2015 at www.asccc.org/resolutions/faculty-diversity.

Academic Senate for California Community Colleges. (2000). Resolution 17.03.

Retrieved on 02/24/2015 at www.asccc.org/resolutions/internships.

Academic Senate for California Community Colleges. (1997). Resolution 03.02.

Retrieved on 02/24/2015 at www.asccc.org/resolutions/proposition-209.

Accrediting Commission of Community and Junior Colleges. (June 2014).

Accreditation Standards. Retrieved on 7/4/2015 at http://www.accjc.org/eligibility-requirementsstandards.

Anthony, L. A. (2002). Faculty of color reconsidered: Reassesssing contributions to scholarship. The Journal of Higher Education, 73(5), 582-602. Retrieved from http://search.proquest.com/docview/205338571?accountid=13802

California Community Colleges Chancellor's Office Management Information Systems Data Mart, Fall 2015 Student Count Report, 2015. Retrieved on 03/05/2016 at www.datamart.ccco.edu.

California Community Colleges Chancellor's Office Management Information Systems Data Mart, Faculty \& Staff Demographics Report, 2015. Retrieved on 03/05/2016 at www.datamart.cccco.edu.

California Community Colleges Chancellor's Office. (2012). Minimum Qualifications for Faculty and Administrators in California Community Colleges.

California Community Colleges Chancellor's Office, Mission and Vision Statement, 2015. Retrieved on 04/19/2015 at http://californiacommunitycolleges.cccco.edu/ChancellorsOffice/MissionandVision.aspx

California Community Colleges Chancellor's Office. (2011). Student Success Scorecard. Retrieved on 02/22/2015 at http://scorecard.cccco.edu/scorecard.aspx).

California Community Colleges Chancellor's Office. (2012). Student Success Taskforce Final Report.

California Online Voter Guide. (1996). Retrieved from http://www.calvoter.org/voter/elections/archive/96gen/props/209.html.

California Postsecondary Education Commission. Total Degrees. Retrieved on 04/09/2016 at http://www.cpec.ca.gov/. 
Chang, A., Welton, A. D., Martinez, M. A. and Cortez, L. (2013). Becoming academicians: An ethnographic analysis of the figured worlds of racially underrepresented female faculty. Negro Educational Review. 64(1/4): 97-118,135.

Cohen, L., Manion, L, and Morrison, K. (2011). Research Methods in Education, $7^{\text {th }}$ Edition. New York, NY: Routledge.

Creswell, J.W. \& Plano Clark, V.L. (2011). Designing Mixed Methods Research, $2^{\text {nd }}$ Edition. Thousand Oaks, CA: Sage.

Cuyjet, M. J. (2008). Bicultural Faculty and Their Professional Adaptation. New Directions for Student Services, (123), 73-82.

Dancy, T., \& Brown, M. (2011). The Mentoring and Induction of Educators of Color: Addressing the Impostor Syndrome in Academe. Journal of School Leadership. 21(4): 607-634.

Darling-Hammond, L. (2010). The flat world and education: How America's commitment to equity will determine our future. New York: Teachers College, Columbia University.

Davis, D.J. (2010). "The academic influence of mentoring upon african american undergraduate aspirants to the professoriate." Urban Review, 42:143-158.

Diggs, G. A., Garrison-wade, D., Estrada, D., \& Galindo, R. (2009). Smiling faces and colored spaces: The experiences of faculty of color pursing tenure in the academy. The Urban Review. 41(4): 312-333.

Dixon-Reeves, R. (2003). Mentoring as a precursor to incorporation: An assessment of the mentoring experience of recently minted Ph.D.s. Journal of Black Studies, 34(1), 12-27. Retrieved from http://search.proquest.com/docview/195618025?accountid=1380

Emerson, G. (2011, February 11). The most diverse states in America. Retrieved on 04/29/2015 from www.mainstreet.com/slideshow/most-diverse-states-america.

Fairlie, R.W., Hoffmann, F. and Oreopoulos, P. (2014). "A community college instructor like me: race and ethnicity interactions in the classroom." American Economic Review, 104(8). 2567-2591.

Fowler, F. (2012). Policy Studies for Educational Leaders: An Introduction, $4^{\text {th }}$ edition. Upper Saddle River, NJ: Pearson.

Fujimoto, E.O. (July 2012). Hiring diverse faculty members in community colleges: A case study in ethical decision making. Community College Review. 40(3): 255274. 
Gabriner, R., Schiorring, and Waldron. (2002). We can do that! A user's guide to diversity practices in california community colleges. California Community College Chancellor's Office.

Garrison-wade, D., Diggs, G. A., Estrada, D., \& Galindo, R. (2012). Lift every voice and sing: Faculty of color face the challenges of the tenure track. The Urban Review, 44(1), 90-112. doi:http://dx.doi.org/10.1007/s11256-011-0182-1

Geiser, S. and Atkinson, R. (2010). "Beyond the master plan: The case for restructuring baccalaureate education in California." Center for Studies in Higher Education at the University of California, Berkeley. Research \& Occasional Paper Series: 16.10 .

Grissom, J.A., Kern. K.C., and Rodriguez, L.A. (2015). "The "Representative Bureaucracy" in education: educator workforce diversity, policy outputs, and outcomes for disadvantaged students." Educational Researcher. 44(3): 185-192.

Gurin, P., Dey, E. L., Hurtado, S., \& Gurin, G. (2002). Diversity and higher education: Theory and impact on educational outcomes. Harvard Educational Review, 72(3), 330-366. Retrieved from http://0search.proquest.com.opac.sfsu.edu/docview/212287515?accountid=13802

Hagedorn, L.S., Chi, W., Cepeda, R.M., and McLain, M. (February 2007). An investigation of critical mass: The role of Latino representation in the success of urban community college students. Research in Higher Education. 48(1): 73-91.

Haley, K.J., Jaeger, A.J., and Levin, J.S. (2014). The influence of cultural social identity of graduate student career choice. Journal of College Student Development. 55(2):101-119.

Helms, J.E. (2003). Racial identity in the social environment. Multicultural Counseling in Schools: A Practical Handbook. 44-58.

Hyers, Lauri L., Syphan, Janet, Cochran, Kelly and Brown, Timothy. (2012). Disparities in the professional development interactions of university faculty as a function of gender and ethnic underrepresentation. The Journal of Faculty Development. 26(1).

Igwebuike, J. G. (2006). Legal and policy implications for faculty diversification in higher education. Negro Educational Review, 57(3), 189-201,265.

Jayakumar, U. M., Howard, T. C., Allen, W. R., \& Han, J. C. (2009). Racial privilege in the professoriate: An exploration of campus climate, retention, and satisfaction. 
The Journal of Higher Education, 80(5), 538. Retrieved from http://search.proquest.com/docview/205340513?accountid $=13802$

Jeffcoat, Kendra and Piland, William E. (2012). Anatomy of a community college diversity program. Community College Journal of Research and Practice. 6: 397-410.

Kennedy, B. (2014). "Unraveling representative bureaucracy: A systematic analysis of the literature." Administration \& Society. 46(4): 395-421.

Kezar, A., Eckel, P., Contreras-mcgavin, M., \& Quaye, S. J. (2008). Creating a web of support: An important leadership strategy for advancing campus diversity. Higher Education, 55(1), 69-92. doi:http://0-dx.doi.org.opac.sfsu.edu/10.1007/s10734007-9068-2

Klein, C. and Peralez, J. (1996). Faculty Internships in California Community Colleges. California Community Colleges, Sacramento:Office of the Chancellor.

Kohoutek, J. (2013). "Three decades of implementation research in higher education: limitations and prospects of theory development." Higher Education Quarterly, 67(1), pp 56-79.

Ladson-Billings, G. (1998). Just what is critical race theory and what's it doing in a nice field like education? Qualitative Studies in Education, 11(1): 7-24.

Ladson-Billings, G. (1995). Toward a critical race theory of education. Teachers College Record. 97(1): 47-68.

Lee, Jo Ann. (June 2010). Students' perceptions of and satisfaction with faculty diversity. College Student Journal. 44(2): 400-412.

Levin, J. S., Haberler, Z., Walker, L., \& Jackson-Boothby, A. (2014). Community college culture and faculty of color. Community College Review. 42(1): 55-74.

Levin, John S, Walker, Laurencia, Haberler, Zachary, \& Jackson-Boothby, Adam. (October 2013). The divided self: The double consciousness of faculty of color in community colleges. Community College Review. 41(4): 311-329.

Lipsky, M. (1994). "Why we must increase diversity." Journal of Policy Analysis and Management, 13(1), 185-186.

Lumpkin, A. (2011). "A model for mentoring university faculty." The Educational Forum. 75: 357-68.

McDavid, James C. \& Hawthorn, Laura R.L. (2013). Program Evaluation \& Performance Measurement: An Introduction to Practice, 2nd edition. Sage. 
Meier, K.J., Doerfler, C., Hawes, D., Hickler, A.K., and Rocha, R. (2006). "The role of management and representation in improving performance of disadvantaged students: An application of bum phillips's “don shula rule." Review of Policy Research, 23(5): 1095-1110.

Meier, K. , \& Smith, K. (1994). "Representative democracy and representative bureaucracy: Examining the top-down and bottom-up linkages." Social Science Quarterly, 75(4), 790.

Miles, M. B., Huberman, A. M. \& Saldaña. J. (2014). Qualitative data analysis: A methods sourcebook ( $3^{\text {rd }}$ edition). Thousand Oaks, CA: Sage.

Nelson Laird, T.,F. (2011). Measuring the diversity inclusivity of college courses. Research in Higher Education, 52(6), 572-588.

Nevarez, C. and Wood, J.L. (2010). Community college leadership and administration: Theory, practice, and change. New York, NY: Peter Lang Publishing.

Ortlieb, E. Biddix, J. and Doepker, G. (2010). "A collaborative approach to higher education induction." Active Learning in Higher Education. 11(2) 109-118.

Piercy, F., Giddings, V., Allen, K., Dixon, B., Meszaros, P., \& Joest, K. (2005). Improving campus climate to support faculty diversity and retention: A pilot program for new faculty. Innovative Higher Education, 30(1), 53-66.

Pitts, D. (2007). "Representative bureaucracy, ethnicity, and public schools." Administration \& Society, 39(4), 497.

Ponjuan, L., Conley, V. M., \& Trower, C. (2011). Career stage differences in pre-tenure track faculty perceptions of professional and personal relationships with colleagues. The Journal of Higher Education, 82(3), 319. Retrieved from http://search.proquest.com/docview/867514040?accountid $=13802$

Reddick, Richard J. and Saenz, Victor B. (Fall 2012). Coming home: Hermanos academicos reflect on past and present relations as professors at their alma mater. Harvard Educational Review. 82(3): 353-438.

Ross, A., Rouse, S. , \& Bratton, K. (2010). "Latino representation and education: Pathways to latino student performance." State Politics \& Policy Quarterly, 10(1), 69-95.

Sadao, K. C. (2003). Living in two worlds: Success and the bicultural faculty of color. Review of Higher Education, 26(4), 397-0_5. Retrieved from http://search.proquest.com/docview/220824044?accountid=13802 
Salazar, C. F. (2009). Strategies to survive and thrive in academia: The collective voices of counseling faculty of color. International Journal for the Advancement of Counselling. 31(3): 181-198.

Smith, D. G., Turner, C. S., Osei-Kofi, N., \& Richards, S. (2004). Interrupting the usual: Successful strategies for hiring diverse faculty. The Journal of Higher Education, 75(2), 133-160. Retrieved from http://search.proquest.com/docview/205320625?accountid=13802

Stanley, C. A. (2006). Coloring the academic landscape: Faculty of color breaking the silence in predominantly white colleges and universities. American Educational Research Journal, 43(4), 701-736.

State of California, Department of Finance, Report P-1 (Race): State and County Population Projections by Race/Ethnicity, 2010-2060. Sacramento, California, December 2014. Retrieved on 04/24/2015 at http://www.dof.ca.gov/research/demographic/reports/projections/P-1/

Title 5, California Code of Regulations. Retrieved from http://www.cde.ca.gov/Ls/fa/sf/title5regs.asp.

Torres, V., Howard-Hamilton, M. F., Cooper, D. L., ERIC Clearinghouse on Higher Education, W. C., Association for the Study of Higher, E. N., \& George Washington Univ., W. T. (2003). Identity Development of Diverse Populations: Implications for Teaching and Administration in Higher Education. ASHE-ERIC Higher Education Report. Jossey-Bass Higher and Adult Education Series.

Umbach, P. D. (2006). The contribution of faculty of color to undergraduate education. Research in Higher Education. 47(3): 317-345.

U.S. Census Bureau. (2013). State \& County Quick Facts. Retrieved on 05/02/2015 at http://quickfacts.census.gov/qfd/states/06000.html.

U.S. Department of Education, National Center for Educational Statistics. Higher Educational General Information Survey (HEGIS), "Degrees and Other Formal Wards Conferred" surveys, 1976-77 and 1980-81; Integrated Postsecondary Education Data System (IPEDS), "Completions Survey" (IPEDS-C:90-99): and IPEDS Fall 2000 through Fall 2013, Completions component. (Table prepared September 2014).

Victorino, C.A., Nylund-Gibson, K., and Conley, S. (2013). "Campus racial climate: A litmus test for faculty satisfaction at four-year colleges and universities." The Journal of Higher Education, 84(6). 769-805. 
Weinberg, S. L. (2008). Monitoring faculty diversity: The need for a more granular approach. The Journal of Higher Education, 79(4), 365. Retrieved from http://search.proquest.com/docview/205335521 ?accountid=13802

Yosso, T. (March 2005). Whose culture has capital? A critical race theory discussion of community cultural wealth. Race Ethnicity and Education. 8(1): 69-91.

Zambrana, R.E., Rashawn, R. Espino, M.M., Castro, C., Cohen, B.D., and Eliason, J. (2015). "'Don't leave us behind': The importance of mentoring for underrepresented minority faculty." American Educational Research Journal February. 52: 40-72. 


\section{APPENDIX 1}

\section{Faculty Diversity Internship Program Survey}

Dear Prospective Research Participant,

I am a final year student in San Francisco State University's Educational Leadership Doctorate program and I am researching the topic of faculty diversity in California community colleges. Specifically, I am conducting a program evaluation of the Faculty Diversity Internship Programs (FDIPs) in California community colleges and my research questions are:

1. What are the promising practices of the Faculty Diversity Internship Program (FDIP)?;

2. What are the barriers and challenges in implementing FDIPs?

3. What is the impact of the FDIP on faculty diversity as a recruitment and retention tool?

As a current and/or former participant in a Faculty Diversity Internship Program (FDIP), you are invited to participate in a program evaluation by completing this survey and an interview about your experience in the FDIP.

Your participation will provide important information on the values and promising practices of FDIP in California community colleges. Your privacy and participation will be respected and valued. The survey includes 27 questions and should take you 10 minutes to 20 minutes.

If you are interested in being interviewed, kindly include your contact information at the end of the survey. This study and the interview will be conducted as a part of my dissertation research in the SFSU Ed.D. program and hopefully, provide insight to the implementation and impact of FDIPS to encourage more community colleges to implement the FDIP to recruit and retain diverse faculty.

You must be 18 years of age or older to participate. There are no risks or benefits to you in participating in this survey. You may choose to participate or not. You may answer only the questions you feel comfortable answering, and you may stop at any time. If you do not wish to participate, there is no penalty to yourself. If you do participate, completion and return of the survey indicates your consent to the above conditions. Your decision whether or not to participate in this program evaluation will have no influence on your present or future status at your current employment.

Any questions or concerns should be directed to the principal investigator, Supinda Sirihekaphong, at supindas@mail.sfsu.edu or the dissertation chair, Associate Professor Sheldon Gen, at sgen@sfsu.edu.

Thank you in advance for your participation.

Sincerely,

Supinda Sirihekaphong

supindas@mail.sfsu.edu

917-676-9888 
1. How did you learn about the FDIP? (Check all that apply)

FDIP Coordinator

$\Gamma$ Graduate School

Flyer

Human Resources Department

Word of Mouth (colleague, faculty mentor, classmate, etc.)

Tother:

2. When did you participate in the FDIP? (example, Fall 2015)

3. Did you participate as a faculty mentor or an intern?

Faculty mentor

C. Intern

4. Where did you participate in the FDIP? Check all that apply.

\begin{tabular}{|l|l|}
\hline & Alameda \\
\hline & Berkeley \\
0 & Cuyamaca \\
0 & Grossmont \\
0 & Imperial Valley \\
0 & Laney \\
\hline & Merritt \\
\hline C & Mira Costa \\
\hline & Mt. San Jacinto \\
\hline & Palomar \\
\hline & San Diego City \\
\hline & San Diego Mesa \\
\hline & San Diego Miramar \\
\hline & Southwestern \\
\hline & Other: \\
\hline
\end{tabular}

5. How long did you participate in the FDIP?

C 1 semester or currently participating in the 1 st semester

O 2 semesters

O 3 semesters

4 semesters

C. More than 4 semesters

6. How long after you completed the FDIP did you obtain a tenure-track position, if applicable?

I have not obtained a tenure-track position.

Less than 6 months

More than 6 months but less than 1 year

More than 1 year but less than 2 years 
More than 2 years but less than 3 years

3 years or more

7. Were you matched with a mentor with the same race/ethnicity as you?

Y Yes

C No

O. Unknown

8. Did you receive training and/or orientation before starting the FDIP?

O Yes

$C \mathrm{No}$

Unknown

9. Do you continue to have an active and positive relationship with your FDIP intern/mentor?

$r$ Yes

C No

U. Unknown

10. My mentorlintern was a good match.

$\begin{array}{lllllll}0 & 1 & 2 & 3 & 4 & 5\end{array}$

Not applicable/Not sure $C: C \quad r \quad r \quad r \quad r \quad$ Strongly Agree

11. My relationship with my mentor/intern helped with my professional development in the area of curriculum development.

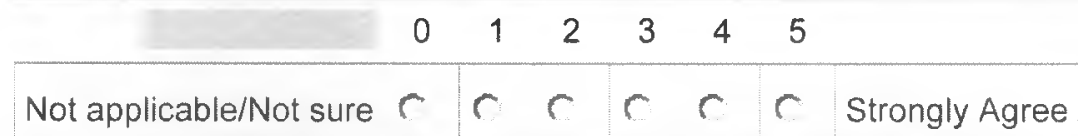

12. My relationship with my mentor/intern helped with my professional development in the area of pedagogy.

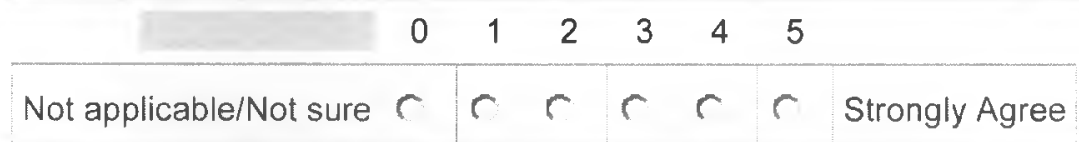

13. My relationship with my mentor/intern helped with my professional development in obtaining employment in a community college.

\begin{tabular}{|l|lllllll|}
\hline & 0 & 1 & 2 & 3 & 4 & 5 \\
\hline Not applicable/Not sure & $r$ & $r$ & $r$ & $r$ & $r$ & $r$ & Strongly Agree \\
\hline
\end{tabular}

14. My relationship with my mentorlintern helped with my professional development in the area of networking within the college.

\begin{tabular}{|l|l|lllllll} 
& 0 & 1 & 2 & 3 & 4 & 5 & \\
\hline Not applicable/Not sure & $r$ & $c$ & $c$ & $c$ & $c$ & $C$ & Strongly Agree
\end{tabular}

15. My relationship with my mentor/intern helped with my professional development in the area of networking within my discipline.

\begin{tabular}{|l|l|lllllll|}
\hline & 0 & 1 & 2 & 3 & 4 & 5 & \\
\hline Not applicable/Not sure & $c$ & $c$ & $c$ & $c$ & $C$ & $C$ & Strongly Agree \\
\hline
\end{tabular}


16. My participation in the FDIP increased my aware and sensitive to diversityrelated issues.

$\begin{array}{lllllll}0 & 1 & 2 & 3 & 4 & 5\end{array}$

Not applicable/Not sure $r \quad r \quad r \quad r \quad r \quad r$ Strongly Agree

17. My participation in the FDIP prepared or improved my work in a diverse classroom/community college.

$\begin{array}{llllll}0 & 1 & 2 & 3 & 4 & 5\end{array}$

Not applicable/Not sure $r \mid r \quad r \quad r \quad r \quad r \quad$ Strongly Agree

18. My involvement in the FDIP was a positive experience.

\begin{tabular}{|l|l|lllllll|l} 
& 0 & 1 & 2 & 3 & 4 & 5 \\
\hline Not applicable/Not sure & $C$ & $C$ & $C$ & $C$ & $C$ & $C$ & Strongly Agree \\
\hline
\end{tabular}

19. Please use as much space as needed to describe additional activities of the FDIP that you participated in and include whether the activties were supportive or challenging.

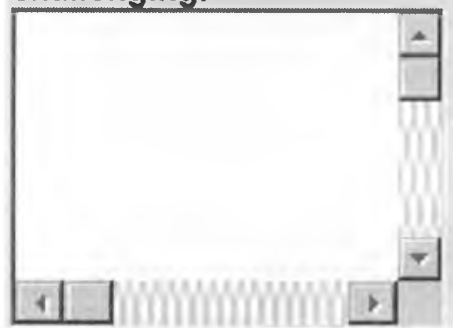


20. Please use as much space as needed. Overall, please describe your experience in the FDIP and the benefits and/or challenges that you may have experienced.

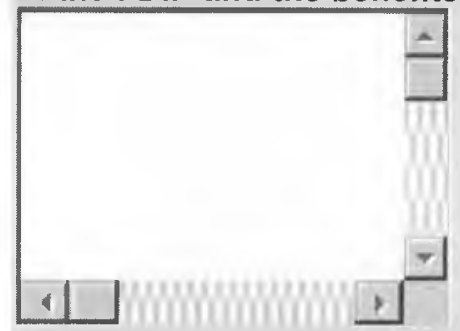

21. Do you have suggestions on how to improve the FDIP?

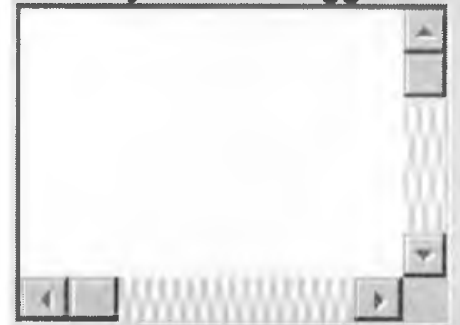

22. Would you recommend the FDIP to others?

C Yes

$r$ No

23. Age

Г 20-29

Г $30-39$

Г $40-49$

$\square 50-59$

$\Gamma 60+$

24. Gender

O Male

C Female

C Other

C. Decline to state

25. Diversity Factors (check all that apply)

C African-American/Black

- American Indian/Native American

C Asian

Chicano/Latino/Hispanic

C Multiracial/ethnic

Pacific Islander

C White

C Disability

C Former Foster Youth

O Sexual Orientation 
Other:

26. Academic Discipline

27. I would like to participate in an interview about my experience in the FDIP. Here is my contact information.

Submit

\section{Interview Questions}

Questions for Faculty Mentor

1. What was your interest and expectations in becoming a faculty mentor?

2. Were you provided training and/or preparation? If not, do you think it is required and if so, what kind of preparation/training do you suggest?

3. What was most rewarding about your participation in the FDIP?

4. Did you face any challenges participating in the FDIP? If so, was there any support/resources provided to assist in any challenges that arose?

5. Did participation in the FDIP improve your teaching and learning in the classroom?

6. Do you think the FDIP has an impact on faculty diversity and/or an impact on the campus climate around diversity?

7. Please provide overall comments and/or suggestions about your experience in FDIP.

\section{Questions for Interns}

1. What was your interest and expectations in participating in the FDIP?

2. Were you provided preparation and/or an orientation? If not, do you think it is required and if so, what kind of preparation/orientation do you suggest?

3. Please describe your relationship with your mentor, how were you matched and how was your experience being a mentee?

4. Did you participate in any workshops/events organized by the FDIP and were they beneficial?

5. What was most rewarding about your participation in the FDIP?

6. Did you face any challenges participating in the FDIP? If so, was there any support/resources provided to assist in any challenges that arose?

7. Did you meet other interns? If yes, was your relationship with them helpful?

8. Do you think the FDIP prepared you to work in a diverse community college?

9. Please provide overall comments and/or suggestions about your experience in FDIP. 
APPENDIX 2: Overall Survey Results

\begin{tabular}{|c|c|c|c|c|c|c|c|c|}
\hline & Interns & $\begin{array}{l}\% \text { of } \\
\text { sub- } \\
\text { group }\end{array}$ & $\begin{array}{l}\% \text { of } \\
\text { total }\end{array}$ & 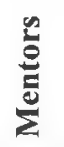 & $\begin{array}{l}\text { o of } \\
\text { sub- } \\
\text { group }\end{array}$ & $\begin{array}{l}\% \text { of } \\
\text { total }\end{array}$ & Total & $\begin{array}{l}\% \text { of } \\
\text { total }\end{array}$ \\
\hline Participant Types & 83 & $100 \%$ & 86 & 13 & $100 \%$ & 14 & 96 & $100 \%$ \\
\hline \multicolumn{9}{|l|}{ Gender } \\
\hline Female & 58 & 70 & 60 & 7 & 54 & 7 & 65 & 68 \\
\hline Male & 22 & 27 & 23 & 6 & 46 & 6 & 28 & 29 \\
\hline Decline to State & 3 & 4 & 3 & 0 & 0 & 0 & 3 & 3 \\
\hline \multicolumn{9}{|l|}{ Age } \\
\hline $20-29$ & 21 & 25 & 22 & $\mathbf{0}$ & 0 & 0 & 21 & 22 \\
\hline $30-39$ & 35 & 42 & 36 & 3 & 23 & 3 & 38 & 40 \\
\hline $40-49$ & 15 & 18 & 16 & 2 & 15 & 2 & 17 & 18 \\
\hline $50-59$ & 5 & 6 & 5 & 5 & 38 & 5 & 10 & 10 \\
\hline $60+$ & 4 & 5 & 4 & 3 & 23 & 3 & 7 & 7 \\
\hline No response & 3 & 4 & 3 & $\mathbf{0}$ & 0 & 0 & 3 & 3 \\
\hline \multicolumn{9}{|l|}{ Diversity Factors } \\
\hline African-American/Black & 10 & 12 & 10 & 0 & 0 & 0 & 10 & 10 \\
\hline Afro-Puerto Rican & 1 & 1 & 1 & 0 & 0 & 0 & 1 & 1 \\
\hline Native American Indian & 2 & 2 & 2 & 0 & 0 & 0 & 2 & 2 \\
\hline Arab & 1 & 1 & 1 & $\mathbf{0}$ & 0 & 0 & 1 & 1 \\
\hline Asian & 11 & 13 & 11 & 2 & 15 & 2 & 13 & 14 \\
\hline Chicano/Latino/Hispanic & 14 & 17 & 15 & 2 & 15 & 2 & 16 & 17 \\
\hline Middle Eastern & 1 & 1 & 1 & 0 & 0 & 0 & 1 & 1 \\
\hline Multiracial/ethnic & 10 & 12 & 10 & 1 & 8 & 1 & 11 & 11 \\
\hline Sexual Orientation & 1 & 1 & 1 & $\mathbf{0}$ & 0 & 0 & 1 & 1 \\
\hline White & 28 & 34 & 29 & 7 & 54 & 7 & 35 & 36 \\
\hline No response & 4 & 5 & 4 & 1 & 8 & 1 & 5 & 5 \\
\hline \multicolumn{9}{|l|}{ Campus } \\
\hline Alameda & 11 & 13 & 11 & 4 & 31 & 4 & 15 & 16 \\
\hline Berkeley & 8 & 10 & 8 & 2 & 15 & 2 & 10 & 10 \\
\hline Cuyamaca & 4 & 5 & 4 & 2 & 15 & 2 & 6 & 6 \\
\hline Grossmont & 13 & 16 & 14 & 0 & 0 & 0 & 13 & 14 \\
\hline Laney & 10 & 12 & 10 & 2 & 15 & 2 & 12 & 13 \\
\hline Merritt & 3 & 4 & 3 & $\mathbf{0}$ & 0 & 0 & 3 & 3 \\
\hline Mira Costa & 11 & 13 & 11 & 0 & 0 & 0 & 11 & 11 \\
\hline Mt. San Jacinto & 2 & 2 & 2 & 0 & 0 & 0 & 2 & 2 \\
\hline Palomar & 4 & 5 & 4 & 0 & 0 & 0 & 4 & 4 \\
\hline SD City & 6 & 7 & 6 & 0 & 0 & 0 & 6 & 6 \\
\hline SD Mesa & 3 & 4 & 3 & 1 & 8 & 1 & 4 & 4 \\
\hline
\end{tabular}




\begin{tabular}{|c|c|c|c|c|c|c|c|c|}
\hline SD Miramar & 7 & 8 & 7 & 2 & 15 & 2 & 9 & 9 \\
\hline Southwestern & 1 & 1 & 1 & $\mathbf{0}$ & 0 & 0 & 1 & 1 \\
\hline \multicolumn{9}{|l|}{ Discipline } \\
\hline Accounting & 1 & 1 & 1 & 0 & 0 & 0 & 0 & 1 \\
\hline Africana Studies & 1 & 1 & 1 & 0 & 0 & 0 & 0 & 1 \\
\hline Biology & 5 & 6 & 5 & 0 & 0 & 0 & 5 & 5 \\
\hline Business & 5 & 6 & 5 & 1 & 8 & 1 & 6 & 6 \\
\hline Chemistry & 2 & 2 & 2 & 1 & 8 & 1 & 3 & 3 \\
\hline Chicano Studies & 1 & 1 & 1 & 0 & 0 & 0 & 1 & 1 \\
\hline Child Development & 3 & 4 & 3 & $\mathbf{0}$ & 0 & 0 & 3 & 3 \\
\hline Communication & 1 & 1 & 1 & $\mathbf{0}$ & 0 & 0 & 1 & 1 \\
\hline Counseling & 17 & 20 & 18 & 2 & 15 & 2 & 19 & 20 \\
\hline Economics & 1 & 1 & 1 & 0 & 0 & 0 & 1 & 1 \\
\hline Education & 1 & 1 & 1 & 0 & 0 & 0 & 1 & 1 \\
\hline English & 16 & 19 & 17 & 3 & 23 & 3 & 19 & 20 \\
\hline ESL/ESOL & 3 & 4 & 3 & 1 & 8 & 1 & 4 & 4 \\
\hline Geography & 1 & 1 & 1 & 1 & 8 & 1 & 2 & 2 \\
\hline History & 5 & 6 & 5 & $\mathbf{0}$ & 0 & 0 & 5 & 5 \\
\hline Library & 1 & 1 & 1 & 1 & 8 & 1 & 2 & 2 \\
\hline Life Science & 1 & 1 & 1 & 0 & 0 & 0 & 1 & 1 \\
\hline Mathematics & 3 & 4 & 3 & 1 & 8 & 1 & 4 & 4 \\
\hline Middle Eastern Studies & 1 & 1 & $l$ & $\mathbf{0}$ & 0 & 0 & 1 & 1 \\
\hline Political Science & 2 & 2 & 2 & 1 & 8 & 1 & 3 & 3 \\
\hline Psychology & 3 & 4 & 3 & 2 & 15 & 2 & 5 & 5 \\
\hline Sociology & 5 & 6 & 5 & $\mathbf{0}$ & 0 & 0 & 5 & 5 \\
\hline Statistics & 1 & 1 & 1 & 0 & 0 & 0 & 1 & 1 \\
\hline Student Affairs & 2 & 2 & 2 & 0 & 0 & 0 & 2 & 2 \\
\hline No response & 2 & 2 & 2 & 0 & 0 & 0 & 2 & 2 \\
\hline \multicolumn{9}{|l|}{ Matched with same race } \\
\hline No & 42 & 51 & 44 & 3 & 23 & 3 & 45 & 47 \\
\hline Yes & 38 & 46 & 40 & 1 & 8 & 1 & 39 & 41 \\
\hline Unknown & 3 & 4 & 3 & 2 & 15 & 2 & 5 & 5 \\
\hline \multicolumn{9}{|l|}{ Recommend FDIP } \\
\hline No & 4 & 5 & 4 & $\mathbf{0}$ & 0 & 0 & 4 & 4 \\
\hline Yes & 76 & 92 & 79 & 13 & 100 & 14 & 89 & 93 \\
\hline No response & 3 & 4 & 3 & $\mathbf{0}$ & 0 & 0 & 3 & 3 \\
\hline \multicolumn{9}{|c|}{ Continued relationship with mentor/intern? } \\
\hline No & 13 & 16 & 14 & 1 & 8 & $l$ & 14 & 15 \\
\hline
\end{tabular}




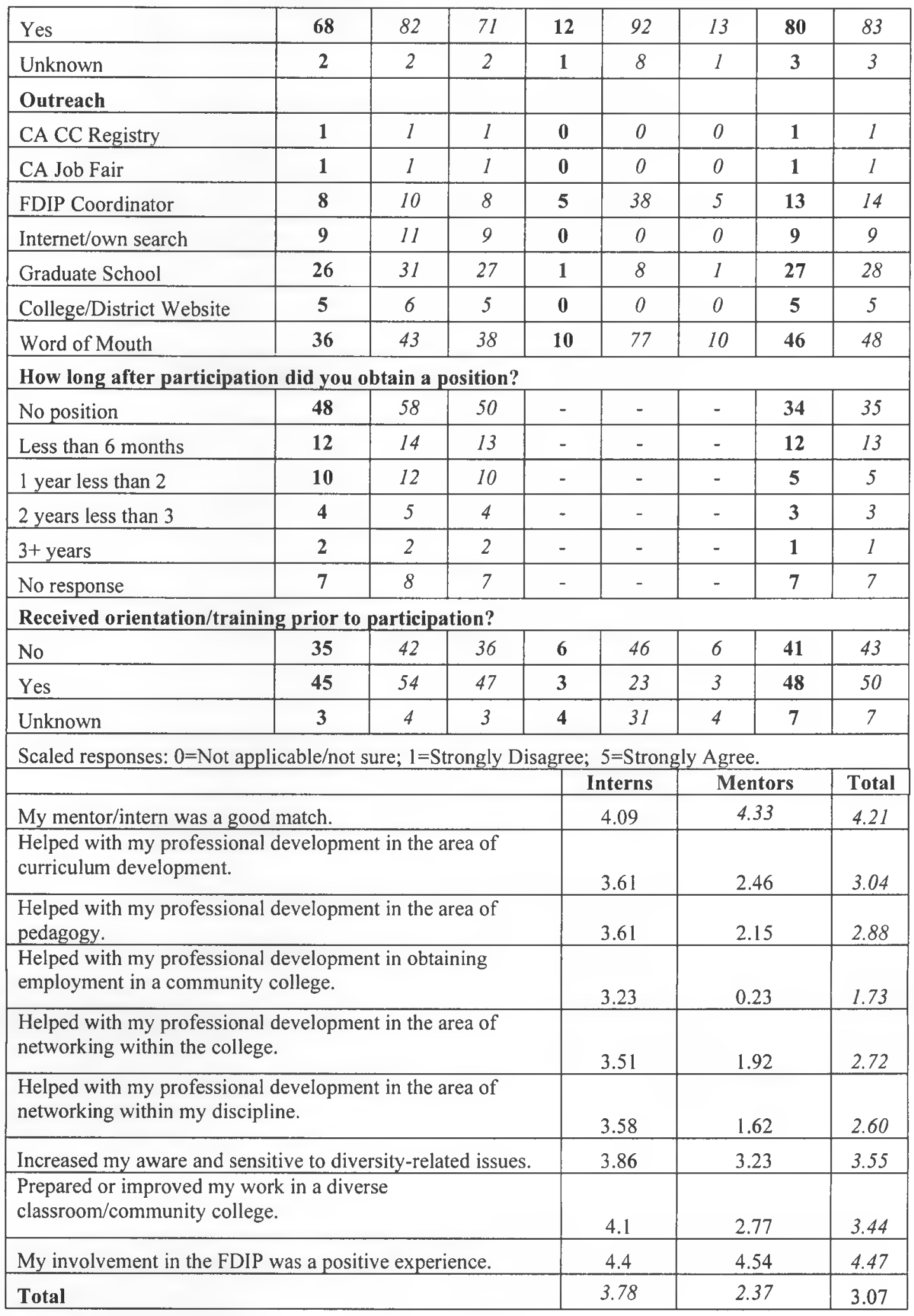

